The Dissertation Committee for Yao You Certifies that this is the approved version of the following:

\title{
Dynamics of dilative slope failure
}

\section{Committee:}

David Mohrig, Supervisor

Peter Flemings, Co-Supervisor

Omar Ghattas

John T. Germaine

Marc Hesse 


\title{
Dynamics of dilative slope failure
}

\author{
by
}

\author{
Yao You, B.S.; M.S.
}

\author{
Dissertation \\ Presented to the Faculty of the Graduate School of \\ The University of Texas at Austin \\ in Partial Fulfillment \\ of the Requirements \\ for the Degree of
}

Doctor of Philosophy

The University of Texas at Austin

December 2013 


\section{Acknowledgements}

I would like to thank my co-advisors, Peter Flemings and David Mohrig, for their strong support and guidance; they pushed me forward when I stuck and they pick me up when I lost confidence. I also want to thank them for their great patience in helping me to present scientific work better, both in presentations and in writing. Both Peter and David's passion for science inspires me to keep exploring and thinking. I would also like to thank my other dissertation committee members, Jack Germaine, Marc Hesse, and Omar Ghattas, for helpful discussions on the research. I also want to thank Jack Germaine for his guidance in properly running geotechnical tests.

This work is based on experiments and I owe it to the lab assistants and managers. I thank David Brown for assisting in designing, preparing, and running the experiments; Mark Andrews for building the data collection system for pore pressure measurements and helping with geotechnical tests; Polito and Donnie Brooks for assisting geotechnical tests; Jim Buttles for his assistance in building the flumes and running the flume experiments; Mauricio Perillo for his assistance on using the ultrasonic transceiver. I would also like to thank Brandon Minton, Tian Dong, Trevor Hutton, and Stephen Heron for their assistance in running the flume experiments.

I thank other faculty members, postdocs, and my colleagues for their assistance in running experiments, helpful discussions, comments on writings, and support for my work. I would especially thank John Shaw for the brain storming we had; a lot of the ideas we discussed may seem silly now but those discussions pushed this work forward tremendously. I also thank Derek Sawyer, Kuldeep Chaudhary, Kristopher Darnel, Audrey Sawyer, Travis Swanson, Aymeric Peyret, Luc Lavier, Ravindra Duddu, Jake 
Jordan, Kiran Sathaye, Anjali Fernandes, Julia Reece, Athma Bhandari, Maria-Katerina Nikolinakou, Katie Delbecq, Virginia Smith, Wayne Wagner, Wen Deng, and Nicolas Huerta.

I thank the staff members in Jackson School of Geosciences for their support on everything happens in the background of this work. I especially thank Mark Wiederspahn for maintaining the computing systems at the Institute for Geophysics, where all my numerical models ran and all my data is saved; Tessa Green for keeping the GeoFluids research group running smoothly; Philip Guerrero for assistance on the administrative aspects of graduate student life; Elsa Jimenez for assistance with financial quests.

I thank my partner Justin Stigall, for his support, patience, and love that carried me through.

Financial support for this work comes from GeoFluids consortium at the University of Texas at Austin (www.beg.utexas.edu/geofluids/index, supported by 11 energy companies), the Ewing Worzel fellowship from the University of Texas Institute for Geophysics, National Science Foundation funded National Center for Earth-surface Dynamics, and RioMAR Industry Consortium. 


\title{
Dynamics of dilative slope failure
}

\author{
Yao You, Ph.D. \\ The University of Texas at Austin, 2013
}

Supervisors: Peter Flemings and David Mohrig

Submarine slope failure releases sediments; it is an important mechanism that changes the Earth surface morphology and builds sedimentary records. I study the mechanics of submarine slope failure in sediment that dilates under shear (dilative slope failure). Dilation drops pore pressure and increases the strength of the deposit during slope failure. Dilation should be common in the clean sand and silty sand deposits on the continental shelf, making it an important mechanism in transferring sand and silt into deep sea. Flume experiments show there are two types of dilative slope failure: pure breaching and dual-mode slope failure. Pure breaching is a style of retrogressive subaqueous slope failure characterized by a relatively slow $(\mathrm{mm} / \mathrm{s})$ and steady retreat of a near vertical failure front. The retreating rate, or the erosion rate, of breaching is proportional to the coefficient of consolidation of the deposit due to an equilibrium between pore pressure drop from erosion and pore pressure dissipation. The equilibrium creates a steady state pore pressure that is less than hydrostatic and is able to keep the deposit stable during pure breaching. Dual-mode slope failure is a combination of breaching and episodic sliding; during sliding a triangular wedge of sediment falls and causes the failure front to step back at a speed much faster than that from the breaching period. The pore pressure fluctuates periodically in dual-mode slope failure. Pore pressure rises during breaching period, weakens the deposit and leads to sliding when the 
deposit is unstable. Sliding drops the pore pressure, stabilizes the deposit and resumes breaching. The frequency of sliding is proportional to the coefficient of consolidation of the deposit because dissipation of pore pressure causes sliding. Numerical model results show that more dilation or higher friction angle in the deposit leads to pure breaching while less dilation or lower friction angle leads to dual-mode slope failure. As a consequence, pure breaching is limited to thinner deposits and deposits have higher relative density. 


\section{Table of Contents}

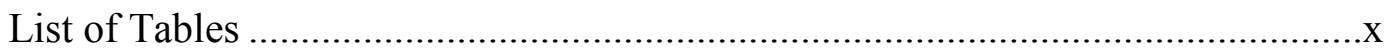

List of Figures ..........................................................................................

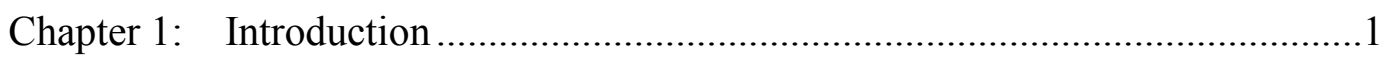

Chapter 2: $1 \mathrm{D}$ analytical model for steady state breaching ...............................5

2.1 Introduction ................................................................................

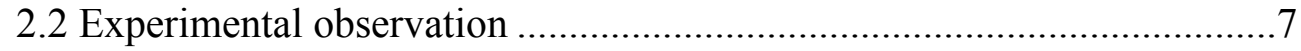

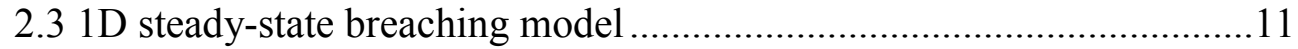

2.4 Equilibrium between the slope failure and pore pressure dissipation.....14

2.5 Characteristics of the steady state pore pressure solution......................17

2.6 Breaching condition ........................................................................2 21

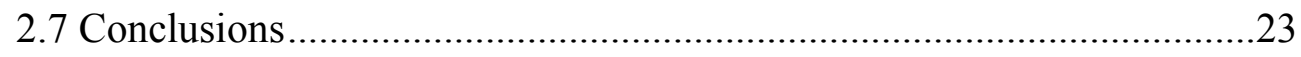

Chapter 3: 2D numerical model for steady state breaching .............................25

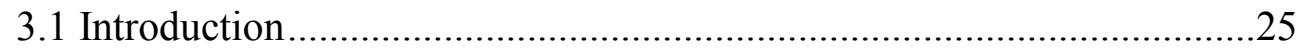

3.2 2D pore pressure model for steady state breaching ...........................28

3.3 Empirical model for dilation potential ............................................ 31

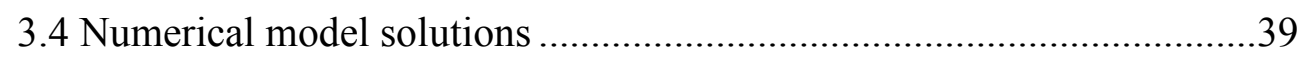

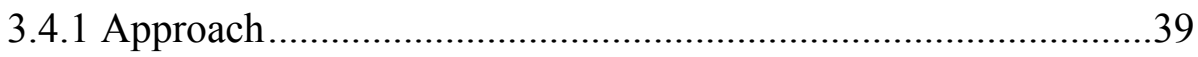

3.4.2 Pore pressure results ....................................................42

3.4.3 Stress path of the sediments during breaching.........................46

3.4.4 Sensitivity study........................................................49

3.7 Variation of erosion rate in the vertical direction .................................54

3.8 Conclusions and discussion ............................................................5

Chapter 4: $\quad$ Dual-mode slope failure ...............................................................61

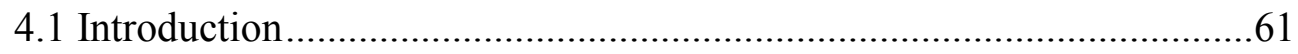

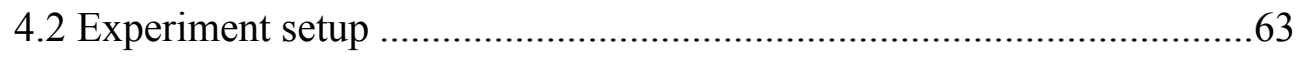

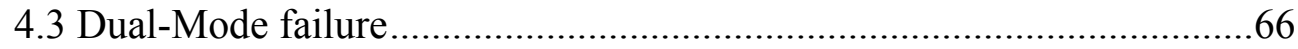

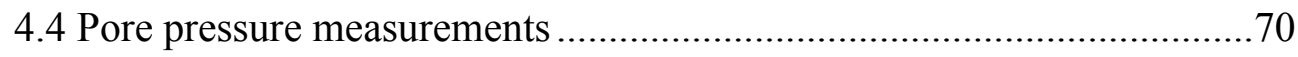


4.5 2D transient pore pressure model .......................................................... 75

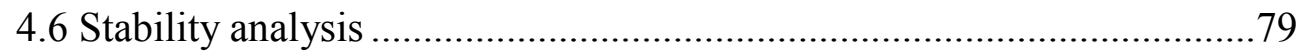

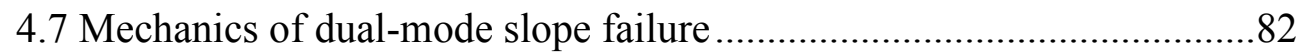

4.8 Conditions for dual-mode slope failure to occur .....................................87

4.9 Potential field sites for dilative slope failure ……………………...........89

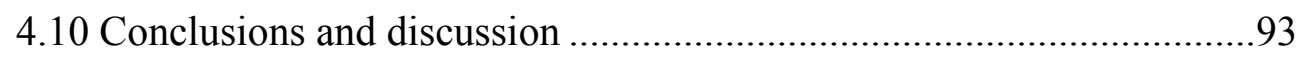

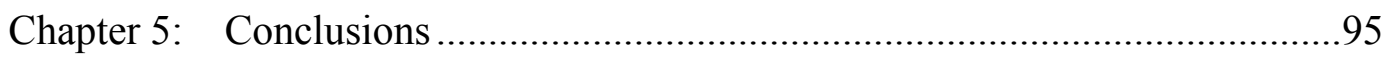

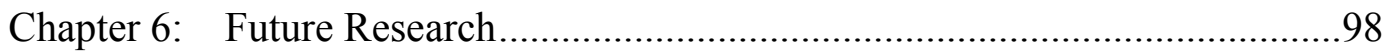

6.1 Study dilative slope failure with centrifuge models ...............................98

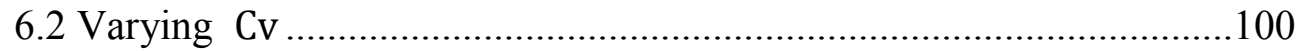

6.3 Develop better models for material properties........................................101

6.4 Experiment with different initial slope angles ......................................102

6.5 Study how common dilation is in the field ...........................................103

Appendix A: Supplementary material for Chapter $2 \ldots \ldots \ldots \ldots \ldots \ldots \ldots \ldots \ldots \ldots \ldots \ldots \ldots \ldots \ldots . . . . .105$

A.1 Pore pressure measurements from all 9 locations ..................................105

A.2 Estimate the modeling parameter $\eta$ and s0 .....................................105

A.3 Estimate the dilation potential of sand at Scripps Canyon from published simple shear test results ...................................................................106

Appendix B: Additional steps in processing triaxial test data ...........................110

Appendix C: Procedure for measuring pore pressure in the flume....................113

C.1 Install tube fittings............................................................................... 114

C.1.1 Tube fitting attached to the transducer .......................................114

C.1.2 Tubing system attached to the inner flume ……………….......116

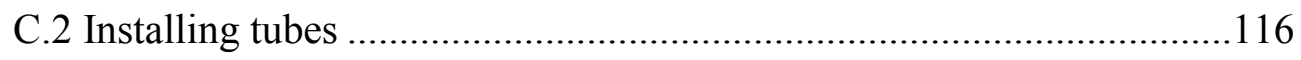

C.3 flush the tubing system....................................................................117

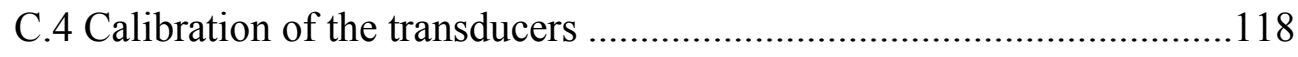

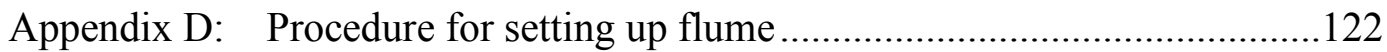

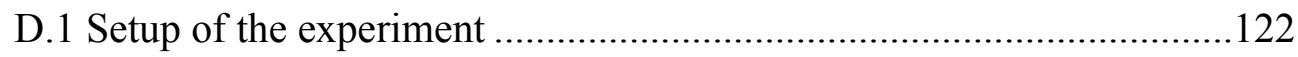

D.2 Running the experiment ....................................................................123 


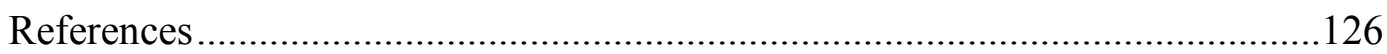




\section{List of Tables}

Table 3.1: List of modeling parameter symbols, explanation, values (if it is a model input), and units.

Table 3.2: Estimated relative density $\left(\mathrm{I}_{\mathrm{D}}\right)$ of clean sand deposits in published literature. Larger values of $I_{D}$ means the deposit has smaller porosity/void ratio. $I_{D}>1$ means the in situ porosity is smaller than the estimated minimum value and $\mathrm{I}_{\mathrm{D}}<0$ means the in situ porosity is larger than the estimated maximum value. Assuming the deposits are less than $10 \mathrm{~m}$ thick, the condition for the deposit to dilate is $I_{D}>0.2$ according to Bolton (1986). 60

Table 4.1. Size of the 4 sliding wedges compared to the associated magnitude of pore pressure drop. The number of the sliding events is according to the order they occur in time (Figure 4.4). 86 


\section{List of Figures}

Figure 2.1: Morphodynamic evolution and pore pressure response during breaching. Initial dimensions of sediment: $\sim 30 \mathrm{~cm}$ tall, $40 \mathrm{~cm}$ wide. The pore pressure is monitored at nine locations and I show two of them here for simplicity (for measurements from all sensors see Figure A.1 in Appendix A). A: After $10 \mathrm{~s}$, sediments are falling from vertical face (breaching front) and forming turbidity current (light gray). B: After 80 $\mathrm{s}$, erosion has shifted breaching front to right and it is approaching blue pressure sensor. Turbidity currents have deposited sediment in front of breaching front. C: Removal of retaining wall results in abrupt drop in pore pressure at both sensors ( $0-22 \mathrm{~s}$, dark gray region). As breaching front approaches each pressure sensor, there is second pressure drop and then rise to hydrostatic pressure (light gray zones at $80 \mathrm{~s}$ and $130 \mathrm{~s}$ for blue and red sensors, respectively). Final pore pressure is lower than initial pore pressure due to drop of water table, which is caused by removal of restraining plate. Chaotic pore pressure signal recorded between $10 \mathrm{~s}$ and $40 \mathrm{~s}$ by all sensors is due to transient slumping of sediments connected to removal of restraining plate; this is not part of steady-state breaching process I focus on in this study. .6

Figure 2.2: Grain size distributions of the silty sand (solid line) and well-sorted fine sand (dashed line) used in the study.

Figure 2.3: Traces of the breaching front during one experiment, the trace lines are separated by 20 s. The dashed line represents the location where I measure the erosion rate (shown in Figure 2.4) 
Figure 2.4: Erosion rate $\mathrm{v}$ estimated from the trace of breaching front (Figure 2.3) against time. $\mathrm{v}$ at time $\mathrm{t}$ represents the average velocity between $\mathrm{t}-20 \mathrm{~s}$ and $\mathrm{t}$; it is calculated as the distance the breaching front travels along the dashed line in Figure 2.3 during this period divided by $20 \mathrm{~s}$. The error bars represents the uncertainty in time $( \pm 1 \mathrm{~s})$. This uncertainty is too small compared to the time scale of the experiment (horizontal axis) therefore only its influence on the erosion rate (vertical axis) is plotted here. .9

Figure 2.5: Excess pore pressure $10 \mathrm{~s}$ (diamonds), $80 \mathrm{~s}$ (squares), $140 \mathrm{~s}$ (triangles), and $190 \mathrm{~s}$ (dashed line) after onset of breaching, plotted with distance from breaching front (Lagrangian coordinates). At each time, there is minimum in pore pressure $\sim 5 \mathrm{~cm}$ behind breaching front. Pore pressure at $140 \mathrm{~s}$ is almost identical to pore pressure at $190 \mathrm{~s}$ in Lagrangian coordinates, suggesting that pore pressure is at steady state. Solid line is excess pore pressure predicted by Equation 4 .

Figure 2.6: Measured steady state excess pore pressure against distance from the breaching front for the fine sand (circles) and silty sand (squares). .17

Figure 2.7: A: The dimensionless distance to the minimum dimensionless excess pore pressure (or maximum pore pressure drop) xm against the controlling parameter $\xi$ for the dimensionless excess pore pressure solution. B: the minimum dimensionless excess pore pressure um against the controlling parameter $\xi$. The circle symbol in both sub figures marks the $\xi$ for fine sand and the square symbol in both sub figures marks the $\xi$ for silty sand. 
Figure 2.8: A: dimensionless excess pore pressure $\frac{\mathrm{u}^{*}}{\beta \mathrm{s}_{0}}$ against dimensionless distance $\frac{\mathrm{xv}}{\mathrm{C}_{\mathrm{v}}}$ from measurements in silty sand (squares) and in fine sand (circiles), and the steady state solution (solid lines, Equation 2.6). The controlling parameter $\xi$ is 24 for the fine sand and 1.5 for the silty sand. B: zoom in of the boxed area in A. Dimensionless excess pore pressure $\frac{\mathrm{u}^{*}}{\beta \mathrm{s}_{0}}$ against dimensionless distance $\frac{\mathrm{xv}}{\mathrm{C}_{\mathrm{v}}}$ from measurements (circles and dashed line) and the steady state solution (solid line, Equation 2.6) for the fine sand. The scales of the axes of the two plots are different. .20

Figure 2.9: Excess p pore pressure against distance from breaching front for the steady state model solution (solid line, Equation 2.5) and critical excess pore pressure $\left(\mathrm{u}_{\mathrm{c}}^{*}\right.$, dashed line). When pore pressure is more than critical pore pressure, Coulomb failure will occur (Equation A.4 in Appendix A). To depth of $2.5 \mathrm{~cm}$, deposit is at failure (shaded region). Internal friction angle of $30^{\circ}$ is assumed.................................................22

Figure 2.10: Ratio of minimum excess pore pressure $\left(u_{m}^{*}\right.$, Figure 2.9$)$ to critical excess pore pressure $\left(\mathrm{u}_{\mathrm{c}}^{*}\right)$ increases linearly with dilation potential $\left(\beta=\frac{1}{2}+\frac{m_{\mathrm{q}}}{2 \mathrm{~m}_{\mathrm{u}}}\right)$. When $\frac{\mathrm{u}_{\mathrm{m}}^{*}}{\mathrm{u}_{\mathrm{c}}^{*}}<1$, sliding and slumping will occur and breaching will not proceed. When $\beta \geq 4, \frac{u_{m}^{*}}{u_{c}^{*}}>1$ and breaching can proceed. Three silty sand samples from Scripps Canyon (squares) have dilation potential $\beta=4.1,8.6$, and 25.4 (not plotted), indicating that they are in regime where breaching can proceed. 24 
Figure 3.1: Sketch of breaching at $10 \mathrm{~s}$ and $80 \mathrm{~s}$, with pore pressure measurements (presented in Chapter 2). A: 10s after initiation. The deposit maintains a vertical failure surface, referred as the breaching front. B: 80 s after initiation. The breaching front still maintains its vertical slope. The slope angle decreases near the top. C: excess pore pressure against distance from breaching front. Each line represents a time step. Excess pore pressure is negative everywhere during breaching. The maximum drop in excess pore pressure occurs around $5 \mathrm{~cm}$ from the breaching front. After 140s, the excess pore pressure does not change significantly, reaching a steady state. .26

Figure 3.2: Sketch of the triaxial shearing device. The specimen is wrapped in a layer of water tight membrane so that it is hydraulically separated from the water chamber. The cell pump and pore pump controls the pressure in the water chamber and specimen respectively. The pore pump also measures the changes in the specimen volume $(\delta V)$. Pore pressure $\left(u_{p}\right)$ is measured from both the top and bottom end of the specimen. A load sensor located on the piston measures the amount of force acting on the specimen in the vertical direction $\left(\mathrm{F}_{\mathrm{v}}\right)$. The chamber water pressure $\left(\mathrm{u}_{\mathrm{c}}\right)$ is measured at the base. The specimens have an averaged diameter of

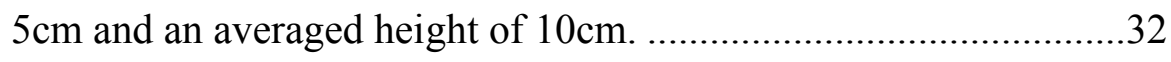


Figure 3.3: Measurements of the isotropic unloading compressibility $\mathrm{m}_{\mathrm{u}}$ (squares) and absolute value of reloading compressibility $\left|\mathrm{m}_{\mathrm{c}}\right|$ (circles) at different mean effective stress p' on the fine sand used in Chapter 2. The relationship between $\mathrm{p}^{\prime}$ and $\mathrm{m}_{\mathrm{u}}$ is the same as the relationship between $\mathrm{p}^{\prime}$ and $\left|\mathrm{m}_{\mathrm{c}}\right|$, and both are best fit with a logarithmic equation (dashed line, $\mathrm{R}^{2}=0.92$ ).

Figure 3.4: A: volumetric strain against differential stress q measured from one drained vertical compression test on the fine sand, with an initial mean effective stress $\mathrm{p}_{0}^{\prime}$ of $14 \mathrm{kPa}$. The solid line represents the total volumetric strain $\varepsilon_{\mathrm{v}}$, from both shear dilation and isotropic loading. The dashed line represents the volumetric strain from shear dilation only. The parameters $\mathrm{m}_{\mathrm{t}}$ and $\mathrm{m}_{\mathrm{q}}$ are defined as the local slopes on the total volumetric strain curve and the volumetric strain from shear curve respectively. $B: m_{t}$ against effective stress ratio $R^{\prime}$ for the same test. Both $R^{\prime}$ and $m_{t}$ reaches their maximum value at the same point $\left(R_{m}^{\prime}, M_{t}\right)$, represented by the filled circle. .36

Figure 3.5: Relationship between normalized $\mathrm{m}_{\mathrm{t}}$ (defined in Figure 3.4A) and the normalized effective stress ratio R'. Each solid grey ling represents results from one drained vertical compression test. The deposit reaches its critical state when $\frac{R^{\prime}}{R_{m}^{\prime}}=1$. I use a power-law relationship to fit all experimental results (dashed line, $\mathrm{R}^{2}=0.87$ ). 38

Figure 3.6: Relationship between the maximum value for $m_{t}$ (denoted as $M_{t}$, defined in Figure 3.4B) and the initial mean effective stress $p_{0}^{\prime}$ from 6 different tests. The relationship between $M_{t}$ and $1 / p_{0}^{\prime}$ is best fit with a linear function $\left(\mathrm{R}^{2}=0.85\right)$. 
Figure 3.7: Contours of the full 2D model results. The horizontal axis (distance to the breaching front) is in logarithmic scale so that changes very close to the breaching front can be highlighted. A: contour of the excess pore pressure $\mathrm{u}^{*}$ in $\mathrm{Pa}$. The two horizontal profiles are located at $\mathrm{y}=10 \mathrm{~cm}$ (line $\mathrm{ab}$ ) and $\mathrm{y}=20 \mathrm{~cm}$ (line $\mathrm{a}^{\prime} \mathrm{b}^{\prime}$ ) and they are investigated in more details in Figure 3.8. B: contour of the total volumetric strain $\varepsilon_{\mathrm{v}}$. C: contour of the dilation potential $\beta$. D: contour of the normalized effective stress ratio $R^{\prime} / R_{m}^{\prime}$ (effective stress ratio divided by its maximum value). The deposit is critical state when $\frac{R^{\prime}}{R_{m}^{\prime}}=1$. All contour levels are calculated using MATLAB ${ }^{\mathrm{TM}}$ contour function, which makes linear interpolation whenever the contour line does not intercept an existing grid point.

Figure 3.8: Horizontal profiles of dilation potential $\beta$ and excess pore pressure $u^{*}$ at $\mathrm{y}=10 \mathrm{~cm}$ (lines $\mathrm{ab}$ ) and $\mathrm{y}=20 \mathrm{~cm}$ (lines $\mathrm{a}^{\prime} \mathrm{b}^{\prime}$ ) respectively. A: excess pore pressure against distance from the breaching front. B: dilation potential against distance from the breaching front. .44

Figure 3.9: Stress path of two representative volumes (RV) in the deposit, located at $\mathrm{x}=100 \mathrm{~cm}, \mathrm{y}=10 \mathrm{~cm}$ (path ba) and $\mathrm{x}=100 \mathrm{~cm}, \mathrm{y}=20 \mathrm{~cm}$ (path b'a') in Euclarian reference frame at the initiation of breaching. The color of the dots represents the distance of the dots to the breaching front.

Figure 3.10: Normalized excess pore pressure $\mathrm{u}^{*} / \mathrm{u}_{\mathrm{m}}^{*}$ against distance from different models compared to the measured steady state excess pore pressure for the fine sand presented in Chapter 2 
Figure 3.11: Dimensionless minimum excess pore pressure $u_{m}^{*}(y) / u_{m}^{*}\left(y_{0}\right)$ for the full 2D model (solid line) and uniform 2D model (dash-dotted line) and dimensionless magnitude of unloading $\left.\frac{\partial \sigma_{3}}{\partial \mathrm{x}}\right|_{(0, \mathrm{y})}\left[\left.\frac{\partial \sigma_{3}}{\partial \mathrm{x}}\right|_{\left(0, \mathrm{y}_{0}\right)}\right]^{-1}$ (dashed line) against dimensionless depth $y / y_{0}$, where the reference depth $\mathrm{y}_{0}=10 \mathrm{~cm}$ (solid line). The slopes of the solid line represent the rate of increase in pore pressure drop in the full 2D model with depth. The slopes of the dash-dotted line represent the rate of increase in pore pressure drop in the uniform 2D model with depth. The dashed line, representing the increase in the magnitude of unloading with depth, has a constant slope of 1 because unloading increases linearly with depth. .52

Figure 3.12: Contour of normalized effective stress ratio $R^{\prime} / R_{m}^{\prime}$ for the uniform $2 D$ model: a 2D model with uniform dilation potential $\beta$. .53

Figure 3.13: Modeled erosion rate, or velocity of the breaching front, $\mathrm{v}$ against depth. Dilation potential is a function of stresses in this model (Equation 14).

Figure 4.1: Side view of the setup of the experiment 65 
Figure 4.2: Dual-mode slope failure captured by video and sonar. A: sketch of breaching mode slope failure. B: sketch of the sliding mode slope failure as the wedge starts to slide down slope. The sliding wedge is thicker near its top therefore as it slides down the location of the failure front could temporary prograde instead of retreat (e.g., circled area in subfigure C). C: ultrasound image showing the retreating of the failure front with time. The gray scale represents the amplitude of the reflected acoustic wave; the white color represents largest amplitudes, i.e., strongest reflectors. The coordinates of the brightest reflectors (e.g., point a) represent the distance the failure front has retreated (horizontal axis, d) at a given time $\mathrm{t}$ (vertical axis). 68

Figure 4.3: Measured excess pore pressure $\mathrm{u}^{*}$ in the deposit. A: measured excess pore pressure at the 4 locations closest to the initial gate (labeled in different colors) against time $t$. The grey color shaded area contains measurements made before releasing the gate. The yellow color shaded area indicates the duration of initiation (pulling gate out). B: measured excess pore pressure from all the sensors (squares) against distance from failure front (x) at 3 different time: 10s (dash dotted line), 18s (dashed line), and 20s (solid line). $\mathrm{x}=0$ is the failure front.

Figure 4.4: Excess pore pressure measurements for all the sensors against time (top figure) compared to the position of the slope failure surface against time (bottom figure, it is Figure 4.2C viewed in a different orientation). The two time series are aligned at the moment the gate starts to slide $(t=0)$. The red dashed lines mark the time when the excess pore pressure $\left(\mathrm{u}^{*}\right)$ suddenly drops in the top figure..... 
Figure 4.5: Dissipation of the excess pore pressure with time from the sensor closest to the initial position of the gate (solid line, u1 in Figure 4.1 and 3A), numerical solution for pore pressure at the location of $\mathrm{u} 1 \mathrm{with}$ default modeling parameters (dashed line), and numerical model solution for pore pressure at the location of $\mathrm{u} 1$ with a coefficient of consolidation $\mathrm{Cv}$ that is 10 times smaller than the default value (dash-dotted line).....78

Figure 4.6: Sketch of the stability analysis and an example of the results. A: sketch of the stability analysis. I consider slope angle $\theta \in\left[30^{\circ}, 90^{\circ}\right]$ in this analysis and slopes extends to the bottom of the failure front (point " $\mathrm{O}$ " ), e.g., slope $s_{1}$. B: factor of safety, FoS, (Equation 4.8) for different slope angles at $\mathrm{t}=2 \mathrm{~s}$ (solid line) and $7.4 \mathrm{~s}$ (dashed line) in the numerical model. The grey shaded area has FoS $<1$ and slopes in this area are unstable. Model results for $\theta>86^{\circ}$ are considered spurious for reasons discussed in the text. Neglecting these high values of $\theta$ it is clear that for this particular case all surfaces are stable and $\mathrm{FoS}_{\mathrm{m}}$ at $\theta=65^{\circ}$ is the least stable of these slopes. .79

Figure 4.7: Modeled minimum factor of safety, $\mathrm{FoS}_{\mathrm{m}}$ (solid line), and minimum excess pore pressure at $\mathrm{y}=10 \mathrm{~cm}, \mathrm{u}_{10}^{*}$ (dashed line), against time, $\mathrm{t}$. I choose $u_{10}^{*}$ against time to represent the trends of excess pore pressure in the deposit. When $\mathrm{FoS}_{\mathrm{m}}<1$ (at $\mathrm{t}=7.4 \mathrm{~s}$ ), the deposit becomes unstable and sliding occurs. .82 
Figure 4.8: Minimum factor of safety against the minimum excess pore pressure at $\mathrm{y}=10 \mathrm{~cm}$, which represents the pore pressure in the deposit. The solid line with circle at the right end marks the model for the deposit in the experiment, referred as the base model. The dashed dotted line with square in the right end (most of the line covered by the solid line) marks a model that is the same as the base model except the dilation potential is increased by 2 times. The dashed line with star in the right end marks a model with $0.5 \mathrm{~m}$ thickness, same dilation potential as base model, and higher friction angle than the base model. 88

Figure 4.9: Summary sketch of the evolution and possible styles of dilative slope failure. 92

Figure 4.10: Sketch of how a storm could generate dilative slope failure. The top figures are cross sections from the locations marked as dashed lines on the associated regional maps positioned underneath each section. 1. prestorm. 2. storm enhanced or generated currents (arrows) cut into the deposit. 3. the cut initiates slope failure and the failure front retreats toward the right-hand side of the figure. 93

Figure A.1: Excess pore pressure measured at 9 locations during one breaching experiment. The two lines colored blue and red are the two sensors presented in Chapter 2. 108

Figure A.2: StressMohr circle for the testing specimen at critical state. Measured normal stress $\sigma_{\mathrm{N}}$ is $\mathrm{OB}$, measured shear stress $\tau$ is BC. The mean stress $\mathrm{p}$ is $\mathrm{OA}$, and the differential stress $\mathrm{q}$ is $\mathrm{AC}$. Line $\mathrm{OC}$ is the failure envelope and the angle AOC is the internal friction angle $\phi$ 
Figure B.1: Total volumetric strain $\varepsilon v$ against differential stress $q$ from a triaxial shear test with an initial mean effective stress of $14 \mathrm{kPa}$. Point A marks the start of the shear. Point B marks the maximum differential stress; it also represents the point of shear failure of the specimen.

Figure B.2: Normalized mt (definition in Equation B.1) against normalized differential stress. Each solid line represents results from one test. The dashed line is the best fit power-law relationship for all the test results (Equation B.3) …………………………………………….....112

Figure C.1: Sketch of the setup for pore pressure measurements.......................121

Figure D.1: Setup of the flume and measuring instruments for slope failure experiments. 125 


\section{Chapter 1: Introduction}

The purpose of this study is to expand our knowledge on the mechanics of submarine slope failure and how sediments are released from submarine slope failure events. Submarine slope failure is an important mechanism that releases sediments stored on the continental shelf into the deep sea (Hampton et al., 1996; Van den Berg et al., 2002; Piper and Normark, 2009). Accurate interpretation of the sedimentary records in subsurface and the morphological changes on the surface of the sea floor requires a complete understanding of submarine slope failure. First, we need to understand the mechanics of submarine slope failure to be able to predict what conditions could lead to slope failure under sea level. Second, we need to understand how sediment is released from slope failure to accurately describe how slope failure redistributes sediments.

Previous studies identify two end members of submarine slope failure. One end member is the liquefaction slope failure that is usually associated with clay rich deposits (Terzaghi, 1956; Morgenstern, 1967; Hampton et al., 1996; McAdoo et al., 2000). During liquefaction large amounts of sediments are released as a slide or slump. The other end member is breaching that occurs in densely packed sand (de Koning, 1970; Van den Berg et al., 2002; Eke et al., 2011). Breaching is characterized by slow release of sand grains over a near-vertical failure surface; the failure surface retreats at a constant rate. Studies suggest that the differences in sediment release between those two end members are due to different types of shear deformation and different excess pore pressure (defined as the difference between the pore pressure and the hydrostatic pore pressure) in the sediment. During liquefaction the sediment contracts under shear, which increases the excess pore pressure (Terzaghi, 1951; Hampton et al., 1996; Flemings et al., 2008). The increase in excess pore pressure decreases the effective stress between sediment grains and weakens 
the deposit (Terzaghi, 1951; Wood, 1990). During breaching the sediment dilates, which decreases the excess pore pressure (Meijer and van Os, 1976; Van Rhee and Bezuijen, 1998). The drop in excess pore pressure increases the effective stress between the sediment grains and strengthens the deposit (Wood, 1990). In summary, excess pore pressure controls the slope failure by changing the effective stress. On the other hand, slope failure generates excess pore pressure. Slope failure release sediments from the deposit, which changes the stresses in the deposit. Changes in stress can generate excess pore pressure in the deposit (Skempton, 1954; Gibson, 1958; Meijer and van Os, 1976).

Previous studies suggest that the excess pore pressure and the slope failure are coupled (Terzaghi, 1951; Meijer and van Os, 1976; Hampton et al., 1996; Van Rhee and Bezuijen, 1998; Flemings et al., 2008). However, studies on the mechanics of submarine slope failure so far separate the excess pore pressure and the slope failure. For example, Meijer and van Os (1976) built a 2D model to show that breaching slope failure generates negative excess pore pressure. However, they assume the rate of sediment release, or erosion rate, is a constant and treat it as an input variable in the model. Because the coupling is missing from those studies they cannot explain why the erosion rate is constant or other features that rely on the interaction between the slope failure and the excess pore pressure. Studies on the interaction between slope failure and excess pore pressure can help us to setup a framework to study the mechanics of slope failure, especially how sediments are released from slope failure. Iverson et al (2000) adopted this approach in studying subarial slope failures. Iverson et al (2000) combines measurements of displacement and pore pressure in subarial slope failure experiments and find that dilative sediment and contractive sediment are associated with different styles of slope failure. Here I apply a similar approach in studying submarine slope failures in sediment that dilates. 
In this study, I investigate the coupling of excess pore pressure and slope failure in two different types of slope failure: breaching and a new type of slope failure that I call the dual-mode slope failure. Both types of slope failure occur in sediments that dilate under shear. I develop a dimensionless parameter called "dilation potential" to quantify the degree of dilation in the sediments and show that this parameter controls the mechanics of dilative slope failure. I also show that the release of sediments in dilative slope failure is controlled by the pore pressure dissipation in the deposit.

In chapter 2, I study the mechanics of pure breaching. I present pore pressure measurements made during breaching, as well as an analytical model that shows how the pore pressure field within the failing deposit is connected to the erosion rate associated with the failure surface. I show that breaching occurs in sediments with dilative potential larger than 4.3. This condition could be common on the continental shelf, making breaching an important mechanism in transferring sediment into the deep ocean. I use the analytical model to show that a dynamic equilibrium exists between the slope failure and the pore pressure dissipation during breaching. This equilibrium leads to a way to estimate the rate of sediment release from breaching using a simple material property, the coefficient of consolidation. Contrary to previous work, I find that the erosion rate is independent of the dilation of the deposit due to the coupling between erosion and pore pressure dissipation. The equilibrium between the erosion and pore pressure dissipation decouples the steady-state pore pressure field from the permeability of the deposit; this is the first time this behavior has been recognized in sediment failures.

In chapter 3, I study the mechanics of breaching in more details with a $2 \mathrm{D}$ numerical model. In this model I show how spatial distribution of the dilation potential affects the excess pore pressure and the release of sediments during breaching. I develop an empirical model for dilation potential based on geotechnical test results from the lab. 
Test results show that the dilation potential increases when the deposit is closer to shear failure. As a result, the majority of dilation as well as the interaction between slope failure and pore pressure occurs close to the failure surface. The experiment results also show that dilation decreases with increasing overburden, as a result, the deposit becomes weaker with increasing depth. I solve for the erosion rate with the 2D numerical model and show that erosion can be treated as being uniform in the vertical direction except for the portion close to the top boundary. Dissipation of pore pressure in the vertical direction accelerates the erosion near the top of the deposit.

In chapter 4, I present a new type of submarine slope failure, the dual-mode slope failure, with experiments. The slope failure is characterized by a periodic switch between breaching and sliding. During breaching mode the sediment is released at a constant rate over a near vertical failure surface. The failure surface retreats at $2.5 \mathrm{~mm} / \mathrm{s}$ for a period of 16s before sliding occurs. During sliding a triangular wedge of sediment slides down along a basal slope of $80^{\circ}$. The deposit becomes stable after the sliding and sediment release is switched back to breaching mode. I present pore pressure measurements and numerical model results to show that the evolution of excess pore pressure switches the slope failure between those two modes. The negative excess pore pressure dissipates towards its steady state during breaching mode; dissipation of the negative excess pore pressure weakens the deposit. The slope failure switches to sliding mode when the magnitude of negative excess pore pressure is too small to keep the deposit stable. This is different from the pure breaching slope failure where the deposit is stable even after the pore pressure reaches its steady state. Sliding increases the magnitude of the negative excess pore pressure; this strengthens the deposit and switches the slope failure back to breaching mode. I show that dilative sediments with smaller dilation potential or smaller friction angle tend to generate dual-mode slope failure instead of breaching slope failure. 


\section{Chapter 2: 1D analytical model for steady state breaching}

\subsection{INTRODUCTION}

Accurate interpretation of Earth-surface morphology and environmental records preserved in sediment accumulations requires a complete understanding of the processes governing the storage and release of sediment on this interface. Breaching is one such process; it is a style of retrogressive subaqueous slope failure that occurs in densely packed sand and is characterized by nearly vertical failure angles, slow and steady retrogressive erosion rates, and production of sustained turbidity currents (Figure 2.1) (Van den Berg et al., 2002; Mastbergen and Van den Berg, 2003; Eke et al., 2011).

Retrogressive slope failures are controlled by the responses of sedimentary deposit to shear. Most granular material either contracts or dilates when subject to shear; the best studied cases are associated with contraction, increased pore pressures, and subsequent liquefaction (Terzaghi, 1951; Hampton et al., 1996; Iverson, 2005). On the other hand, dilation and the development of negative excess pore pressure near the failure surface lead to breaching (Meijer and van Os, 1976; Van Rhee and Bezuijen, 1998). This breaching can be initiated by scour from focused channel flow, or an initial liquefaction slope failure (Van den Berg et al., 2002). Mastbergen and Van den Berg (2003) and Eke et al. (2011) proposed that breaching may be one of the processes by which sands are released into turbidity currents and transported down Scripps Canyon (offshore southern California). Because breaching produces sustained turbidity currents, the sands delivered downslope may build thick uniform turbidites (Van den Berg et al., 2002). Previous studies associate breaching with fine-grained sand (de Koning, 1970; Meijer and van Os, 1976; Van Rhee and Bezuijen, 1998; Van den Berg et al., 2002); however, Houthuys 
(2011) speculated that breaching could also be the mechanism that contributes to building coarse sand turbidites. An understanding of the mechanism of breaching is important to correctly interpret these turbidites.

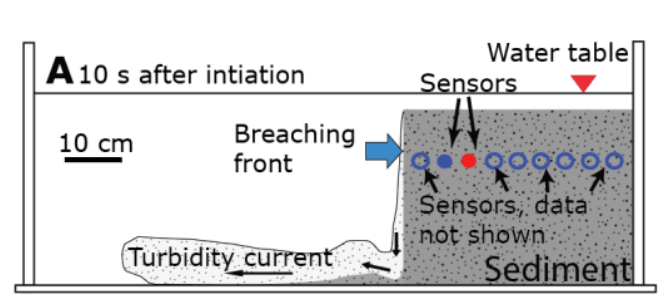

C Pore pressure measurements during breaching

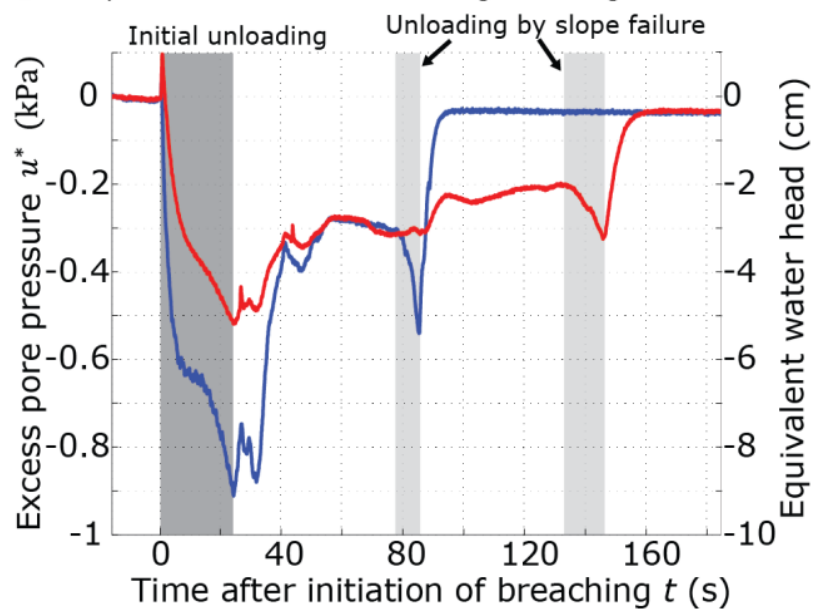

Figure 2.1: Morphodynamic evolution and pore pressure response during breaching. Initial dimensions of sediment: $\sim 30 \mathrm{~cm}$ tall, $40 \mathrm{~cm}$ wide. The pore pressure is monitored at nine locations and I show two of them here for simplicity (for measurements from all sensors see Figure A.1 in Appendix A). A: After $10 \mathrm{~s}$, sediments are falling from vertical face (breaching front) and forming turbidity current (light gray). B: After $80 \mathrm{~s}$, erosion has shifted breaching front to right and it is approaching blue pressure sensor. Turbidity currents have deposited sediment in front of breaching front. C: Removal of retaining wall results in abrupt drop in pore pressure at both sensors $(0-22 \mathrm{~s}$, dark gray region). As breaching front approaches each pressure sensor, there is second pressure drop and then rise to hydrostatic pressure (light gray zones at $80 \mathrm{~s}$ and $130 \mathrm{~s}$ for blue and red sensors, respectively). Final pore pressure is lower than initial pore pressure due to drop of water table, which is caused by removal of restraining plate. Chaotic pore pressure signal recorded between $10 \mathrm{~s}$ and $40 \mathrm{~s}$ by all sensors is due to transient slumping of sediments connected to removal of restraining plate; this is not part of steady-state breaching process I focus on in this study. 
The increase in porosity during breaching is a result of both unloading and shear dilation as the deposit undergoes slow retrogressive failure (Meijer and van Os, 1976; Van Rhee and Bezuijen, 1998). Shear dilation is the dominant mechanism generating the negative excess pore pressure, or underpressure (Meijer and van Os, 1976). As the pore pressure drops, the effective stress increases and stabilizes the deposit. Dissipation of this underpressure must occur for slope failure to continue (Van Rhee and Bezuijen, 1998; Van Rhee, 2007). This dissipation is focused at the failure surface, releasing one grain layer at a time (Van Rhee, 2007). Shear dilation and unloading associated with these failing grains continuously generates underpressure that strengthens the remaining deposit. Here I study the interaction between the pore pressure field and the erosion rate of the failing surface during breaching. I build a physical model that treats the pore pressure field and the erosion rate as coupled variables, rather as variables that do not directly affect one another (Meijer and van Os, 1976; Van Rhee and Bezuijen, 1998; Van Rhee, 2007). I show how this coupling leads to a coevolution of values for the erosion rate and the pore pressure field that could not be otherwise predicted. I also present a model that describes what material properties are necessary for breaching.

\subsection{EXPERIMENTAL OBSERVATION}

I deposit silty sand (median diameter, $\mathrm{D}_{50}=0.14 \mathrm{~mm}$, grain size is presented in Figure 2.2) into one end of a flume filled with water, and restrain the sediment with a vertical mesh plate. The mesh plate allows water to flow through but holds the sediment in place, creating a submerged water-saturated deposit. The plate is removed quickly from the tank to initiate breaching (Figure 2.1A). The deposit does not collapse after the release of the gate and the breaching front starts to retreat. The breaching front maintains 
a slope that is larger than $90^{\circ}$ except for the portion near the top of the deposit, where the slope reduces to $0^{\circ}$ at the top surface. The height of the breaching front decreases with time but its shape is similar at different time (Figure 2.3). The breaching front retrogrades slowly and steadily as the sediment on the vertical face erodes (Figure 2.4) and forms turbidity currents. The average speed of the breaching front, also referred as the erosion rate, is $0.14 \mathrm{~cm} / \mathrm{s}$. These observations are consistent with field examples (Van den Berg et al., 2002) and previous flume studies (Van Rhee and Bezuijen, 1998; Eke et al., 2011).

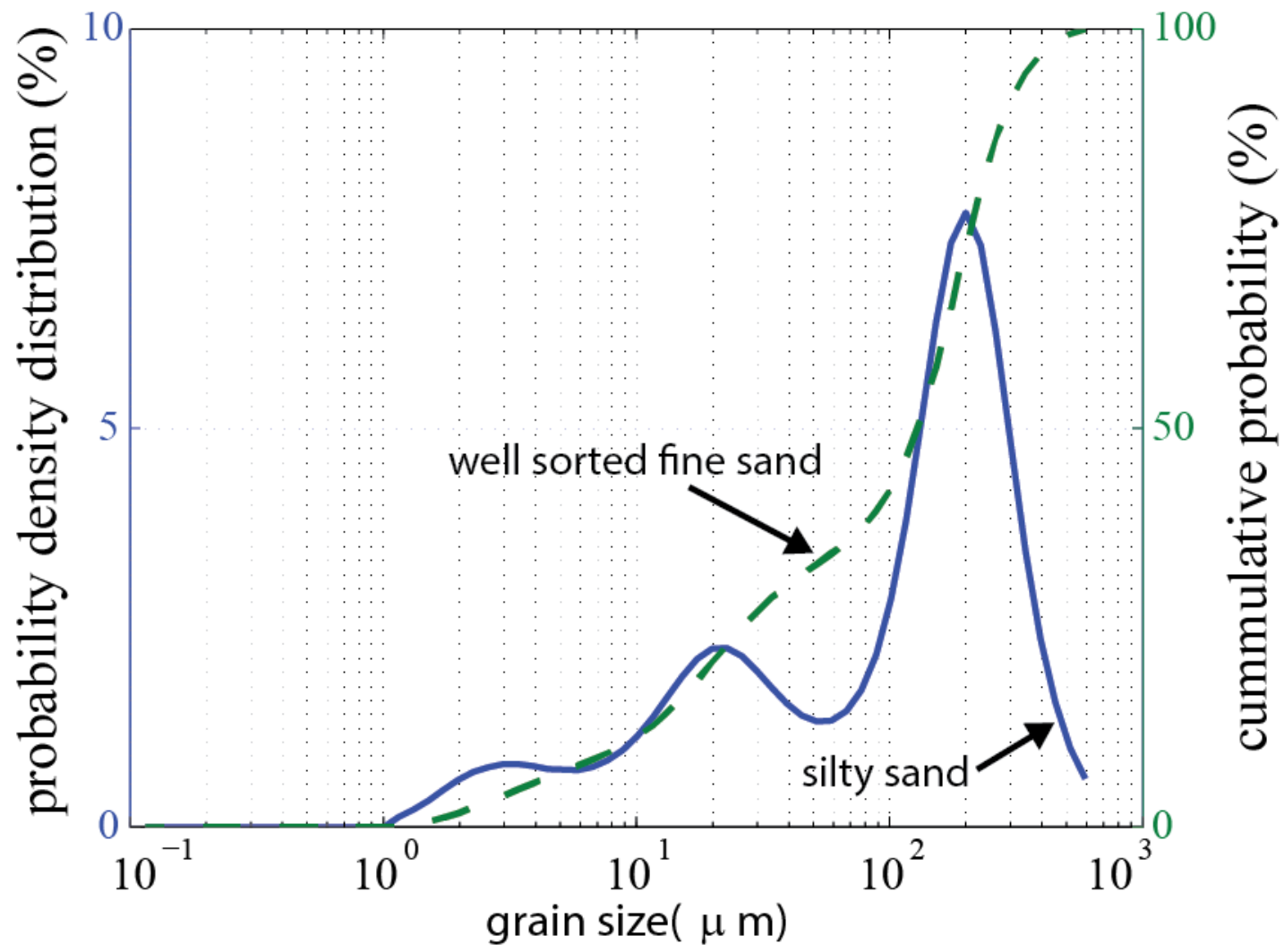

Figure 2.2: Grain size distributions of the silty sand (solid line) and well-sorted fine sand (dashed line) used in the study. 


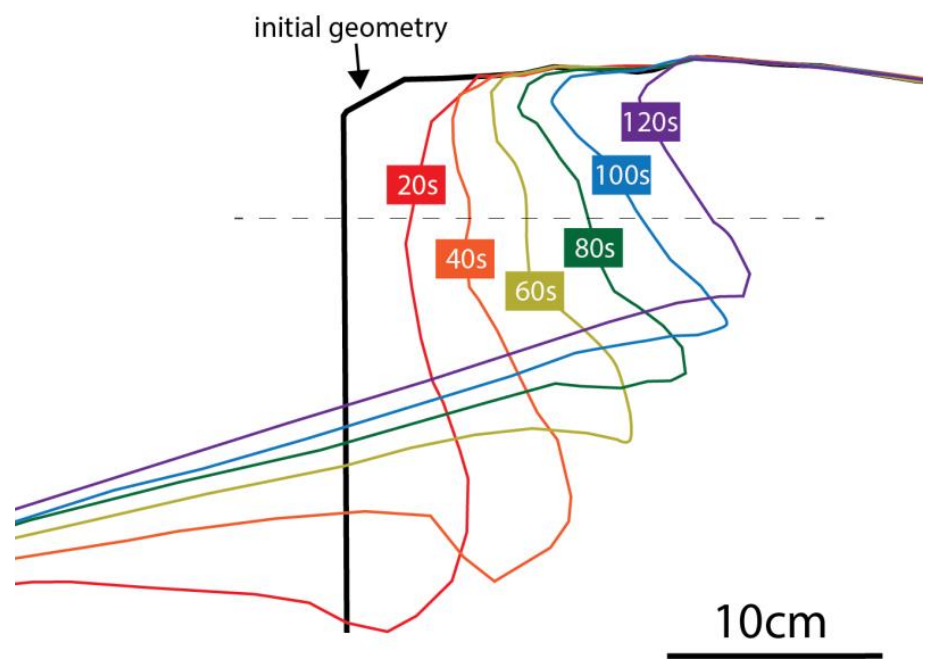

Figure 2.3: Traces of the breaching front during one experiment, the trace lines are separated by $20 \mathrm{~s}$. The dashed line represents the location where I measure the erosion rate (shown in Figure 2.4).

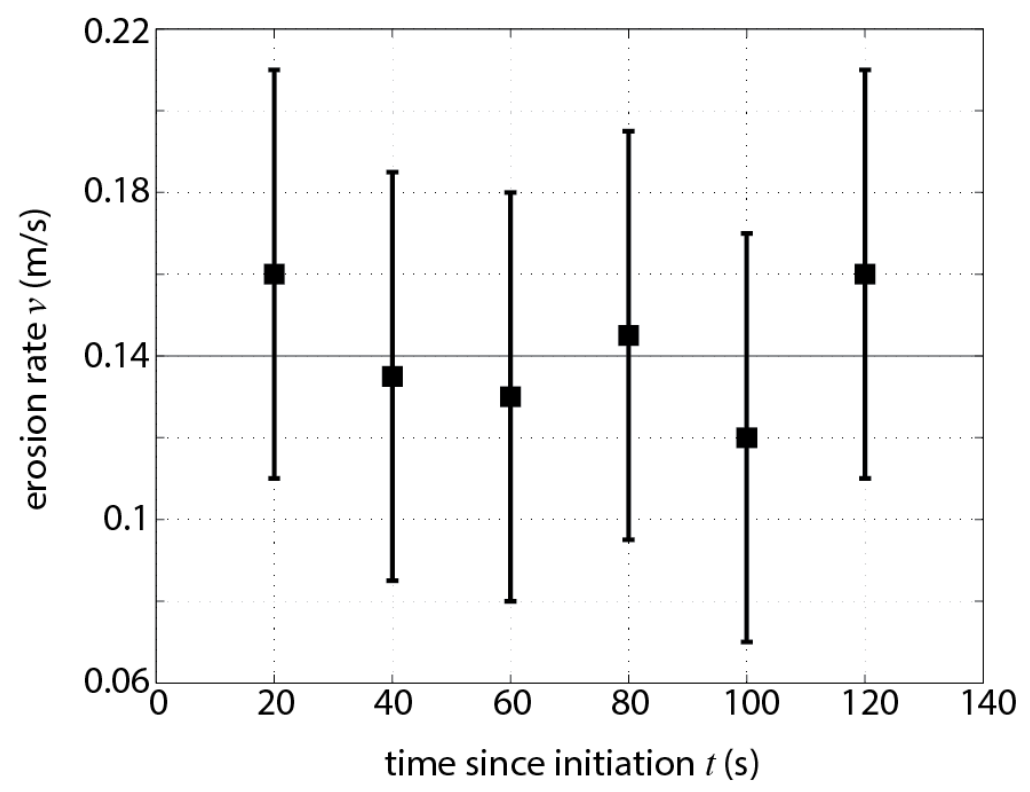

Figure 2.4: Erosion rate $v$ estimated from the trace of breaching front (Figure 2.3) against time. $v$ at time $t$ represents the average velocity between $t-20 \mathrm{~s}$ and $t$; it is calculated as the distance the breaching front travels along the dashed line in Figure 2.3 during this period divided by 20s. The error bars represents the uncertainty in time $( \pm 1 \mathrm{~s})$. This uncertainty is too small compared to the time scale of the experiment (horizontal axis) therefore only its influence on the erosion rate (vertical axis) is plotted here. 
The pore pressure is monitored with pressure sensors plumbed to the sediment by thin stainless steel tubes. Two distinct pore pressure drops are recorded by each sensor. The first drop occurs immediately after the plate is removed (Figure 2.1C). I interpret this drop to be the result of unloading and shear dilation of the deposit caused by removal of the confining vertical plate (Casagrande, 1936; Skempton, 1954; Iverson et al., 2000). The second drop is recorded by a sensor as the breaching front approaches its location in the sedimentary deposit (Figure 2.1C). In the experiment the pore pressure begins to drop when the horizontal distance separating the breaching front and the sensor is about $3 \mathrm{~cm}$. Just before the breaching front passes the sensor location, the pore pressure abruptly rises to hydrostatic pressure over a period of about $10 \mathrm{~s}$ (Figure 2.1C). I interpret this second style of pore pressure decline to be caused by a local unloading and shear dilation of the sediment deposit in the vicinity of the breaching front (Meijer and van Os, 1976; Van den Berg et al., 2002). This pore pressure signal is similar to the one created during the initiation of breaching, only with smaller magnitude. As a result, this pore pressure signal is recorded by the nearest sensor only (Figure 2.1C).

The spatial variation in pore pressure response can be viewed from a Lagrangian reference frame that follows the breaching front (Figure 2.5). In this reference frame the minimum pore pressure always occurs about $3 \mathrm{~cm}$ in front of the breaching surface, and pore pressure rises toward hydrostatic pressure with greater distance into the deposit (Figure 2.5). This spatial pattern for pore pressure was noted in previous studies of breaching (Meijer and van Os, 1976; Van Rhee and Bezuijen, 1998). The experiment in this study shows that the general pattern of pore pressure is maintained through time, converging onto a steady-state profile after $140 \mathrm{~s}$ (cf. pore pressure at $140 \mathrm{~s}$ and $190 \mathrm{~s}$ in Figure 2.5). 


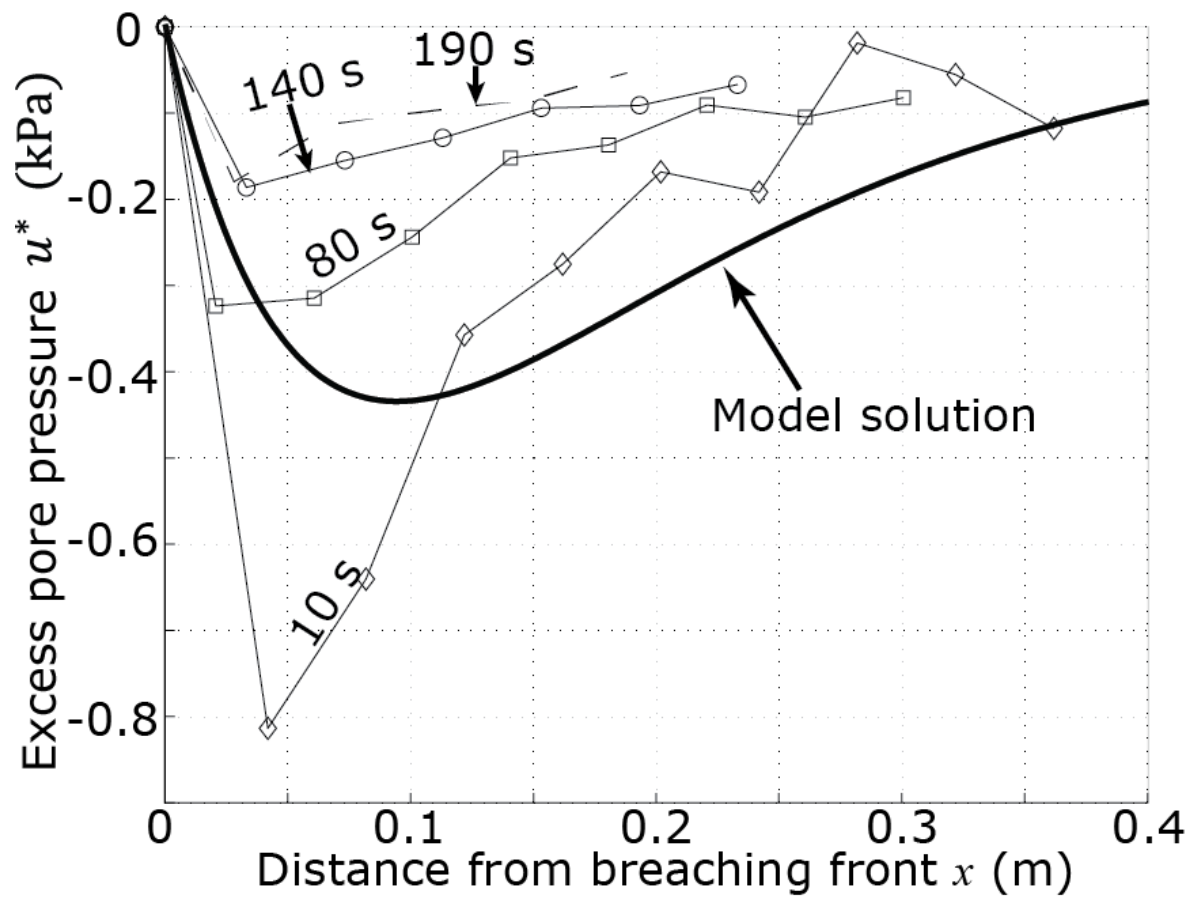

Figure 2.5: Excess pore pressure $10 \mathrm{~s}$ (diamonds), $80 \mathrm{~s}$ (squares), $140 \mathrm{~s}$ (triangles), and $190 \mathrm{~s}$ (dashed line) after onset of breaching, plotted with distance from breaching front (Lagrangian coordinates). At each time, there is minimum in pore pressure $\sim 5 \mathrm{~cm}$ behind breaching front. Pore pressure at $140 \mathrm{~s}$ is almost identical to pore pressure at $190 \mathrm{~s}$ in Lagrangian coordinates, suggesting that pore pressure is at steady state. Solid line is excess pore pressure predicted by Equation 4.

\subsection{D STEADY-STATE BREACHING MODEL}

The existence of a steady-state pore pressure profile suggests that a balance exists between the pore pressure dissipation, which triggers slope failure, and the continuous dilation, which produces negative pore pressure. I describe this balance in a onedimensional steady-state model. Consider a sediment volume with constant material properties moving with the breaching front at steady erosion rate $v$; the pore pressure in the Lagrangian reference frame can be written as 


$$
C_{\mathrm{v}} \frac{\partial^{2} u^{*}}{\partial x^{2}}+v \frac{\partial u^{*}}{\partial x}-v \beta \frac{\partial \sigma_{3}}{\partial x}=0, \text { for } x>0,
$$

where $u^{*}$ is the excess pore pressure, $\sigma_{3}$ is the least principal stress (assumed to be horizontal), $C_{v}$ is the coefficient of consolidation $\left(C_{v}=\frac{k}{\mu m_{u}}\right.$ where $k$ is the permeability, $\mu$ is the viscosity, and $m_{u}$ is the isotropic unloading compressibility), $\beta$ is a dimensionless parameter I refer as dilation potential $\left(\beta=\frac{1}{2}+\frac{m_{q}}{2 m_{u}}\right.$, where $m_{q}$ is the volumetric strain per unit differential stress) and $\beta>\frac{1}{2}$ for dilative material. The permeability $k$ is measured with constant head tests (ASTM, 1970). The material properties $m_{u}$ and $m_{q}$ can be measured with a traxial shearing device and I present the procedures to measure those two parameters in Chapter 3. Both parameters changes with stresses, but in this chapter I consider both parameters as constants so that an analytical solution to Equation 2.1 is possible.

The first two terms in Equation 2.1 describe pore pressure dissipation by Darcy flow with a moving boundary. The third term describes the pore pressure sink produced by continuous dilation that is a function of the change in the least principal stress, $\sigma_{3}$. Excess pore pressure is assumed to equal 0 both at the breaching front and $x \rightarrow \infty$. The water table does not change during breaching, thus $\partial u=\partial u^{*}$. This equation is similar to the Meijer and van Os (1976) model, with three key differences. First, I use a simplified dilation model where I assume that the dilative volumetric strain is only a function of differential stress, while Meijer and van Os (1976) also considered the effect of the mean effective stress and the effective stress ratio. The Meijer and van Os (1976) treatment of dilation is more sophisticated, but analytical solutions are unobtainable. By simplifying the model and obtaining an analytical solution I are able to better understand the interactions between each of the processes connected to breaching. The other two differences lie in the ways I model stress transmission and the erosion process (explained in the following). 
I assume that the change in least principal stress, the source for continuous dilation, declines exponentially with distance from the breaching front:

$$
\frac{\partial \sigma_{3}}{\partial x}=\eta s_{0} e^{-\eta x}, \text { for } x>0,
$$

where $s_{0}$ is the value of least principal stress as $x \rightarrow \infty$, and $\eta$ is a constant that defines the rate of stress decay with distance. Equation 2.2 is consistent with our measured initial pore pressure profile at $10 \mathrm{~s}$ (Figure 2.5); it also explains the localized pore pressure signal produced by the continuous dilation (Figure 2.1C). Previous studies have shown similar behavior in dry granular material undergoing localized unloading (Balmforth and Kerswell, 2005; Lube et al., 2005; Siavoshi and Kudrolli, 2005) and when subjected to a stress pulse (Hostler, 2004). This model is different from the linear elastic model used by Meijer and van Os (Meijer and van Os, 1976) and it results in more dilation close to the breaching front.

The drop in pore pressure caused by dilation creates a pore pressure gradient (Figure 2.5A) that drains water into the deposit through the breaching front. As a consequence, the pore pressure near the front increases and the effective stress decreases, which results in failure and erosion. The volumetric strain $\left(\varepsilon_{v}\right)$ times the erosion rate $(v)$, which is the change in volume per time, must equal the flux of water per unit area $(Q)$ into the deposit, $\varepsilon_{v} v=Q$. I assume that the volumetric strain is proportional to the minimum pore pressure, $\varepsilon_{v}=E_{0} u_{\mathrm{m}}$, where $E_{0}$ is a function of the friction angle of the deposit and the stress level prior to breaching. Hence,

$$
v=\frac{Q}{E_{0} u_{m}^{*}}=-\left.\frac{k}{E_{0} u_{m}^{*}} \frac{\partial u^{*}}{\partial x}\right|_{x=0} .
$$

Solutions for Equations 2.1, 2.2, and 2.3 yield

$$
\begin{aligned}
& v=\delta \eta C_{\mathrm{v}}, \\
& u^{*}=\frac{\delta \eta s_{0}}{\delta-1}\left(e^{-\eta x}-e^{-\frac{v}{C_{\mathrm{v}}} x}\right),
\end{aligned}
$$


where $\delta=\frac{W\left[\frac{m_{u}}{E_{0}} \log \left(\frac{m_{u}}{E_{0}}\right)\right]}{\log \left(\frac{m_{u}}{E_{0}}\right)}$ and $W(x)$ is the Lambert W-function (Polya and Szegö, 1970).

\subsection{EQUILIBRIUM BETWEEN THE SLOPE FAILURE AND PORE PRESSURE DISSIPATION}

The erosion rate $(v)$ is proportional to the coefficient of consolidation $\left(C_{\mathrm{v}}\right)$ (Equation 2.4). Thus during breaching, more rapid dissipation (high $C_{\mathrm{v}}$ ) is balanced by more rapid erosion, as has been shown by previous studies (Van Rhee and Bezuijen, 1998; Van Rhee, 2007). An interesting result from the solution (Equation 2.4) is that the erosion rate is independent of the dilation potential $(\beta)$. A larger $\beta$ generates a larger change in porosity, which requires a greater volume of water to flow into the dilated material. However, the larger dilation potential also generates more underpressure, resulting in a larger flow rate. These two effects compensate for each other to produce an erosion rate that is independent of the dilation potential. This result conflicts with the prediction of Van Rhee (2007), who suggested that the erosion rate is lower for greater dilation potential; however, Van Rhee (2007) did not couple the pore pressure field with the erosion process and therefore did not include the feedback that produces an erosion rate that is independent of dilation potential.

There is a dynamic equilibrium between pressure dissipation and continuous dilation. At steady state, the slope failure triggered by the pore pressure dissipation always produces a dilative strain in the remaining deposit that returns the pore pressure back to its original level. This is because the magnitude of dilation is proportional to the erosion rate (Equation 2.1), and the erosion rate is proportional to the coefficient of consolidation (Equation 2.4). This feedback keeps the pore pressure profile at steady state in the Lagrangian reference frame. One consequence of this dynamic equilibrium is that the steady-state pore pressure is independent of the permeability $k$. This can be shown 
mathematically by substituting Equation 2.4 into Equation 2.5, which removes $C_{\mathrm{v}}$ $(=k / \mu E)$ from the pore pressure solution.

I use a group of parameters $\left(C_{\mathrm{v}}=1.4 \times 10^{-4} \mathrm{~m}^{2} \mathrm{~s}^{-1}, \beta=4.5, m_{\mathrm{v}}=3.5 \times 10^{-7} \mathrm{~Pa}^{-1}\right.$, $\eta=15, s_{0}=400 \mathrm{~Pa}$ ) measured from the lab and fit $E_{0}=1.4 \times 10^{-6} \mathrm{~Pa}^{-1}$ to the measured erosion rate in order to predict the steady-state pore pressure field connected with our experiment. The modeled pressure distribution is similar in shape to the observed pressure (140 s in Figure 2.5); confirming the form of the analytical solution. However, the magnitude of the pore pressure drop predicted by the model is twice the observed values (Figure 2.5). This discrepancy may result from our assumption of constant material properties. For example, if the coefficient of consolidation $\left(C_{\mathrm{v}}\right)$ increases as sediment dilates, then the pore pressure minimum will be closer to hydrostatic pressure than the modeled example. In addition, I do not include vertical draining in the $1 \mathrm{D}$ model; the draining of pore pressure in the vertical direction could reduce the magnitude of the underpressure.

To explore the control of material properties on breaching I carry out experiments using two types of sediments, silty sand and well sorted fine sand (grain sizes are presented in Figure 2.2). During breaching, the erosion rate of the fine sand is 4 times that of the silty sand, and the excess pore pressure profiles at steady state are identical (Figure 2.6). Geotechnical analysis shows that the compressibility of the two materials are similar but the permeability of the fine sand is 65 times that of the silty sand, which means the $C_{v}$ for the fine sand should be 65 times that of the silty sand (Equation 2.1). Equation 2.4 and 2.5 predict that materials of similar compressibility have similar pore pressure profiles, as is observed. However, Equation 2.4 also predicts that the erosion rate for the fine sand should be 65 times larger than the silty sand (i.e., proportional to $C_{\mathrm{v}}$ ) whereas I only observe a 4 times difference. The discrepancies can be explained an 
overestimation of the coefficient of consolidation $C_{v}$ for the fine sand or an underestimation of the coefficient of consolidation for the silty sand.

There are two possible sources for the mismatch of $C_{v}$ and I use the silty sand as an example. First, the underestimation of the $C_{v}$ for the silty sand could due to an underestimation of the permeability $k$ from the lab. I measure permeability $k$ in the direction the sediments are deposited. However, the 1D model considers the pore water flow, therefore the permeability, in the direction perpendicular to the direction the sediments are deposited. The difference in the direction of the permeability could cause and underestimation its value, especially in a silty sand deposit where stratification due to sorting can occur in the direction of sedimentation (Freeze and Cherry, 1977). Second, the underestimation of $C_{v}$ for the silty sand could due to an overestimation of $m_{u}$ from the lab. I measure the values for $m_{u}$ with isotropic stress condition, i.e., the major and minor principal stresses are the same. However, the deposit in the experiment experience anisotropic stress conditions; the vertical stress is larger than the horizontal stress due to removal of the horizontal support. The different stress conditions alters the fabric of the deposit (Oda, 1972; Oda et al., 1980) and could change the values for $m_{u}$, thus $C_{v}$. More research on how to properly model the compressibility is required to resolve this discrepancy. Further discussion on this topic is presented in Chapter 6: Future Research. 


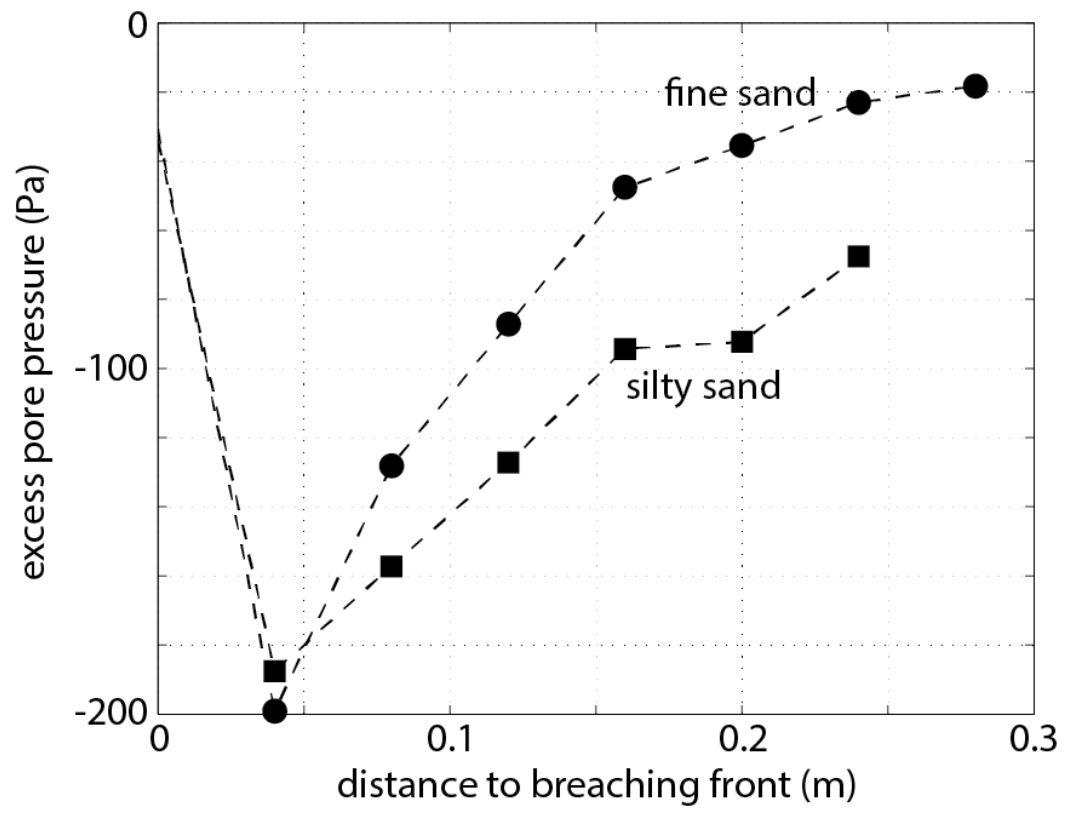

Figure 2.6: Measured steady state excess pore pressure against distance from the breaching front for the fine sand (circles) and silty sand (squares).

\subsection{CHARACTERISTICS OF THE STEADY STATE PORE PRESSURE SOLUTION}

To further explore the control of material properties on the steady state excess pore pressure solution (Equation 2.5) I introduce dimensionless form of the excess pore pressure solution. Let $\left\langle u^{*}\right\rangle=\frac{u^{*}}{\beta s_{0}}$ be the dimensionless excess pore pressure and $\langle x\rangle=\frac{x v}{C_{v}}$ be the dimensionless distance, then the steady state solution transforms into the following

$$
\left\langle u^{*}\right\rangle=\frac{\left.\exp \left(-\frac{\eta C_{v}}{v}(x\rangle\right)\right)-\exp (-\langle x\rangle)}{\frac{\eta C_{v}}{v}-1}
$$

The dimensionless parameter $\frac{\eta C_{v}}{v}$ is the ratio between two length scales, $C_{v} / v$ and $1 / \eta$, and it controls the dimensionless steady state solution. The length scale $1 / \eta$ represents the distance where the unloading, or the decrease in horizontal stress, is $1 / e$ times (37\%) that of the breaching front (Equation 2.2). Therefore $1 / \eta$ represents the 
characteristic distance for changes in stress and the source for excess pore pressure. The length scale $\frac{C_{v}}{v}$ represents the changes of pore pressure due to advection (through the moving boundary) and diffusion (through pore water flow). To illustrate its physical meaning, I setup a boundary condition problem similar to Equations 2.1 with two changes. First, there is no source term in this problem. Second, the excess pore pressure at breaching front equals to a finite non-zero value $u_{0}$. Therefore,

$$
\begin{aligned}
& \frac{d^{2} u^{*}}{d x^{2}}+v \frac{d u^{*}}{d x}=0 \\
& u^{*}(0)=u_{0} \\
& \lim _{x \rightarrow \infty} u^{*}(x)=0
\end{aligned}
$$

This set of equations describes the changes of pore pressure due to advection and diffusion, without the influence of a source. The solution to this problem is

$$
u^{*}=u_{0} \exp \left(-\frac{v}{C_{v}} x\right)
$$

The solution shows that the length $C_{v} / v$ is the distance where the excess pore pressure is $1 / e$ times $(37 \%)$ that of the boundary value.

In summary the parameter $\frac{\eta C_{v}}{v}$ combines all the factors that control the spatial variation in pore pressure: $1 / \eta$ controls the changes in source of pore pressure and $C_{v} / v$ controls the changes in pore pressure due to advection and diffusion. I denote

$$
\xi=\frac{\eta C_{v}}{v}
$$

as the controlling parameter for dimensionless excess pore pressure $\left\langle u^{*}\right\rangle$. The location and value of the minimum for $\left\langle u^{*}\right\rangle$ are both functions of $\xi$. The location $\left\langle x_{m}\right\rangle=\frac{\log \xi}{\xi-1}$, i.e., the dimensionless distance to the minimum $\left\langle u^{*}\right\rangle$ decreases as $\xi$ increases (Figure 2.7A). The value of the minimum dimensionless excess pore pressure, $\left\langle u_{m}\right\rangle$, is $-\xi^{-\frac{\xi}{\xi-1}}$. $\left\langle u_{m}\right\rangle$ increases in value (becomes less negative and closer to hydrostatic pore pressure) as $\xi$ increases in value (Figure 2.7B). 

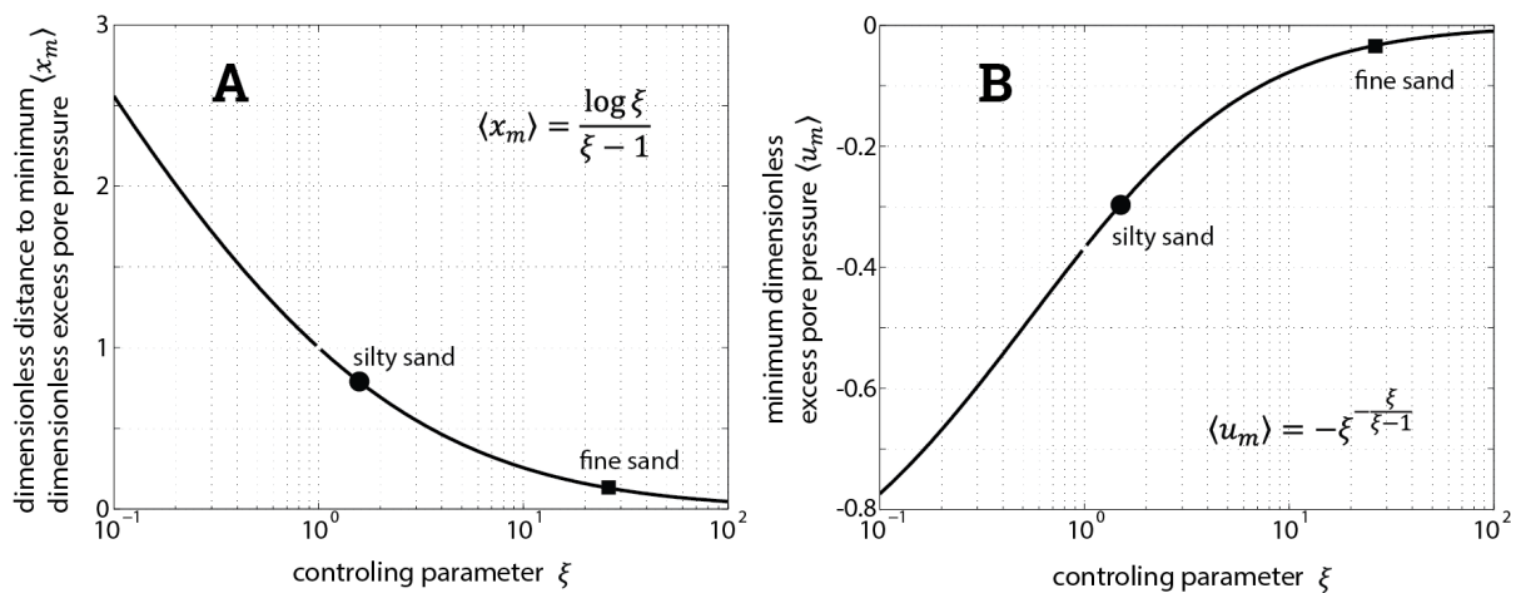

Figure 2.7: A: The dimensionless distance to the minimum dimensionless excess pore pressure (or maximum pore pressure drop) $\left\langle x_{m}\right\rangle$ against the controlling parameter $\xi$ for the dimensionless excess pore pressure solution. B: the minimum dimensionless excess pore pressure $\left\langle u_{m}\right\rangle$ against the controlling parameter $\xi$. The circle symbol in both sub figures marks the $\xi$ for fine sand and the square symbol in both sub figures marks the $\xi$ for silty sand.

I use two the silty sand and fine sand experiment results (Figure 2.6) to test the dimensionless solution. The controlling parameter $\xi$ is 24 for the fine sand and 1.5 for the silty sand, a 16 fold difference. The two types of sediment have very different dimensionless pore pressure $\left\langle u^{*}\right\rangle$ profile, even though the actual pore pressure profile are very similar (Figures 2.6 and 2.8 ). The modeled $\left\langle u^{*}\right\rangle$ roughly fits the measured $\left\langle u^{*}\right\rangle$ for the silty sand (Figure 2.8A) but does not fit very well for the fine sand (Figure 2.8B). The model overestimates $\left\langle x_{m}\right\rangle$ for both types of deposit but fits much better for the silty sand case. The overestimation of $\left\langle x_{m}\right\rangle$ could due to the assumption that dilation potential is a constant. In the next Chapter I show that in a model with spatial variations of dilation potential, the location for minimum excess pore pressure is closer to the breaching front (i.e., $\left\langle x_{m}\right\rangle$ is smaller) than a model with constant dilation potential. (Section 3.4.4, Figure 2.10) 

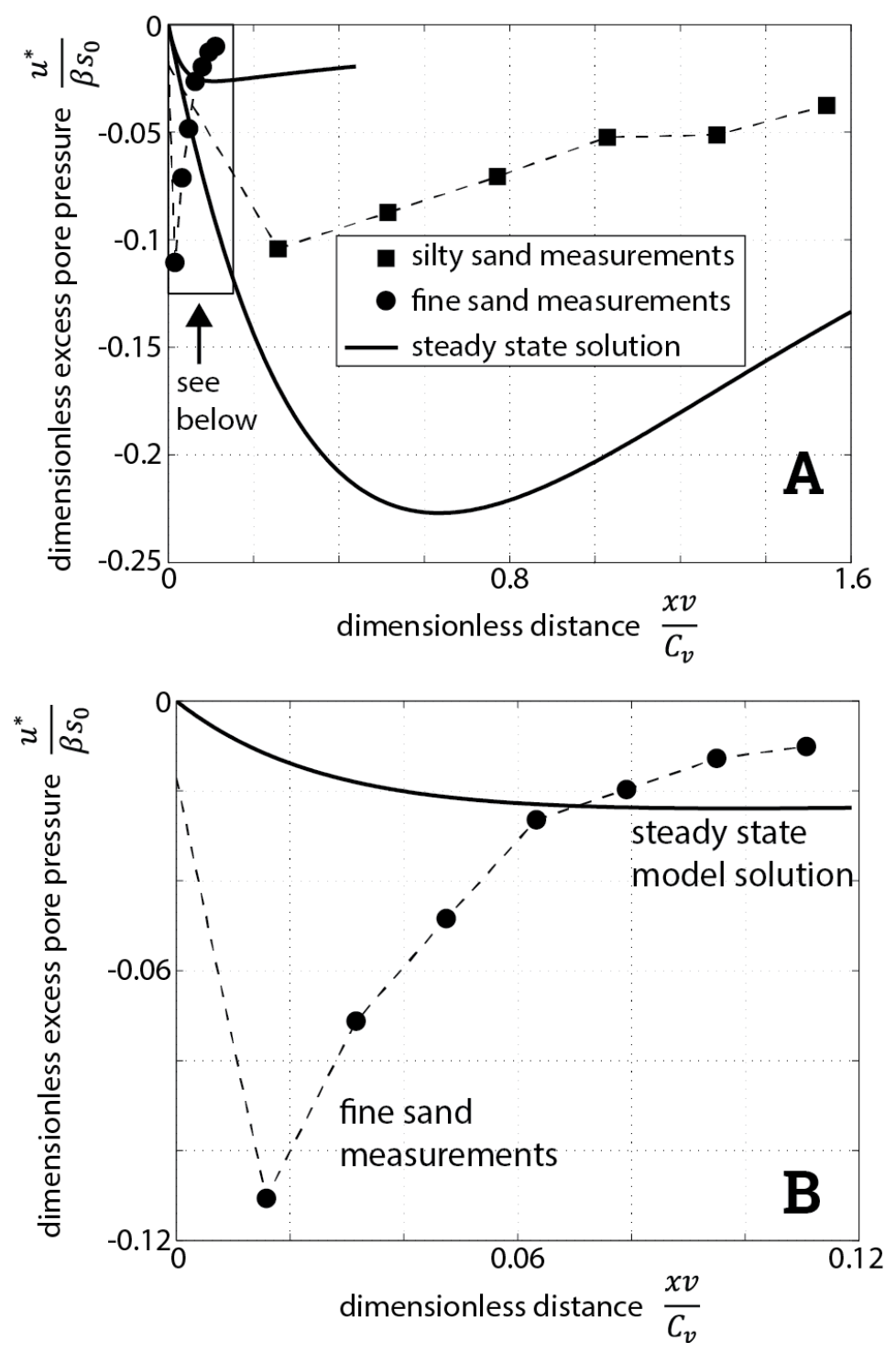

Figure 2.8: A: dimensionless excess pore pressure $\frac{u^{*}}{\beta s_{0}}$ against dimensionless distance $\frac{x v}{C_{v}}$ from measurements in silty sand (squares) and in fine sand (circiles), and the steady state solution (solid lines, Equation 2.6). The controlling parameter $\xi$ is 24 for the fine sand and 1.5 for the silty sand. B: zoom in of the boxed area in A. Dimensionless excess pore pressure $\frac{u^{*}}{\beta s_{0}}$ against dimensionless distance $\frac{x v}{C_{v}}$ from measurements (circles and dashed line) and the steady state solution (solid line, Equation 2.6) for the fine sand. The scales of the axes of the two plots are different. 
The model overestimates the value for maximum dimensionless pore pressure drop $\left|\left\langle u_{m}\right\rangle\right|$ for the silty sand while underestimates the value for $\left|\left\langle u_{m}\right\rangle\right|$ for the fine sand (Figure 2.8). Because the absolute value of $\left\langle u_{m}\right\rangle$ increases (becomes more negative) as $\xi$ decreases (Figure 2.7B), an overestimation of $\left|\left\langle u_{m}\right\rangle\right|$ for the silty sand suggests that I underestimated the controlling parameter $\xi$ for the silty sand. By definition of $\xi$ (Equation 2.11), this means I underestimated the value for the coefficient of consolidation $C_{v}$ for the silty sand in the model. With similar reason, the underestimation of $\left|\left\langle u_{m}\right\rangle\right|$ for the fine sand suggests that I overestimated the value of $C_{v}$ for the fine sand. Possible sources for the error in $C_{v}$ are explained at the end of last section; a possible solution to this error is to find a better model for the compressibility of the deposit (further discussions are presented in Chapter 6).

\subsection{BREACHING CONDITION}

I determine the zone of shear instability near the breaching front for our model by solving for the critical underpressure $\left(u_{c}^{*}<0\right)$ necessary for failure using the MohrCoulomb criterion (Figure 2.9); failure will occur where underpressure are higher than

this critical value $\left(u^{*}>u_{c}^{*}\right.$, or $u^{*} / u_{c}^{*}<1$ since $\left.u_{c}^{*}<0\right)$. In our example this zone extends from the breaching front to a depth of $2.5 \mathrm{~cm}$, indicating that this region is prone to failure (Figure 2.9, shaded region). 


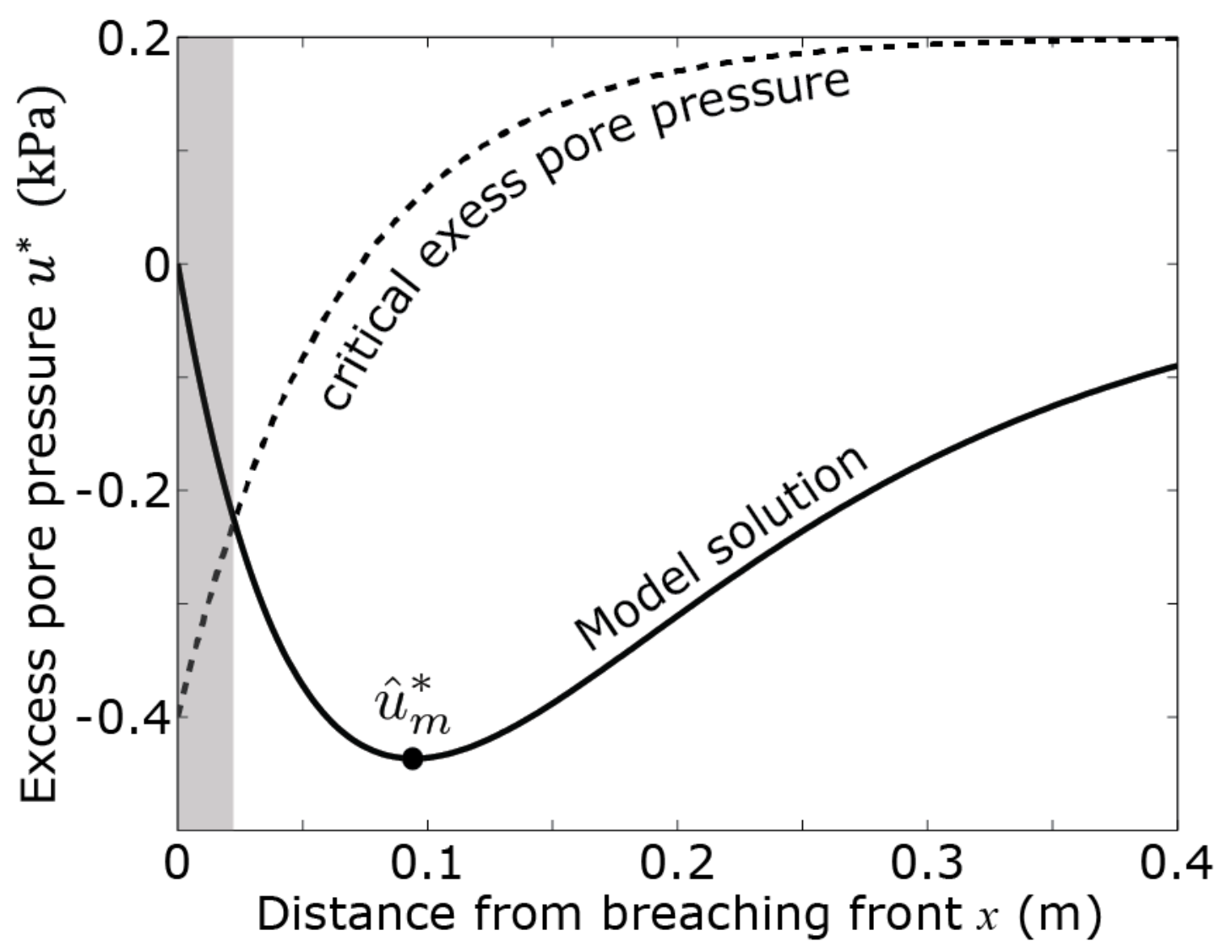

Figure 2.9: Excess pore pressure against distance from breaching front for the steady state model solution (solid line, Equation 2.5) and critical excess pore pressure ( $u_{c}^{*}$, dashed line). When pore pressure is more than critical pore pressure, Coulomb failure will occur (Equation A.4 in Appendix A). To depth of $2.5 \mathrm{~cm}$, deposit is at failure (shaded region). Internal friction angle of $30^{\circ}$ is assumed.

I extend the stability analysis to find the dilation potential $(\beta)$ needed for breaching to occur. For breaching to take place, the deposit has to be stable everywhere except locations very close to the breaching front; otherwise I would expect the entire deposit to fail or slide. A necessary condition for breaching can therefore be described by the inequality $u^{*} / u_{c}^{*}>1$. For simplicity, I use the minimum excess pore pressure $\left(u_{m}^{*}\right)$, which is proportional to the dilation potential $(\beta)$, to represent the actual excess pore 
pressure and I consider the stress conditions at the breaching front. I find that material with a dilation potential greater than 4 can breach (Figure 2.10); the deposit must be sufficiently densely packed so that unloading produces a significant increase in pore volume per unit differential stress.

I can estimate the dilation potential for the sand samples collected at the head of Scripps Canyon from shear test results (Dill, 1964, for details see Appendix A). I find that $\beta$ is larger than the critical value of 4 for most of the samples (Figure 2.10), satisfying the derived condition. In general, sediments deposited on the continental shelf that are subject to shaking from waves and shearing by gravity (Dill, 1969) are candidates to have dense packing (Rutgers, 1962; Scott et al., 1964; Visscher and Bolsterl.M, 1972) and high dilation potential (Bolton, 1986), consistent with breaching. More field observations and in situ measurements of $\beta$ are clearly needed to accurately determine the role of breaching in slope failures on the continental shelf.

\subsection{ConClusions}

In conclusion, I find that coupling of the pore pressure field with the erosion rate of breaching has a significant impact on the calculated values for both variables. The model developed in this study shows that breaching can occur in any granular material with sufficient dilation potential. My work also provides a framework and motivation for considering the occurrence of breaching on the surfaces of other planets and moons (Dromart et al., 2007; Metz et al., 2009) where liquid and granular materials exist. 


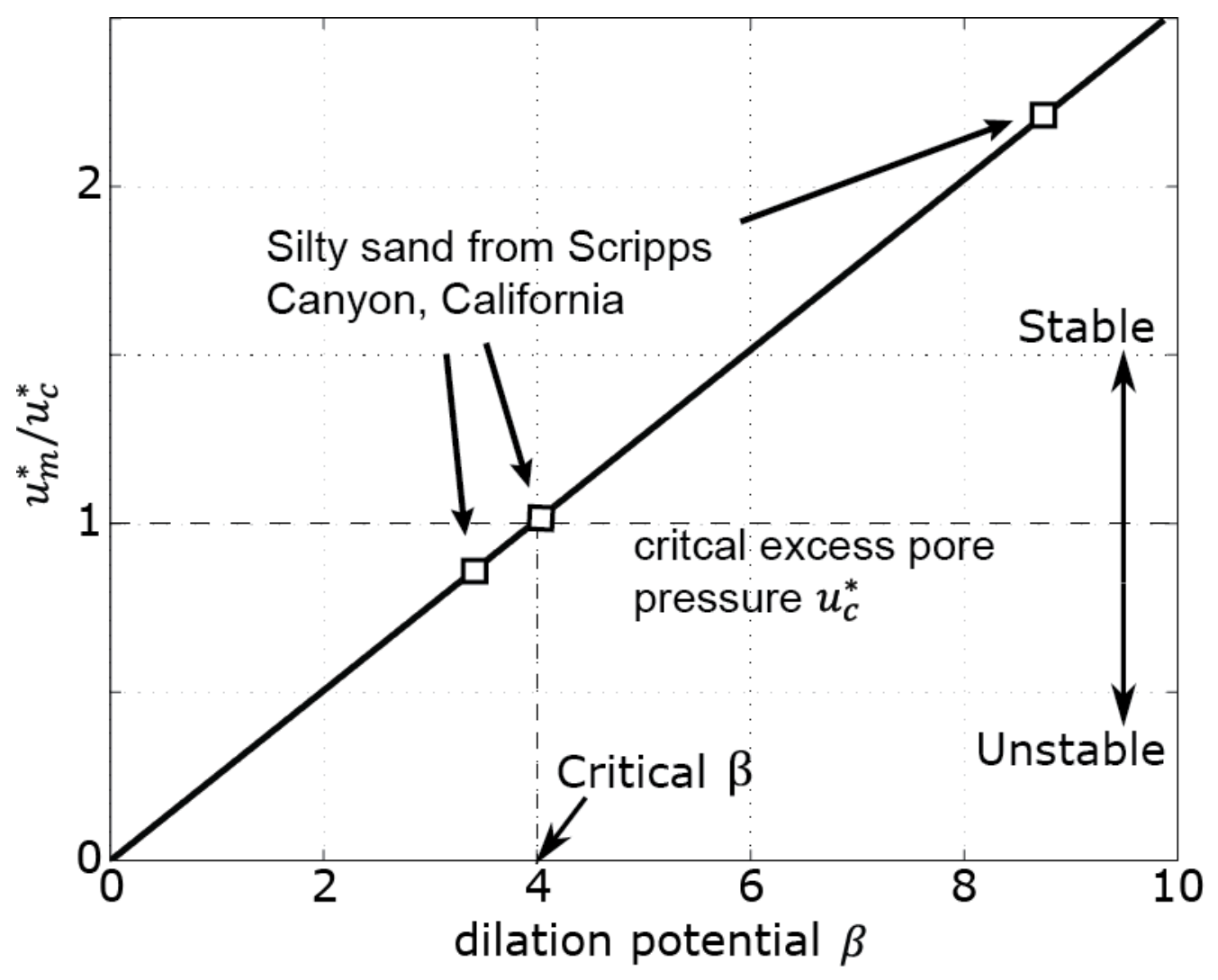

Figure 2.10: Ratio of minimum excess pore pressure $\left(u_{m}^{*}\right.$, Figure 2.9) to critical excess pore pressure $\left(u_{c}^{*}\right)$ increases linearly with dilation potential $\left(\beta=\frac{1}{2}+\frac{m_{q}}{2 m_{u}}\right)$. When $\frac{u_{m}^{*}}{u_{c}^{*}}<1$, sliding and slumping will occur and breaching will not proceed. When $\beta \geq 4, \frac{u_{m}^{*}}{u_{c}^{*}}>1$ and breaching can proceed. Three silty sand samples from Scripps Canyon (squares) have dilation potential $\beta=$ 4.1, 8.6, and 25.4 (not plotted), indicating that they are in regime where breaching can proceed. 


\section{Chapter 3: 2D numerical model for steady state breaching}

\subsection{INTRODUCTION}

Submarine slope failures act to release sediments stored on the continental shelf. Understanding the mechanics of slope failure is therefore crucial to understanding where slope failures occur and how sediments are released during slope failure events. Past studies identified two end members of slope failure: liquefaction and breaching. Liquefaction slope failure is usually associated with clay-rich deposits; increase in shear stress in the deposit drives the elevation of pore pressures until the deposit liquefies and releases large volumes of sediments all in once (Terzaghi, 1956; Morgenstern, 1967; Lowe, 1976; Hampton et al., 1996). Breaching occurs in clean sand and silty sand, and is a type of retrogressive slope failure during which shear failure drives a drop in pore pressures so that sediments are slowly and steadily released from a near vertical failure surface that is referred as the breaching front (Figure 3.1A and B) (Van Rhee and Bezuijen, 1998; Van den Berg et al., 2002; Eke, 2008). The velocity of the breaching front is on the order of $\mathrm{mm} / \mathrm{s}$ and the retreating of the breaching front can last for periods up to days (Van Rhee and Bezuijen, 1998; Eke, 2008).

During breaching the release of sediments increases the shear stress on the deposit, especially close to the breaching front (Meijer and van Os, 1976; Van Rhee and Bezuijen, 1998). The increase in shear stress causes dilation in densely packed sediments (Casagrande, 1936; Bolton, 1986). Dilation generates negative excess pore pressure (i.e.,

the pore pressure drops below the hydrostatic pressure), which increases the effective stress and strength of the deposit so that it maintains a near-vertical slope (Meijer and van Os, 1976; Van Rhee and Bezuijen, 1998). The negative excess pore pressure can reach a 
steady state (compare pore pressure at 140s and 190s in Figure 3.1C), and the magnitude of the steady state excess pore pressure depends on the degree of dilation and magnitude of unloading (Meijer and van Os, 1976). Chapter 2 shows that in order for a failing deposit to maintain a steady state excess pore pressure its dilation potential, a parameter measuring degree of dilation, must be larger than 4 .
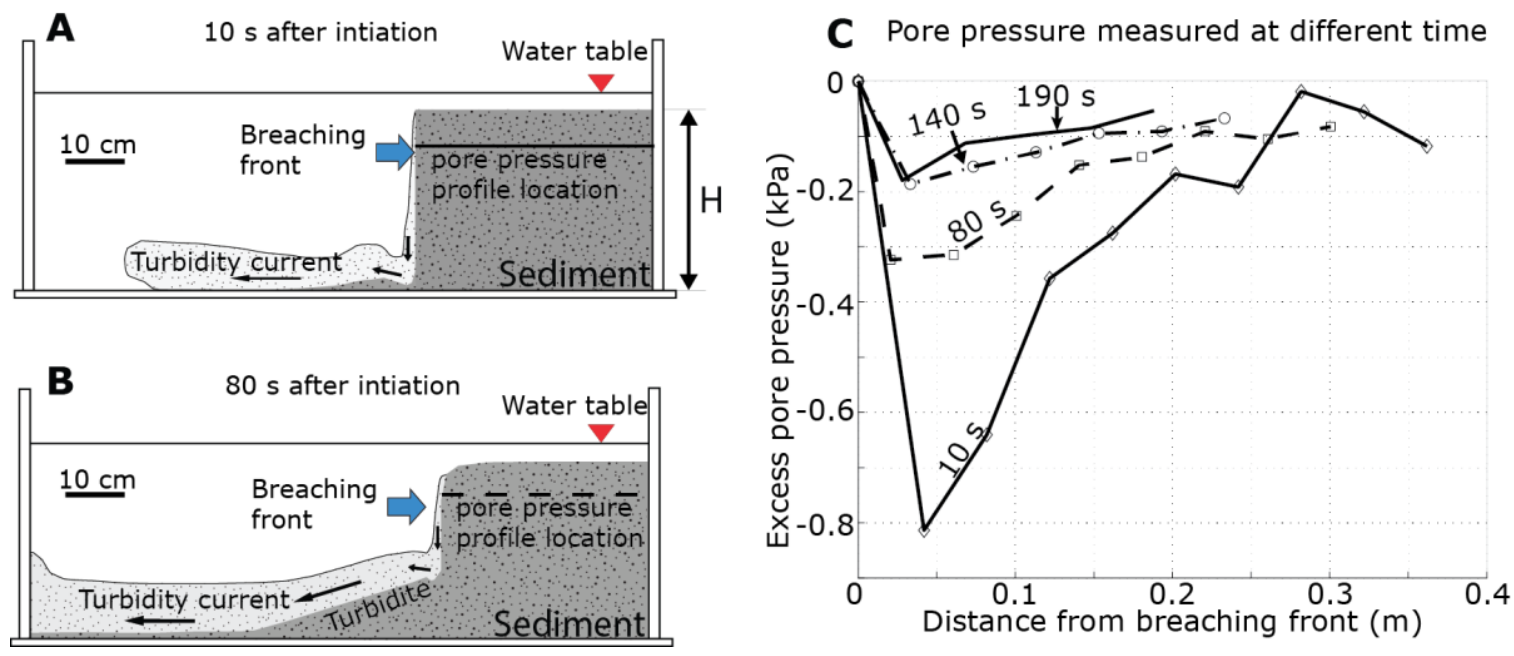

Figure 3.1: Sketch of breaching at $10 \mathrm{~s}$ and $80 \mathrm{~s}$, with pore pressure measurements (presented in Chapter 2). A: 10s after initiation. The deposit maintains a vertical failure surface, referred as the breaching front. B: 80 s after initiation. The breaching front still maintains its vertical slope. The slope angle decreases near the top. C: excess pore pressure against distance from breaching front. Each line represents a time step. Excess pore pressure is negative everywhere during breaching. The maximum drop in excess pore pressure occurs around $5 \mathrm{~cm}$ from the breaching front. After $140 \mathrm{~s}$, the excess pore pressure does not change significantly, reaching a steady state.

Breaching can serve as a sediment source for sustained turbidity currents (Mastbergen and Van den Berg, 2003; Eke et al., 2011). The style of sediment release during breaching is drastically different from liquefaction slope failure, where sediments are released rapidly over a short period of time (Morgenstern, 1967; Lowe, 1976; 
Hampton et al., 1996). Sustained turbidity currents can be generated by other mechanisms such as hyperpycnal flow, where sediment laden river water associated with flooding plunges to the sea floor and continues to travel down slope as a bottom current (Kneller and Branney, 1995; Mulder et al., 2003; Lamb and Mohrig, 2009). Accurate interpretation of sedimentary records constructed by sustained turbidity currents requires us to understand how sediments are released during breaching. Chapter 2 and past studies find that the retreating velocity of the breaching front, also referred as the erosion rate, is proportional to the coefficient of consolidation for the deposit (Van Rhee, 2007). This is because pore pressure generation from release of sediments is balanced by the dissipation of pore pressure from water flow; this equilibrium creates a steady state pore pressure and erosion rate for breaching.

Previous studies provide a foundation for us to understand the mechanics of breaching. However, all of them fail to include the vertical dimension or thickness of the deposit in their analyses of breaching mechanics. Vertical variations of stresses, pore pressure, and material properties are missing in 1D models. While Meijer and van Os's study (Meijer and van Os, 1976) is based on a 2D model, they did not use the model to systematically analyze changes in slope failure and pore pressure distribution as a function of burial depth. These vertical variations of stress, pore pressure, and material properties can change the distribution of excess pore pressure in the deposit, which in turn can affect the mechanics of the slope failure. Variations in material properties could also allow the erosion rate to change in the vertical direction. Understanding how erosion rate varies in the vertical direction is not only required for us to accurately predict how sediments are released by breaching, it is also crucial to understanding how breaching slope failure evolves. Breaching requires the maintenance of a relatively stable slope angle for the breaching front. Breaching will cease when this slope angle drops down to 
the angle of repose; steepening of this slope would lead to overhanging and ultimately collapse of sediments.

In this chapter I study the pore pressure distribution in the deposit and the erosion rate of breaching using 2D numerical models. I build a 2D pore pressure model similar to that of Meijer and van Os (1976) with one important difference, I model the stress in the deposit using laboratory-defined values of the material properties rather than by simply imposing a linear elastic behavior. I model dilation as a function of both the stress ratio and mean effective stress using geotechnical test results. I compare this stress dependent dilation model to a model where dilation is uniform and to the 1D steady state model presented in Chapter 2. These comparisons show that the majority of the excess pore pressure drop is focused close to the breaching front due to the decrease of dilation with distance into the stable deposit. It also shows that the deposit becomes weaker with increasing thickness due to a decrease in dilation with depth. I model the erosion rate of breaching in $2 \mathrm{D}$ for the first time. I couple this erosion rate model to the $2 \mathrm{D}$ pore pressure model. The coupled model illustrates that while the erosion rate can be accurately considered a constant in the vertical direction, the boundary conditions at the top of the 2D model do affect the erosion rates observed very close to this boundary.

\subsection{D PORE PRESSURE MODEL FOR STEADY STATE BREACHING}

I model the excess pore pressure in two dimensions by conserving the volume of pore water. Because the excess pore pressure $\left(u^{*}\right)$ at steady state is constant in time, the pore volume change due to pore water flow must be compensating the pore volume change due to changes in the mean effective stress $p^{\prime}$ and differential stress $q$ (Meijer 
and van Os, 1976). I assume incompressible flow, then in the Lagrangian reference frame that moves with the breaching front we have,

$$
\begin{aligned}
& \frac{\partial Q_{x}}{\partial x}+\frac{\partial Q_{y}}{\partial y}=v\left(m_{u} \frac{\partial p^{\prime}}{\partial x}+m_{q} \frac{\partial q}{\partial x}\right) \\
& p^{\prime}=\frac{\sigma_{1}+\sigma_{3}}{2}-u^{*} \\
& q=\frac{\sigma_{1}-\sigma_{3}}{2}
\end{aligned}
$$

where $Q_{x}\left(\mathrm{~ms}^{-1}\right)$ and $Q_{y}\left(\mathrm{~ms}^{-1}\right)$ are the pore water volumetric fluxes per unit area in the horizontal $(x)$ and vertical $(y)$ directions, $v$ is the velocity of the breaching front, $m_{u}$ $\left(\mathrm{Pa}^{-1}\right)$ is the volumetric strain per unit decrease in mean effective stress (referred as the isotropic unloading compressibility), $m_{q}\left(\mathrm{~Pa}^{-1}\right)$ is the volumetric strain per unit increase in differential stress, $\sigma_{1}$ is the major principal stress, and $\sigma_{3}$ is the minor principal stress. The horizontal coordinate $x$ is defined as the distance to the breaching front.

I simplify the model (Equation 3.1) using a few assumptions. First, I assume the flow of pore water obeys Darcy's law so that the water fluxes are proportional to gradients in excess pore pressure, $u^{*}$. Second, I assume that the minimum principal stress $\sigma_{3}$ is the horizontal stress and changes with distance to the breaching front, $x$, following Chapter 2. Third, I assume that the vertical stress is the major principal stress $\sigma_{1}$ and it is a constant. Last, I assume that the breaching front is a straight vertical wall and the erosion rate $v$ is uniform (I relax this assumption later in this chapter). Consequently the model domain is a rectangle with a vertical height equal to the height of the breaching front. I apply these assumptions to the Equations 3.1-3.3 and obtain

$$
\begin{aligned}
& C_{v x} \frac{\partial^{2} u^{*}}{\partial x^{2}}+C_{v y} \frac{\partial^{2} u^{*}}{\partial y^{2}}+v \frac{\partial u^{*}}{\partial x}-v \beta \frac{\partial \sigma_{3}}{\partial x}=0, \text { for } 0<\mathrm{x}<\mathrm{L} \text { and } 0<\mathrm{y}<\mathrm{H} \\
& \beta=\frac{1}{2}+\frac{m_{q}}{2 m_{u}} \\
& u^{*}(0, y)=0, u^{*}(x, 0)=0 \\
& \left.\frac{\partial u^{*}}{\partial x}\right|_{(L, y)}=0,\left.\frac{\partial u^{*}}{\partial y}\right|_{(x, H)}=0
\end{aligned}
$$


where $C_{v x}$ and $C_{v y}$ are the coefficients of consolidation for the deposit in the horizontal ( $x$ ) and vertical $(y)$ directions, $\mathrm{L}$ is the total length of the domain, $\mathrm{H}$ is the total height (Figure 3.1), and $\beta$ is the dilation potential. The coefficient of consolidation $c_{v}$ is defined as $k\left(m_{u} \mu\right)^{-1}$, where $k$ is the permeability of the deposit and $\mu$ is the viscosity of water. I choose a large value for $\mathrm{L}$ so that the pore pressure is hydrostatic far from the breaching front, near $x=\mathrm{L}$. The last term on the left hand side of Equation 3.4 is the source for pore pressure changes and it is the changes in minimum principal stress multiplied by the dilation potential $\beta$.

The change of the minimum principal stress, assumed to be the horizontal stress, is (following Chapter 2),

$$
\frac{\partial \sigma_{3}}{\partial x}=k_{0} \rho_{s} g y e^{-\eta x}
$$

where $k_{0}$ is the ratio between the horizontal and vertical stress in the far field, $\rho_{s}$ is the density of the submerged sediment, $g$ is acceleration by gravity, and $\eta$ is a constant that describes the decay of unloading with distance away from the breaching front. This model is different from the linear elastic model in Meijer and van Os (1976); the model in this study predicts a much great gradient in stress with distance $x$ near the breaching front. Studies suggest linear elastic model may not be appropriate for sand because sand does not have tensile strength and the grain to grain deformation is nonlinear at low mean effective stresses (Hostler, 2004). A detailed discussion of the granular physics is beyond the scope of this study; here I adopt the empirical model for its simplicity and its good fit with pore pressure measurements shown in Chapter 2.

Dilation potential $\beta$ determines how the pore pressure responds to the changes in stress. When $\beta=0, m_{q}=-m_{u}$ and there is no pore pressure in response to unloading. The volume changes that results from the increase in differential stress $q$ is equal and opposite to the volume change that results from decreases in mean effective stress $p^{\prime}$, 
resulting no change in the pore volume and pore pressure. The deposit is contractive in this case, i.e., volume decreases with increasing differential stress. When $\beta>0.5$, $m_{q}>0$ and the material is dilative (i.e., increases in volume with increasing differential stress). In this case, the pore pressure drops due to both increase in $q$ and decreases in $p^{\prime}$ during lateral unloading. In other words, dilation amplifies the pore pressure drop during breaching and dilation potential $\beta$ quantifies how large the amplifications are. Larger values of $\beta$ mean there is more dilation and more pore pressure drop during breaching. In this study, I model $\beta$ as a function of the effective stresses. As a result, $\beta$ depends on the excess pore pressure, $u^{*}$, making Equation 3.4 nonlinear. In the following section I present the experimental procedures used to determine the relationship between $\beta$ and the effective stresses.

\subsection{EMPIRICAL MODEL FOR DILATION POTENTIAL}

The dilation potential $\beta$ is a function of $m_{u}$ and $m_{q}$ (Equation 3.5). In order to determine these functions, I first find the relationship between $m_{u}$ and effective stresses and then the relationship between $m_{q}$ and effective stresses. After separately determining these two relationships I combine them to obtain the relationship between $\beta$ and effective stresses. I use a Trautwein triaxial shearing device (Figure 3.2) to measure $m_{u}$ and $m_{q}$. The procedures used to prepare a specimen for the two tests are the same and are described in detail in geotechnical testing guides (ASTM, 2006); the effects of the membrane that encases the specimen (Figure 3.2) are ignored when interpreting the testing results. I collected measurements on the fine sand $\left(D_{50}=0.19 \mathrm{~mm}\right.$, very well sorted) used in Chapter 2. The deposits I study are subaqueous clean sand with no overburden other than their own weight; therefore the mean effective stress $p^{\prime}$ in the 
deposit can be less than $7 \mathrm{kPa}$, the lowest stress I can achieve in the shearing device. As a result, I must extrapolate values produced using the triaxial shearing device into lower $p^{\prime}$ conditions considered when using the numerical model.

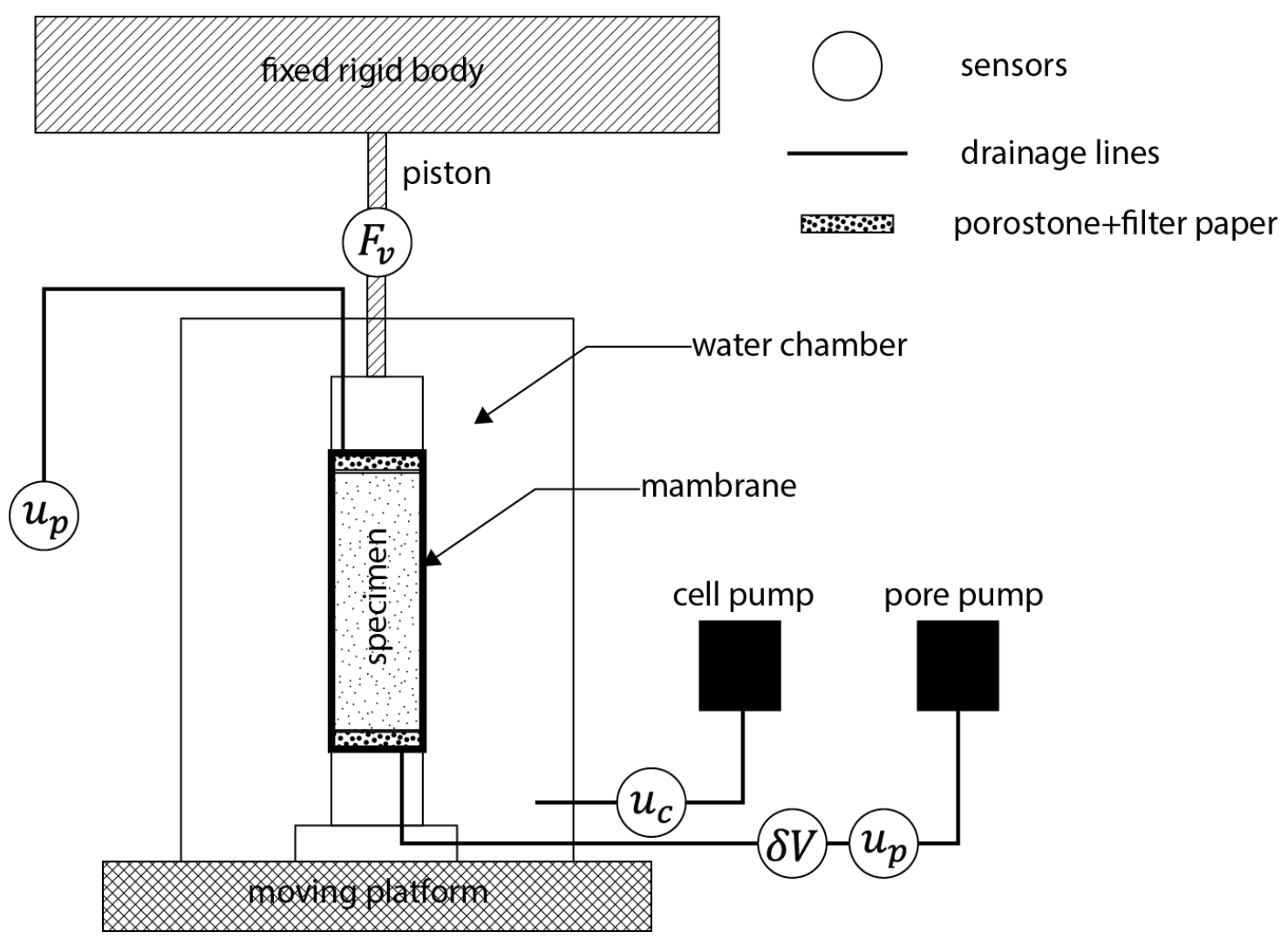

Figure 3.2: Sketch of the triaxial shearing device. The specimen is wrapped in a layer of water tight membrane so that it is hydraulically separated from the water chamber. The cell pump and pore pump controls the pressure in the water chamber and specimen respectively. The pore pump also measures the changes in the specimen volume $(\delta V)$. Pore pressure $\left(\mathrm{u}_{\mathrm{p}}\right)$ is measured from both the top and bottom end of the specimen. A load sensor located on the piston measures the amount of force acting on the specimen in the vertical direction $\left(F_{v}\right)$. The chamber water pressure $\left(\mathrm{u}_{\mathrm{c}}\right)$ is measured at the base. The specimens have an averaged diameter of $5 \mathrm{~cm}$ and an averaged height of $10 \mathrm{~cm}$. 
The isotropic unloading compressibility $m_{u}$ is the volumetric strain per unit decrease in mean effective stress (Equation 3.1). I measure $m_{u}$ with an isotropic unloading test. In this test, I decrease the vertical and horizontal stresses from their initial value $p_{0}^{\prime}$ by the same amount $\left(\delta p^{\prime}\right)$ and record the corresponding changes in the specimen volume $\delta \mathrm{V}$. I calculate the volumetric strain $\varepsilon_{v}$ of the specimen as $\delta \mathrm{V} / \mathrm{V}_{0}$, where $\mathrm{V}_{0}$ is the initial volume of the specimen (positive $\varepsilon_{v}$ means increase in volume). By definition, $m_{u}$ equals to $\delta \mathrm{V} / \mathrm{V}_{0} p^{\prime}$ at mean effective stress $p_{0}^{\prime}$. By repeating this procedure I obtain $m_{u}$ at progressively smaller mean effective stresses (at $p_{0}^{\prime}-\delta p^{\prime}$, $p_{0}^{\prime}-2 \delta p^{\prime}$, etc). The value of $m_{u}$ increases as the mean effective stress decreases (Figure 3.3). This relationship is best fit by the logarithmic function,

$$
m_{u}=a_{0}+a_{1} \log _{10} p^{\prime}
$$

where $\mathrm{a}_{0}=8.7 \times 10^{-7} \mathrm{~Pa}^{-1}, \mathrm{a}_{1}=-1.8 \times 10^{-7} \mathrm{~Pa}^{-1}$ are constants.

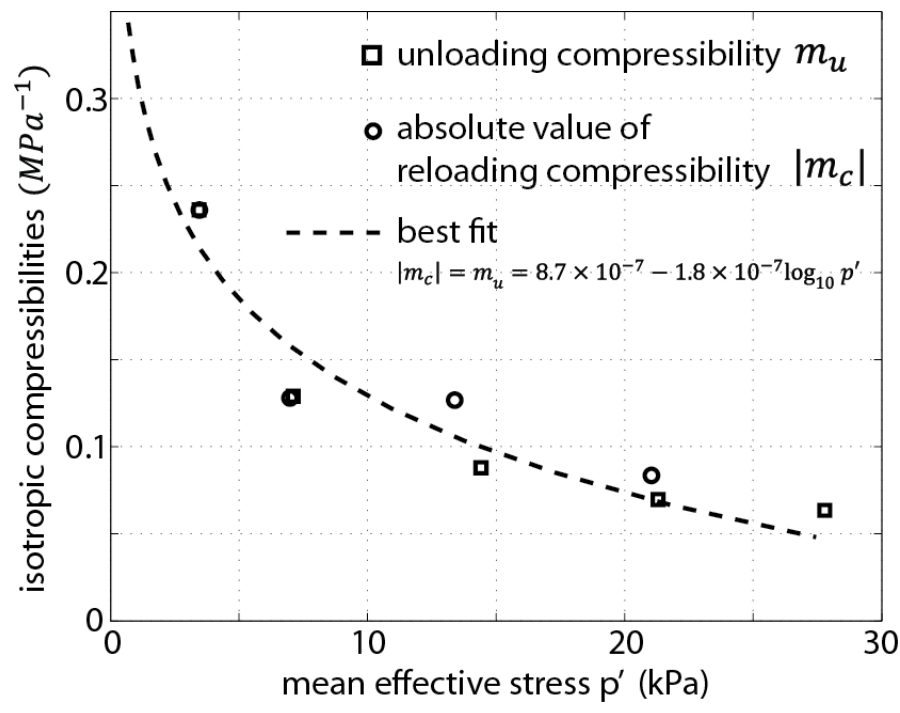

Figure 3.3: Measurements of the isotropic unloading compressibility $m_{u}$ (squares) and absolute value of reloading compressibility $\left|m_{c}\right|$ (circles) at different mean effective stress $p^{\prime}$ on the fine sand used in Chapter 2. The relationship between $p^{\prime}$ and $m_{u}$ is the same as the relationship between $p^{\prime}$ and $\left|m_{c}\right|$, and both are best fit with a logarithmic equation (dashed line, $R^{2}=0.92$ ). 
I find $m_{q}$, the volumetric strain per unit increase in differential stress, with drained vertical compression tests. In these tests, the horizontal stresses on the specimen are held constant while the vertical stress is increased; the specimen is being sheared during the test. As a result both the mean effective stress $p^{\prime}$ and the differential stress $q$ increases at the same rate on the specimen. The resulting volume change is a combination of volume changes from increases in mean effective stress $p^{\prime}$ and increases in the differential stress $q, \varepsilon_{v}=\frac{\delta V}{V_{0}}=m_{c} \delta p^{\prime}+m_{q} \delta q=\left(m_{q}+m_{c}\right) \delta q$. Simplified as

$$
m_{q}+m_{c}=\frac{\delta V}{V_{0} \delta q}
$$

where $m_{c}$ is the volumetric strain per unit increase in $p^{\prime}$, under the condition that the current $p^{\prime}$ is smaller than the maximum $p^{\prime}$ the specimen has ever experienced $(96 \mathrm{kPa}$, this number is also referred as the pre-consolidation stress in civil engineer literatures). I define

$$
m_{t}=m_{q}+m_{c}
$$

$m_{t}$ represents the total volumetric strain, from both dilation and compression, from increases in the vertical stress in the drained vertical compression test. $m_{c}$ is not measured in the drained vertical compression test. As a result, $m_{q}$ cannot be directly obtained from just the drained vertical compression test. Instead, I determine the values for $m_{t}$ from the shear test and $m_{c}$ from another test independently then combine the results to calculate the value for $m_{q}$ as $m_{t}-m_{c}$.

I use similar procedures I used to measure $m_{u}$ to measure $m_{c}$. In this test I increase $p^{\prime}$ and calculate $m_{c}$ as $\delta \mathrm{V} / \mathrm{V}_{0} \delta \mathrm{p}^{\prime}$. The absolute value of $\mathrm{m}_{\mathrm{c}}$ increases as the mean effective stress decreases and this relationship is the same as Equation 3.9. But $m_{c}$ represents decrease in volume while $m_{u}$ represents increase in volume, therefore

$$
m_{c}=-m_{u}
$$

I assume both $m_{u}$ and $m_{c}$ are independent of the differential stress $q$. 
The value for $m_{t}$ is calculated from direct measurements from the drained vertical compression test as the slope between volumetric strain $\left(\varepsilon_{v}=\frac{\delta V}{V_{0}}\right)$ and the differential stress $q$ (Equations 3.10, Figure 3.4A). Test results show that $m_{t}$ is a function of the effective stress ratio $R^{\prime}=\frac{\sigma_{1}^{\prime}}{\sigma_{3}^{\prime}}$. For example, the test with an initial mean effective stress $p_{0}^{\prime}=14 k P a$ (i.e., $p^{\prime}$ prior to shear) shows that $m_{t}$ increases as $R^{\prime}$ increases, i.e., when the specimen is closer to shear failure (Figure 3.4B). $m_{t}$ reaches its maximum value $M_{t}$ when $R^{\prime}$ reaches its maximum value $R_{m}^{\prime}$, i.e., when the specimen fails. Because that $m_{t}$ is on the order of $10^{-6} \mathrm{~Pa}^{-1}$ while $m_{c}$ is on the order of $10^{-7} \mathrm{~Pa}^{-1}$, volumetric strain from the isotropic compression is small compared to the total volumetric strain (Figure 3.4A). 

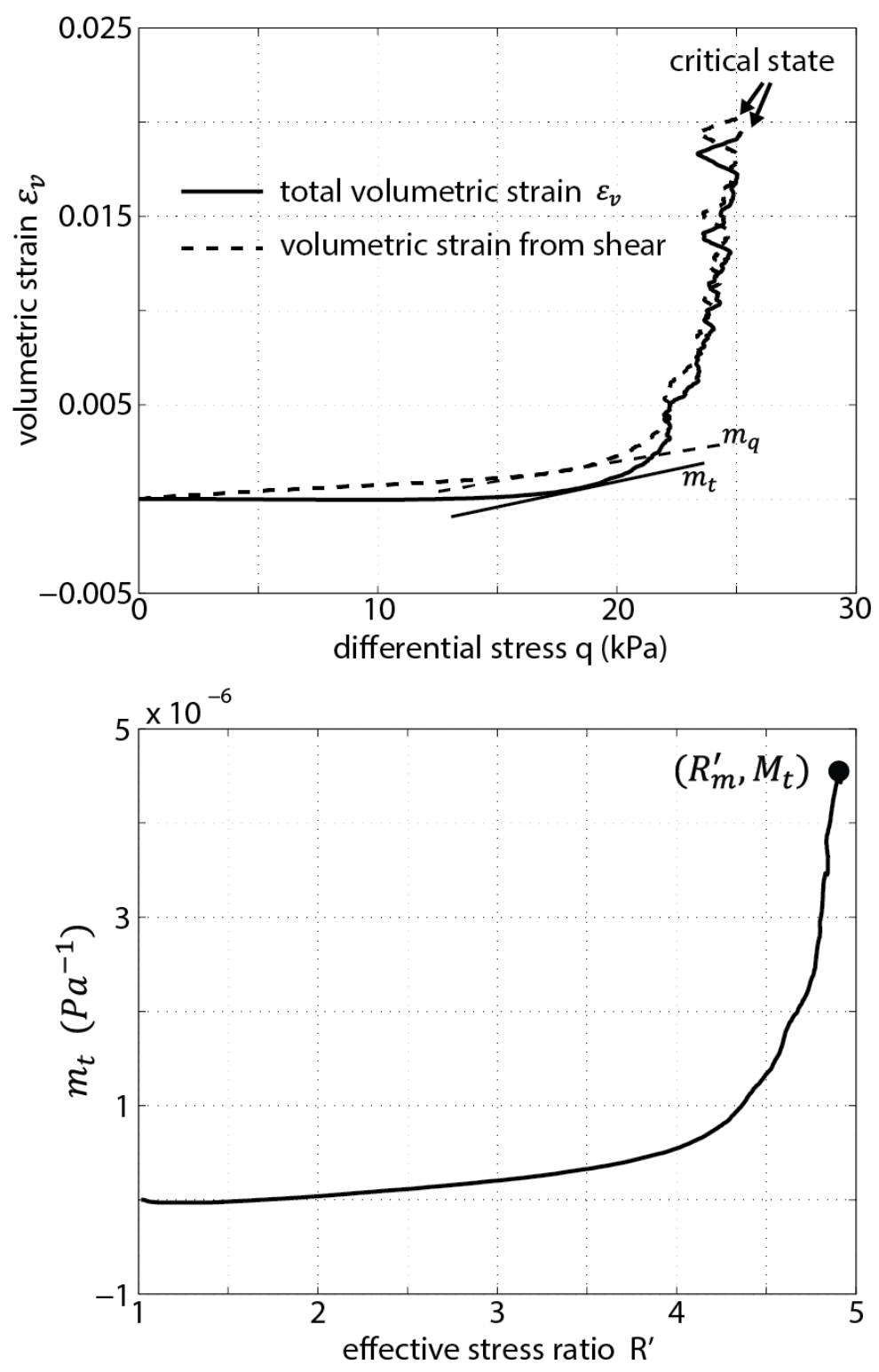

Figure 3.4: A: volumetric strain against differential stress $q$ measured from one drained vertical compression test on the fine sand, with an initial mean effective stress $p_{0}^{\prime}$ of $14 \mathrm{kPa}$. The solid line represents the total volumetric strain $\varepsilon_{v}$, from both shear dilation and isotropic loading. The dashed line represents the volumetric strain from shear dilation only. The parameters $m_{t}$ and $m_{q}$ are defined as the local slopes on the total volumetric strain curve and the volumetric strain from shear curve respectively. B: $m_{t}$ against effective stress ratio $R^{\prime}$ for the same test. Both $R^{\prime}$ and $m_{t}$ reaches their maximum value at the same point $\left(R_{m}^{\prime}, M_{t}\right)$, represented by the filled circle. 
I run 6 such drained tests with 5 different initial mean effective stress $p_{0}^{\prime}$ at $7 \mathrm{kPa}$, $14 \mathrm{kPa}$ (includes a duplicated test, one of them shown in Figure 3.4 ), 21kPa, 28kPa, and $56 \mathrm{kPa}$. Test results show the relationship between $\mathrm{m}_{\mathrm{t}}$ and the effective stress ratio $R^{\prime}$ is independent of $p_{0}^{\prime}$ (each test is represented by a single gray line in Figure 3.5). The relationship between $m_{t}$ and $R^{\prime}$ for all the test data is best fit with the power-law function

$$
m_{t}=M_{t}\left(R^{\prime} / R_{m}^{\prime}\right)^{b_{0}}
$$

where $b_{0}=4.8$ is a constant.

Test results from experiments with different initial mean effective stress $p_{0}^{\prime}$ show that the value of $M_{t}$ decreases as the initial mean effective stress $\mathrm{p}_{0}^{\prime}$ increases (Figure 3.6). The relationship between $\mathrm{M}_{\mathrm{t}}$ and $\mathrm{p}^{\prime}{ }_{0}$ is best fit with the function

$$
M_{t}=\frac{b_{1}}{p_{0}^{\prime}}+b_{2}
$$

where $b_{1}=0.042$ (dimensionless) and $b_{2}=8.3 \times 10^{-7} \mathrm{~Pa}^{-1}$ are constants. From Equations 3.5 and 3.10-3.14 we can model dilation potential $\beta$ with

$$
\beta=1+\frac{1}{2 m_{u}}\left(\frac{b_{1}}{p_{0}^{\prime}}+b_{2}\right)\left(\frac{R^{\prime}}{R_{m}^{\prime}}\right)^{b_{0}}
$$

The model shows that dilation potential increases with increasing normalized effective stress ratio $R^{\prime} / R_{m}^{\prime}$, i.e., when the material is closer to shear failure. Because the deposit near the breaching front is closer to failure, Equation 3.15 suggests that there is more dilation near the breaching front. The model also suggests that dilation potential is larger with increasing depth, where the initial mean effective stress is larger. 


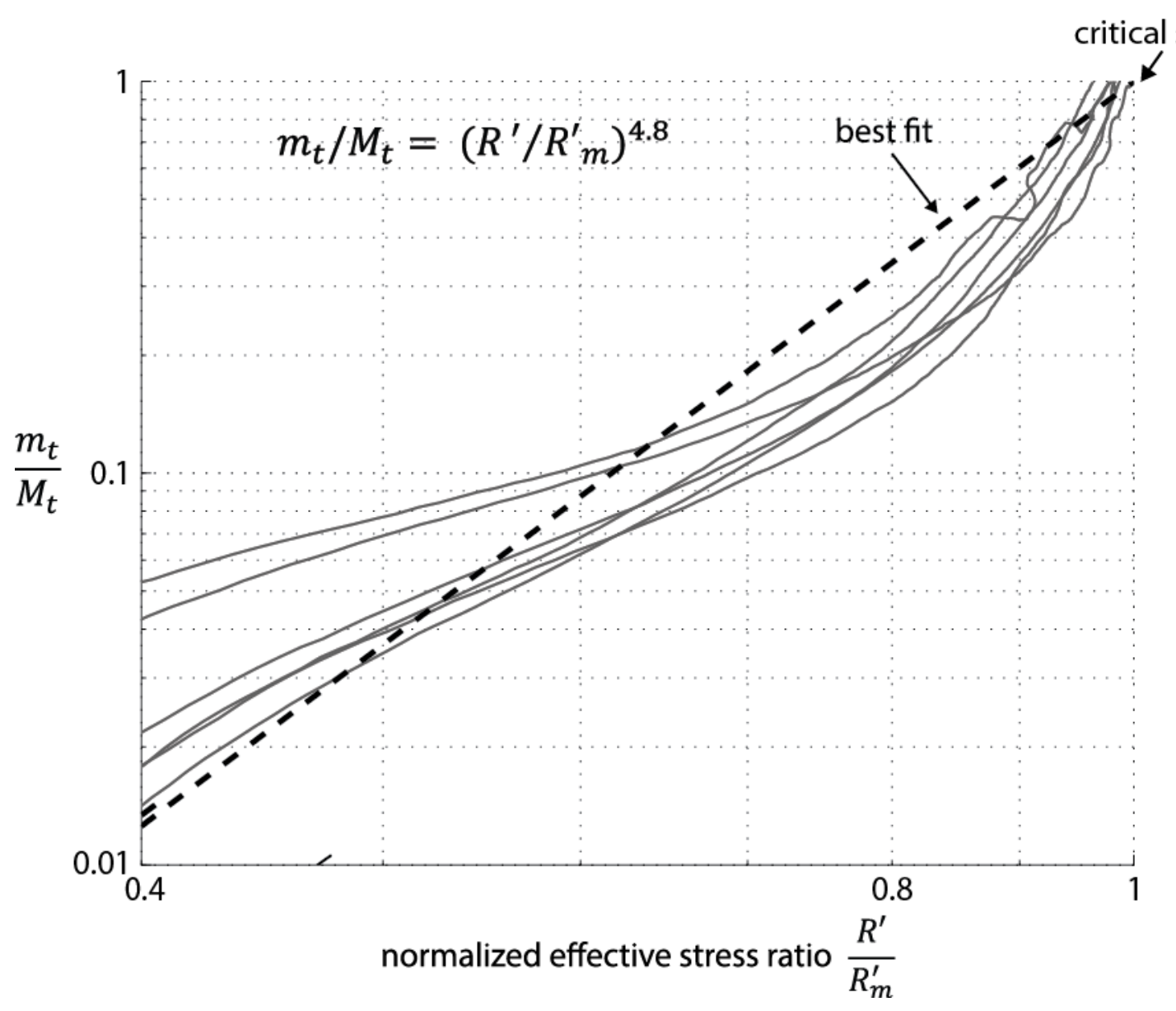

Figure 3.5: Relationship between normalized $m_{t}$ (defined in Figure 3.4A) and the normalized effective stress ratio $R^{\prime}$. Each solid grey ling represents results from one drained vertical compression test. The deposit reaches its critical state when $\frac{R^{\prime}}{R_{m}^{\prime}}=1$. I use a power-law relationship to fit all experimental results (dashed line, $R^{2}=0.87$ ). 


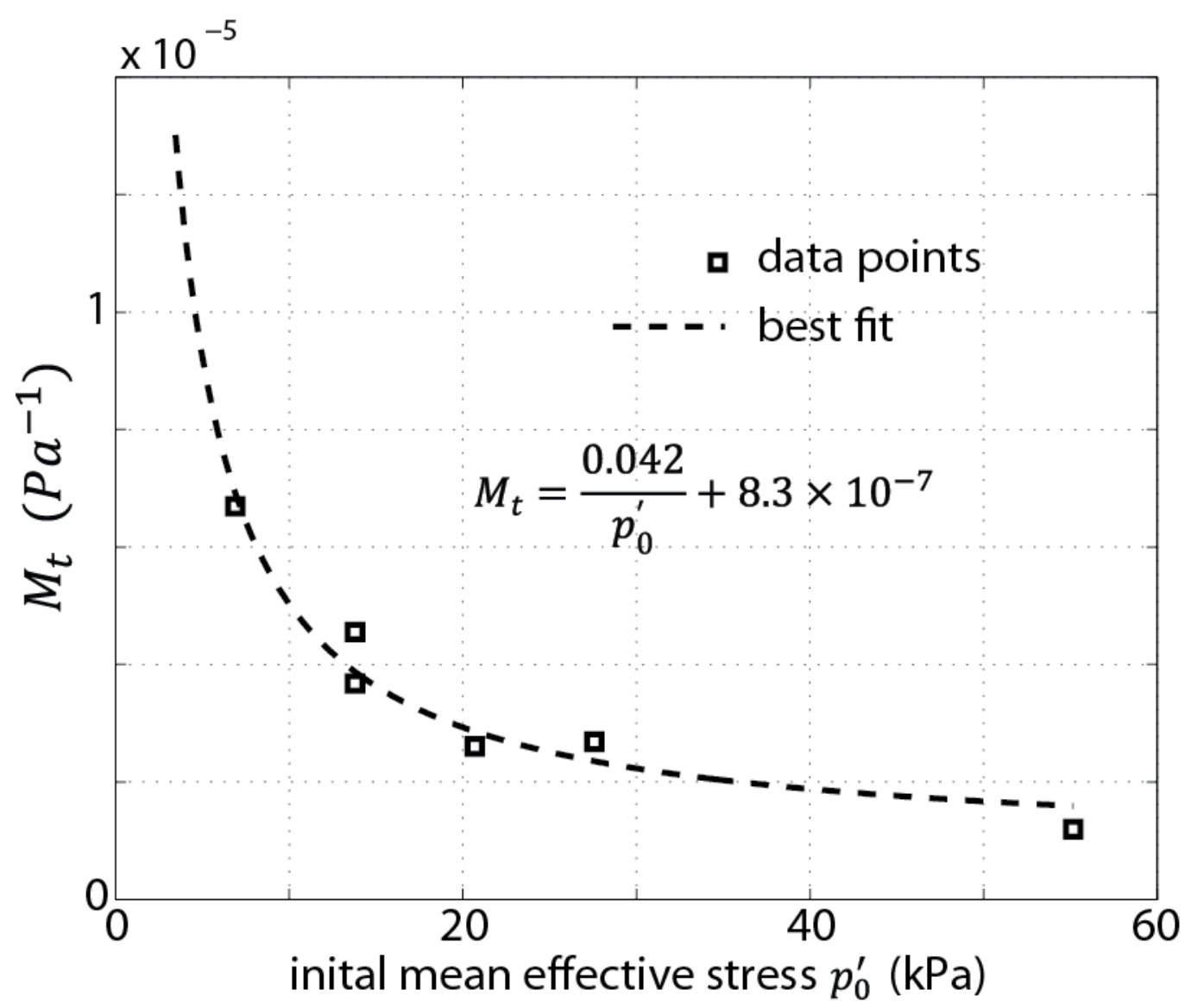

Figure 3.6: Relationship between the maximum value for $m_{t}$ (denoted as $M_{t}$, defined in Figure 3.4B) and the initial mean effective stress $p_{0}^{\prime}$ from 6 different tests. The relationship between $M_{t}$ and $1 / p_{0}^{\prime}$ is best fit with a linear function $\left(R^{2}=0.85\right)$.

\subsection{NUMERICAL MODEL SOLUTIONS}

\subsubsection{Approach}

I solve for the excess pore pressure $u^{*}$ and the dilation potential $\beta$ with finite difference methods. Because $u^{*}$ and $\beta$ are interdependent, the governing equation (Equation 3.4) is nonlinear. In addition, the power law relationship between dilation potential $\beta$ is very sensitive to the effective stress ratio $R^{\prime}$ (which is a function of $u^{*}$ ) 
due to the large index 4.8 in Equation 3.15. As a result of these two challenges, I could not find a converging numerical solution for $u^{*}$ and $\beta$ of Equation 3.4 and 3.15 using an iterative method. To overcome this problem I use a transient solution to approximate the steady state solution. Equation 3.4 is rewritten as a transient problem as follows,

$$
\frac{\partial u^{*}}{\partial t}=C_{v x} \frac{\partial^{2} u^{*}}{\partial x^{2}}+C_{v y} \frac{\partial^{2} u^{*}}{\partial y^{2}}+v \frac{\partial u^{*}}{\partial x}-v \beta \frac{\partial \sigma_{3}}{\partial x}
$$

with the initial condition

$$
u^{*}(t=0)=\frac{y u_{0}}{h_{0}}
$$

where $u_{0}$ is the measured excess pore pressure immediately after initiation (experiments presented in Chapter 2) and $h_{0}=8 \mathrm{~cm}$ is the depth at which the measurements are made. I assume the principal stresses $\left(\sigma_{1}\right.$ and $\left.\sigma_{3}\right)$ do not change with time in the Lagrangian reference frame; as a result the dilation potential $\beta$ is only a function of the excess pore pressure $u^{*}$. Therefore, when $u^{*}$ converges $\beta$ also converges. The deposit is assumed to have a height of $50 \mathrm{~cm}$ and a length of $100 \mathrm{~cm}$. I use the single point iterative method at each time step to solve for both the dilation potential $\beta$ and excess pore pressure $u^{*}$. I start with excess pore pressure from the last time step as an initial guess, calculate $\beta$ with Equation 3.15, substitute the results into Equation 3.16 and solve for an updated $u^{*}$; I repeat these steps until the relative difference between two consecutive pressure solutions is less than $1 \%$. I use the fully implicit method for time discretization. The spatial grid has a size of $1 \mathrm{~cm}$, or 50 times the mean grain size of the deposit. The time step size is $0.1 \mathrm{~s}$. I set the erosion rate $v$ equal to the one observed in the experiment, $4 \mathrm{~mm} / \mathrm{s}$. Values for other model parameters are the same as the ones used in Chapter 2 and they are listed in Table 3.1. The value for $k_{0}$ is chosen by using Jaky (1944), where $k_{0}=1-\sin \phi^{\prime}$ with $\phi^{\prime}$ being the friction angle at critical state. Assuming $\phi^{\prime}=30^{\circ}, k_{0}=0.5$. I use the SuperLU solver in this numerical model (Demmel et al., 1999; Li et al., 1999). 


\begin{tabular}{|c|c|c|c|}
\hline $\begin{array}{l}\text { Parameter } \\
\text { symbol }\end{array}$ & Explanation & $\begin{array}{l}\text { Value, if it } \\
\text { is an input }\end{array}$ & Unit \\
\hline$\beta$ & Dilation potential, Equation 5 & & \\
\hline$\varepsilon_{v}$ & Volumetric strain & & \\
\hline$\eta$ & Stress exponent, Equation 8 & 15 & $m^{-1}$ \\
\hline$\mu$ & Viscosity of water & $1 \times 10^{-3}$ & Pas \\
\hline$\rho_{S}$ & Density of submerged sediment & $1.1 \times 10^{3}$ & $\mathrm{~kg} \mathrm{~m}^{-3}$ \\
\hline$\sigma_{1}$ & Major principal stress & & $P a$ \\
\hline$\sigma_{3}$ & Minor principal stress & & $P a$ \\
\hline$C_{v x}$ & Horizontal coefficient of consolidation & & $m^{2} s^{-1}$ \\
\hline$C_{v y}$ & Vertical coefficient of consolidation & & $m^{2} s^{-1}$ \\
\hline$E_{0}$ & $\begin{array}{l}\text { Fitting parameter for erosion rate model, } \\
\text { Equation } 17\end{array}$ & $3 \times 10^{-6}$ & $P a^{-1}$ \\
\hline$g$ & Gravitational acceleration & 9.8 & $m^{2} s^{-1}$ \\
\hline$k_{0}$ & $\begin{array}{l}\text { Ratio between the horizontal and the } \\
\text { vertical stress }\end{array}$ & 0.5 & \\
\hline$k_{x}$ & Horizontal permeability & $1 \times 10^{-12}$ & $m^{2}$ \\
\hline$k_{y}$ & Vertical permeability & $1 \times 10^{-12}$ & $m^{2}$ \\
\hline$m_{q}$ & $\begin{array}{l}\text { Volumetric strain per unit increase in } \\
\text { differential stress, Equation } 1\end{array}$ & & $P a^{-1}$ \\
\hline$m_{u}$ & $\begin{array}{l}\text { Volumetric strain per unit decrease in } \\
\text { mean effective stress, Equation } 1\end{array}$ & & $P a^{-1}$ \\
\hline$m_{c}$ & $\begin{array}{l}\text { Volumetric strain per unit increase in } \\
\text { mean effective stress before the mean } \\
\text { effective stress reaches its previous } \\
\text { maximum value }\end{array}$ & & $P a^{-1}$ \\
\hline$p^{\prime}$ & Mean effective stress & & $P a$ \\
\hline$q$ & Differential stress & & $P a$ \\
\hline$R^{\prime}$ & Effective stress ratio & & \\
\hline$u^{*}$ & Excess pore pressure & & $P a$ \\
\hline$u_{m}^{*}$ & Maximum pore pressure drop & & $P a$ \\
\hline$v$ & Velocity of the breaching front & $4 \times 10^{-3}$ & $m s^{-1}$ \\
\hline$x_{m}$ & Location for maximum pore pressure drop & & $\mathrm{cm}$ \\
\hline
\end{tabular}

Table 3.1: List of modeling parameter symbols, explanation, values (if it is a model input), and units.

I use the solution at 200 s to approximate the steady state solution. The selection of this time scale is supported by Chapter 2 using similar sediment and deposit sizes that 
show pore pressures reaching steady state after 140s (Figure 3.1C). The results show that at 200 s the relative changes in excess pore pressure with time is insignificant, on the

order of $10^{-5} \mathrm{~s}^{-1}$, therefore the solution for the transient model at $200 \mathrm{~s}$ can indeed be used to approximate the steady state solution.

\subsubsection{Pore pressure results}

Numerical solutions for the excess pore pressure $u^{*}$ at 200s show that the excess pore pressure changes greatly in both the horizontal and vertical direction (Figure 3.7A). At a given depth $y, u^{*}$ drops from hydrostatic, i.e., $u^{*}=0$, to its minimum value $u_{m}^{*}$ at a distance $x \approx 5 \mathrm{~cm}$ (Figure 3.8A). Then the value of $u^{*}$ rises to hydrostatic as the distance increases. The changes of pore pressure between the breaching front and the location for the minimum excess pore pressure (also referred as the maximum pore pressure drop in this paper) $x_{m}$ is much greater than the changes of pore pressure beyond $x_{m}$. At a given distance from the breaching front $x$, the drops in $u^{*}$ increases with increasing depth $y$. 
A: excess pore pressure $u^{*}(\mathrm{~Pa})$

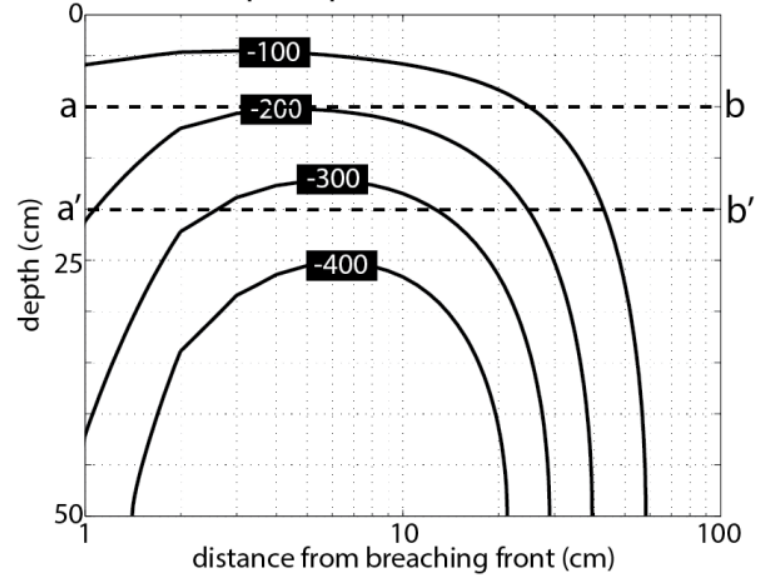

C: dilation potential $\beta$

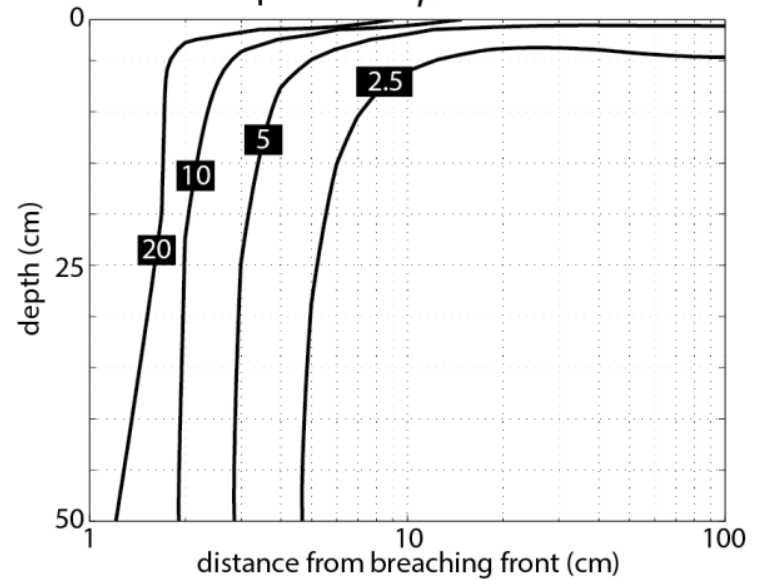

B: total volumetric strain $\varepsilon_{v}$

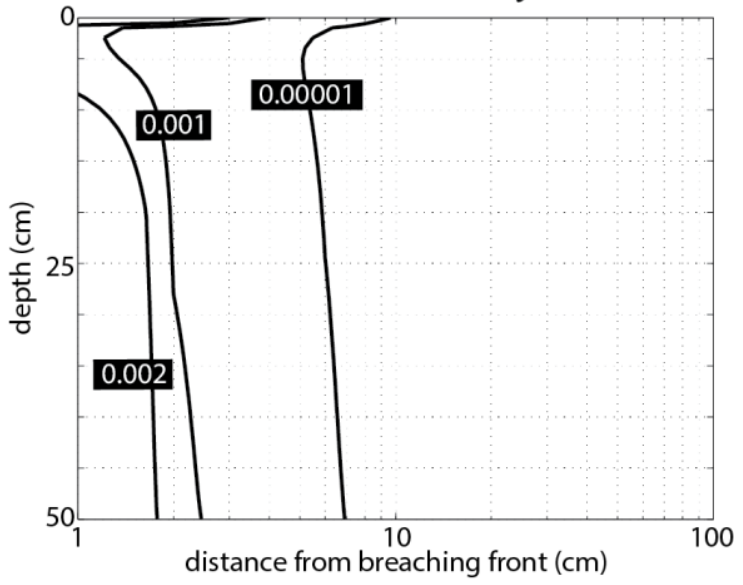

D: normalized effective stress ratio $R^{\prime} / R_{m}^{\prime}$

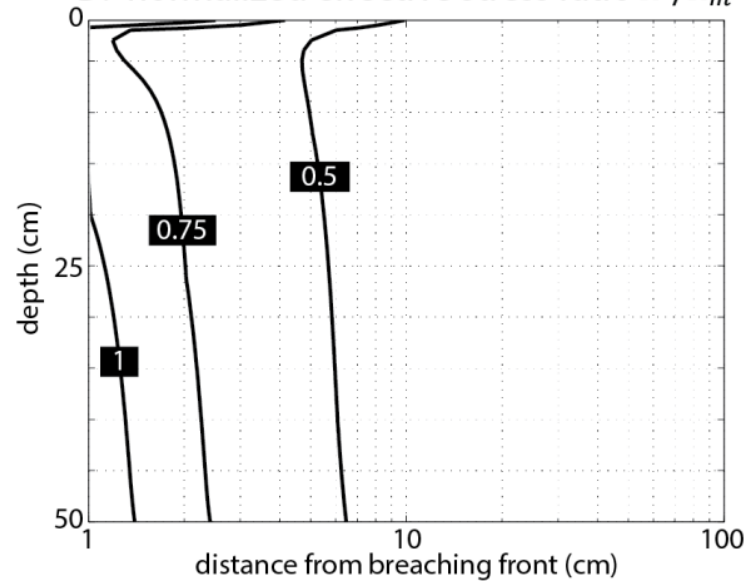

Figure 3.7: Contours of the full 2D model results. The horizontal axis (distance to the breaching front) is in logarithmic scale so that changes very close to the breaching front can be highlighted. A: contour of the excess pore pressure $u^{*}$ in $\mathrm{Pa}$. The two horizontal profiles are located at $y=10 \mathrm{~cm}$ (line $\mathrm{ab}$ ) and $y=20 \mathrm{~cm}$ (line a'b') and they are investigated in more details in Figure 3.8. B: contour of the total volumetric strain $\varepsilon_{v}$. C: contour of the dilation potential $\beta$. D: contour of the normalized effective stress ratio $R^{\prime} / R_{m}^{\prime}$ (effective stress ratio divided by its maximum value). The deposit is critical state when $\frac{R^{\prime}}{R_{m}^{\prime}}=1$. All contour levels are calculated using MATLAB $^{\mathrm{TM}}$ contour function, which makes linear interpolation whenever the contour line does not intercept an existing grid point. 

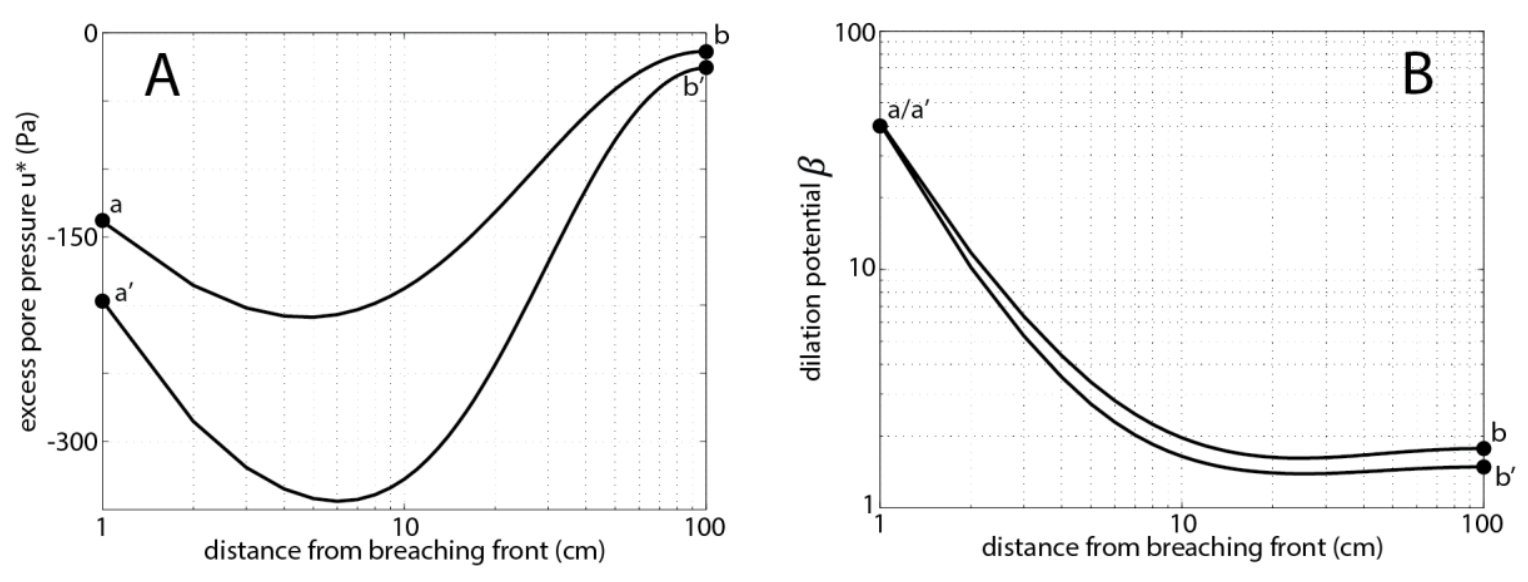

Figure 3.8: Horizontal profiles of dilation potential $\beta$ and excess pore pressure $u^{*}$ at $y=10 \mathrm{~cm}$ (lines $\mathrm{ab}$ ) and $y=20 \mathrm{~cm}$ (lines a'b') respectively. A: excess pore pressure against distance from the breaching front. B: dilation potential against distance from the breaching front.

I calculate the volumetric strain $\varepsilon_{v}$ in the deposit by integrating the changes of pore volume of the deposit from its initial state to the approximated steady state (200s). Results show that the volumetric strain decreases very rapidly with distance from the breaching front (Figure 3.7B). $\varepsilon_{v}$ decreases from 0.002 for $x<2 \mathrm{~cm}$ to less than 0.00001 at $x=10 \mathrm{~cm}$, more than 20 fold change. The rapid decrease of volumetric strain means that most of the changes in the porosity occur very close to the breaching front. This result matches the observation made by Van Rhee and Bezuijen (1998), in which the authors found that the porosity in the deposit suddenly increases within $5 \mathrm{~cm}$ from the breaching front. The volumetric strain increases with increasing depths $y$ for $y>5 \mathrm{~cm}$ and increases very quickly with decreasing depth for $y<5 \mathrm{~cm}$ (Figure 3.7B).

The spatial variations of the excess pore pressure solutions $u^{*}$ and the volumetric strain $\varepsilon_{v}$ are driven by two factors that control the source for pore pressure changes and the volume change (last term in Equation 3.16, $v \beta \frac{\partial \sigma_{3}}{\partial x}$ ). One factor is the variation of unloading $\frac{\partial \sigma_{3}}{\partial x}$, and thus, the differential stress $q$ and effective stress ratio $R^{\prime}$, in both the 
horizontal and vertical directions. The other factor is the variation of the dilation potential $\beta$ in the two dimensions. In addition to those two factors, the spatial variation of $u^{*}$ also depends on the boundary conditions for pore pressure (Equations 3.6 and 3.7). I discuss how these factors control the changes in $u^{*}$ and $\varepsilon_{v}$ in each of the two dimensions below.

In the horizontal direction, the magnitude of unloading decreases exponentially with distance from the breaching front (Equation 3.8). Numerical solution shows that the dilation potential $\beta$ also decreases with increasing distance from the breaching front (Figure 3.7C and Figure 3.8B). For example, at depth $y=10 \mathrm{~cm}$ (line ab in Figure 3.8B) $\beta$ decreases from $\sim 40$ at $x=1 \mathrm{~cm}$ to $\sim 2$ at $x=10 \mathrm{~cm}$, a 20 fold change. The drastic decrease in $\beta$ with distance is due to the high sensitivity of $\beta$ to the effective stress ratio $R^{\prime}$ (Equation 3.15) and the decrease of $R^{\prime}$ with increasing distance from the breaching front. $R^{\prime}$ decreases from its maximum value $R_{m}^{\prime}$ at $x=1 \mathrm{~cm}$ to less than half of $R_{m}^{\prime}$ at $x=10 \mathrm{~cm}$ (Figure 3.7D). As a result of both the decrease in unloading and dilation potential with increasing distance, the source for pore pressure drop and the volumetric strain decreases with increasing distance. Because the excess pore pressure $u^{*}=0$ at the breaching front (Equation 3.6), the maximum pore pressure drop is located at $5 \mathrm{~cm}$ away from the breaching front instead of on the breaching front.

In the vertical direction, the magnitude of unloading increases linearly with depth (Equation 3.8). The dilation potential $\beta$ decreases with depth, but at a very slow rate for depth larger than $5 \mathrm{~cm}$. For example, $\beta$ at $y=10 \mathrm{~cm}$ (line ab in Figure 3.8B) is on average only 1.1 times larger than the $\beta$ at $y=20 \mathrm{~cm} . \beta$ decrases with depth because it is proportional to $1 / p_{0}^{\prime}$ (Equation 3.15) and the initial mean effective stress $p_{0}^{\prime}$ increases with increasing depth. The increase of unloading is more than enough to compensate the slow decrease of $\beta$ with increasing depth for $y>5 \mathrm{~cm}$, as a result, the 45 
magnitude of pore pressure drop and the volumetric strain increases with increasing depth for $y>5 \mathrm{~cm}$ (Figure 3.7A and B). For depths less than $5 \mathrm{~cm}$, the decrease of $\beta$ is much faster than the increase of unloading with increasing depth. As a result, the volumetric strain decreases with increasing depth for $y<5 \mathrm{~cm}$. Because the $u^{*}=0$ at the top surface $y=0$ (Equation 3.6), pore pressure dissipates faster closer to the top boundary. As a consequence, the magnitude of pore pressure drop still increases with increasing depth for $y>5 \mathrm{~cm}$.

Because $\beta$ decreases with depth, the pore pressure drop does not increase as rapidly as the increase in the magnitude of unloading with increasing depth. For example, the magnitude of unloading at $y=20 \mathrm{~cm}$ is twice as much as the magnitude of unloading at $y=10 \mathrm{~cm}$ (Equation 3.8). However, in the full 2D model the maximum pore pressure drop at $y=20 \mathrm{~cm}$ (on line a'b' in Figure 3.8A) is only 1.8 times larger than the maximum pore pressure drop at $y=10 \mathrm{~cm}$ (on line ab in Figure 3.8A). Because the pore pressure drop does not increase as rapidly as the increase of unloading with increasing depth, the deposit will become less stable with increasing thickness. As the magnitude of unloading increases with increasing depth, the shear in the deposit increases. However, the negative excess pore pressure, the stabilization factor for the deposit, does not increase as rapidly as the shear, the destabilizing factor for the deposit. As a result, the stability of the deposit decreases with depth, as indicated by the increase of normalized effective stress ratio $R^{\prime} / R_{m}^{\prime}$ with depth (Figure 3.7C).

\subsubsection{Stress path of the sediments during breaching}

I use a stress path diagram to illuminate the evolution of the breaching systems (Figure 3.9). I track the stress path of a representative sediment volume (RV) in the Eulerian reference frame whose origin is fixed at the breaching front at $t=0$. Because 
the breaching front retrogrades at the speed $v$ in the Eulerian reference frame, the distance between the breaching front and the RV shortens with time $t$ and its position is represented in the moving Lagrangian reference frame as $x=x_{0}-v t$, where $x_{0}$ is the position of the RV in the fixed Eulerian reference frame. For example, point b' in Figure 3.9 represents the stress state of the RV located at the right boundary of the model $(100 \mathrm{~cm}, 20 \mathrm{~cm})$ at the initiation of breaching and point a' in the same figure represents the stress state of the same RV when it is on the breaching front $(0 \mathrm{~cm}, 20 \mathrm{~cm})$. The path $\mathrm{b}^{\prime}$ ' represents the stress path of this RV from initiation of breaching (point b' in Figure 3.9) to the time it is on the breaching front (point a' in Figure 3.9).

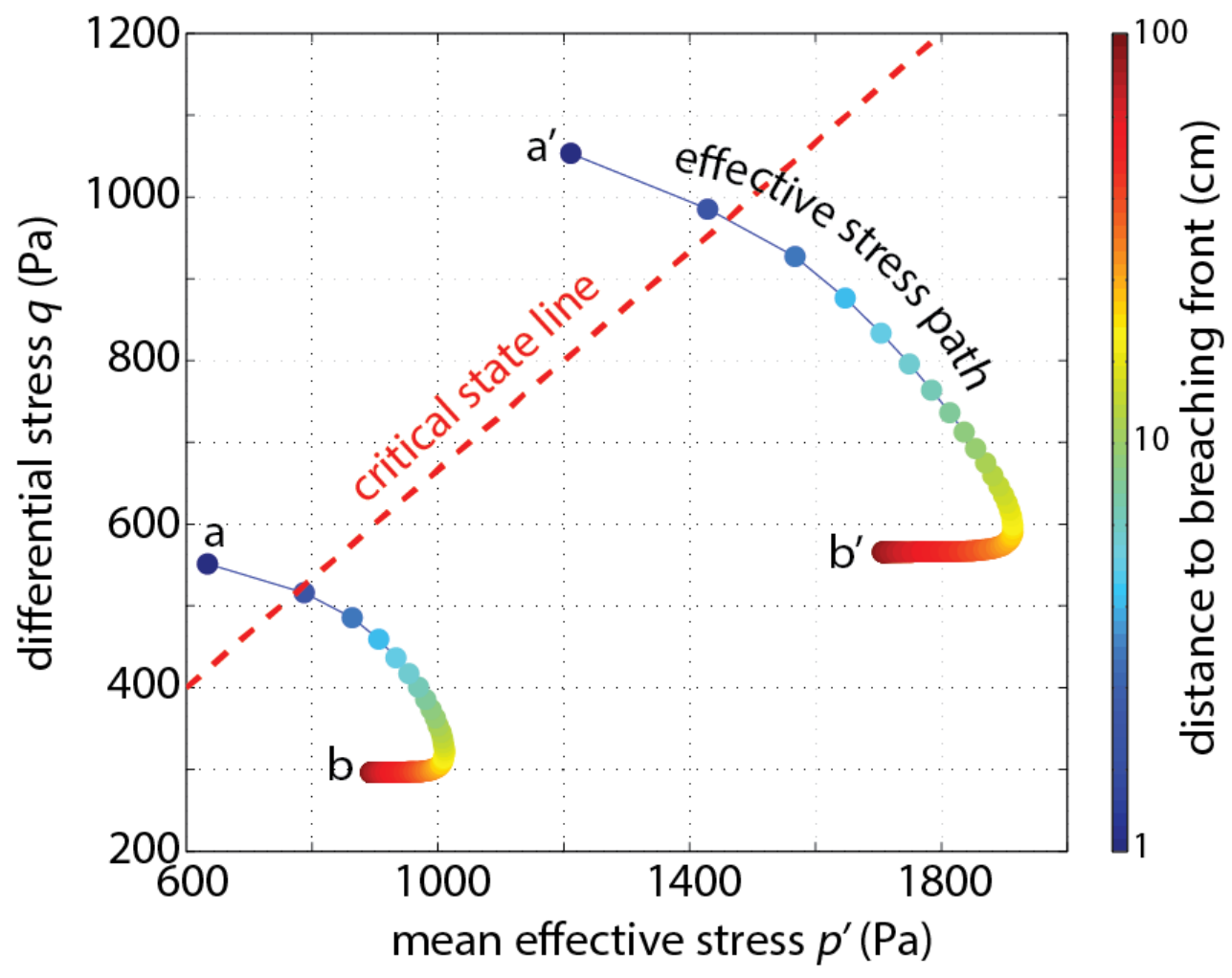

Figure 3.9: Stress path of two representative volumes (RV) in the deposit, located at $x=100 \mathrm{~cm}, y=10 \mathrm{~cm}$ (path ba) and $x=100 \mathrm{~cm}, y=20 \mathrm{~cm}$ (path b'a') in Euclarian reference frame at the initiation of breaching. The color of the dots represents the distance of the dots to the breaching front. 
The stress path of a RV in the far field first moves away from the critical state line due to increases in the mean effective stress $p^{\prime}$ (represented by the dots with red to yellow color in Figure 3.9). $p^{\prime}$ (Equation 3.2) increases because excess pore pressure is negative in the far field where the magnitude of unloading is very small. The source for negative excess pore pressure is unloading; this suggests that the pore pressure drop should be insignificant and $p^{\prime}$ should not change much if the unloading is small. However, pore pressure dissipation redistributes the excess pore pressure and extends the range of significant pore pressure drop beyond the extent of significant unloading.

As the breaching front retreats closer to the RV, the amount of unloading increases and becomes significant compared to the pore pressure drop. As a result the increase of $p^{\prime}$ slows down and the slope of the stress path becomes steeper. When the breaching front is less than $10 \mathrm{~cm}$ from this RV (green and blue colored dots in Figure 3.9), $p^{\prime}$ starts to decrease and the stress path starts to move toward the critical state line. $p^{\prime}$ decreases because the magnitude of unloading becomes significant at $x<10 \mathrm{~cm}$. When the breaching front is less than $6 \mathrm{~cm}$ away from the RV (at the point of largest negative excess pore pressure) the magnitude of excess pore pressure decreases rapidly as the breaching front moves closer to the RV (blue colored dots in Figure 3.9). The RV reaches the critical state when it is exposed on the breaching front. The stress path for an $\mathrm{RV}$ at a deeper depth $(y=20 \mathrm{~cm}$, path b'a' in Figure 3.9) is similar to one at a shallower depth $(y=10 \mathrm{~cm}$, path ba in Figure 3.9). The RV at the deeper depth reaches critical state at a greater distance from the breaching front, before the RV at the shallower depth reaches critical state. This is shown in Figure 3.9, where the RV located at $y=20 \mathrm{~cm}$ is at critical state at a horizontal distance $x=2 \mathrm{~cm}$ from the breaching front while the RV at $y=10 \mathrm{~cm}$ is not at critical state yet when it is $2 \mathrm{~cm}$ away from the breaching front. This difference shows that the stability of the deposit decreases with depth. 


\subsubsection{Sensitivity study}

I compare the normalized excess pore pressure $u^{*} / u_{m}^{*}\left(u_{m}^{*}\right.$ is the maximum pore pressure drop) at 200s to the measured steady state excess pore pressure for the fine sand from Chapter 2. The size of the deposit in the model is the same to the initial size of the deposit in the experiment. In the experiment, the excess pore pressure is measured at a depth of $10 \mathrm{~cm}$ beneath the top surface of the deposit. The numerical solution for excess pore pressure at $y=10 \mathrm{~cm}$ matches the measured excess pore pressure in form well (Figure 3.10). The modeled maximum pore pressure drop $u_{m}^{*}(-210 \mathrm{~Pa})$ underestimates the $u_{m}^{*}(-240 \mathrm{~Pa})$ by $\sim 20 \%$. This underestimation is likely due to uncertainties in the permeability $k$ of the deposit in the model.

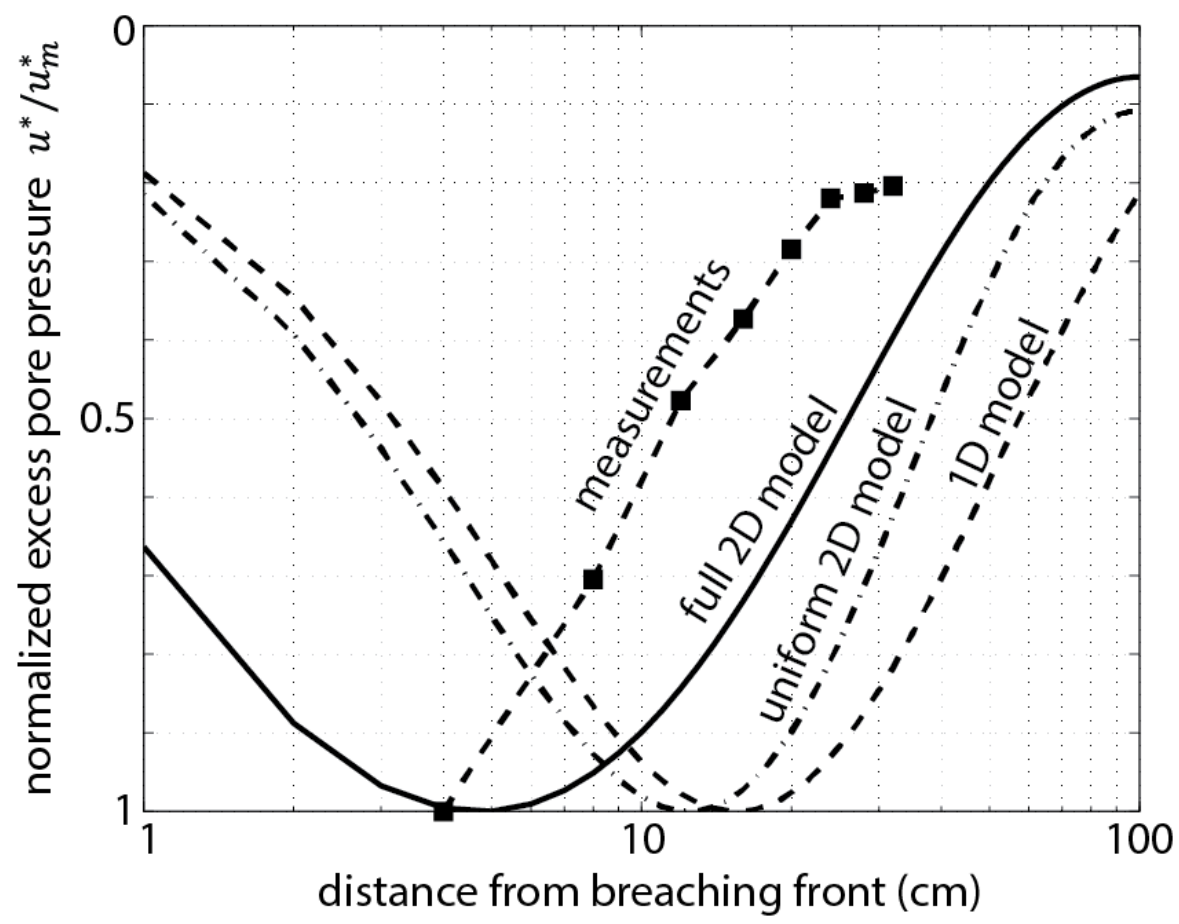

Figure 3.10: Normalized excess pore pressure $u^{*} / u_{m}^{*}$ against distance from different models compared to the measured steady state excess pore pressure for the fine sand presented in Chapter 2. 
The stress path show that the spatial variations in the excess pore pressure $u^{*}$ controls the evolution of breaching. Therefore it is important to understand what controls the spatial variation of $u^{*}$. Numerical model results from the full 2D model show that the excess pore pressure is controlled by the dilation potential $\beta$ and the boundary conditions of pore pressure. In this section, I quantify how the two factors affect the distribution of $u^{*}$ with sensitivity studies. First, I compare the model results from the full $2 \mathrm{D}$ model to a $2 \mathrm{D}$ model that is the same with the full $2 \mathrm{D}$ model except that the dilation potential $\beta$ is a constant (referred as uniform 2D model). The comparison will show how the spatial variation in $\beta$ affects the spatial variation in the excess pore pressure $u^{*}$. Then I compare the solutions from the uniform 2D model to the steady state 1D model presented in Chapter 2 (Equation 2.5) to show how the boundary conditions that govern the vertical flow affects pore pressure solutions.

I compare excess pore pressure in the horizontal direction from the uniform $2 \mathrm{D}$ model (dash-dotted line in Figure 3.10) and the full 2D model (solid line in Figure 3.10). The location for maximum pore pressure drop $x_{m}$ from the uniform $2 \mathrm{D}$ model is $3 \mathrm{~cm}$, or $60 \%$, greater than the value predicted by the full $2 \mathrm{D}$ model while the normalized excess pore pressure at $x>x_{m}$ from the full 2D model is closer to hydrostatic than that from the uniform 2D model (Figure 3.10). In both models the magnitude of unloading decays at the same rate with distance (Equation 3.8). With uniform dilation potential the source for excess pore pressure is proportional to the magnitude of unloading, therefore the source for pore pressure drop decays at the same rate as the decay of unloading with increasing distance. In the full 2D model the dilation potential is much higher near the breaching front (Figures 3.7C and 3.8B). As a result, the source for pore pressure drop decays faster with increasing distance, causing the maximum pore pressure drop to be closer to the breaching front in the full 2D model. The faster decay of the source for pore 
pressure drop also makes the pore pressure in the far field closer to hydrostatic in the full 2D model.

I compare the excess pore pressure in the vertical direction between the uniform 2D model and the full 2D model (Figure 3.11). I illustrate the differences with dimensionless excess pore pressure $\frac{u^{*}(y)}{u^{*}\left(y_{0}\right)}$, where $y_{0}=10 \mathrm{~cm}$ is the reference depth, and dimensionless unloading at the breaching front $\left.\frac{\partial \sigma_{3}}{\partial x}\right|_{(0, y)}\left[\left.\frac{\partial \sigma_{3}}{\partial x}\right|_{\left(0, y_{0}\right)}\right]^{-1}$. I compare how the dimensionless $u^{*}$ from the both 2D models and the dimensionless unloading change with the dimensionless depth $\frac{y}{y_{0}}$. Because the magnitude of unloading increases linearly with depth $y$ (Equation 3.8), the dimensionless unloading equals to the dimensionless depth (dashed line in Figure 3.11). In the uniform 2D model, because $\beta$ is a constant, the source for pore pressure drop also increases linearly with depth. As a consequence, the dimensionless excess pore pressure (dash-dotted line in Figure 3.11) is close to the dimensionless unloading except for part near the bottom boundary. The divergence between the two near the bottom boundary is due to the impermeable boundary condition at the base. The impermeable boundary condition reduces the pore pressure gradient near the bottom boundary therefore the dimensionless pore pressure becomes smaller. In the full 2D model, the dimensionless pore pressure (solid line in Figure 3.11) diverges from the dimensionless unloading everywhere. Moreover, the dimensionless pore pressure from full $2 \mathrm{D}$ model is smaller than the dimensionless pore pressure from the uniform $2 \mathrm{D}$ model for depths larger than the reference depth $y_{0}$. The difference between the full 2D model and the uniform $2 \mathrm{D}$ model is due to the decrease of dilation potential $\beta$ with increasing depth. As depth increases from the reference point $\left(y>y_{0}\right.$, or dimensionless depth larger than 1), $\beta$ in the full 2D model decreases while $\beta$ in the uniform 2D model remains constant. As a result, the source for pore pressure drop in the full 2D model 
decreases and its dimensionless pore pressure becomes smaller than that from the uniform 2D model.

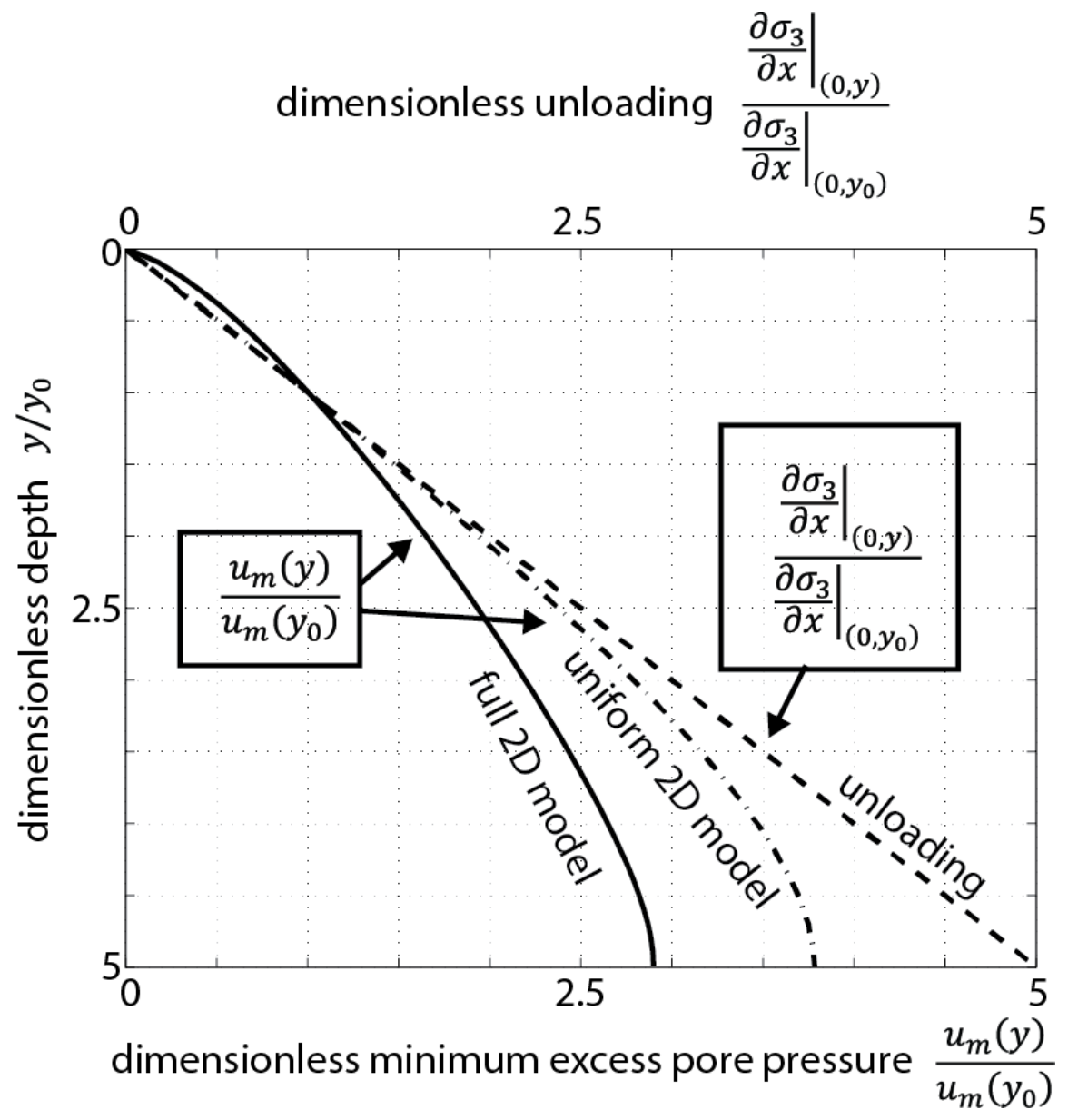

Figure 3.11: Dimensionless minimum excess pore pressure $u_{m}^{*}(y) / u_{m}^{*}\left(y_{0}\right)$ for the full 2D model (solid line) and uniform 2D model (dash-dotted line) and dimensionless magnitude of unloading $\left.\frac{\partial \sigma_{3}}{\partial x}\right|_{(0, y)}\left[\left.\frac{\partial \sigma_{3}}{\partial x}\right|_{\left(0, y_{0}\right)}\right]^{-1}$ (dashed line) against dimensionless depth $y / y_{0}$, where the reference depth $y_{0}=10 \mathrm{~cm}$ (solid line). The slopes of the solid line represent the rate of increase in pore pressure drop in the full 2D model with depth. The slopes of the dash-dotted line represent the rate of increase in pore pressure drop in the uniform $2 \mathrm{D}$ model with depth. The dashed line, representing the increase in the magnitude of unloading with depth, has a constant slope of 1 because unloading increases linearly with depth. 
Because the pore pressure drop increases at a similar rate as the increase in unloading (hence the changes in stresses) in the uniform 2D model, the normalized effective stress ratio $R^{\prime} / R_{m}^{\prime}$ of the deposit does not change significantly with the depth (Figure 3.12). In other words, the stability of the deposit does not depend on its thickness if the dilation potential $\beta$ were a constant. However, traxial tests show that $\beta$ decreases with increasing mean effective stress (Equation 3.15), hence increasing depth of the deposit. As a result, the full 2D model shows that the stability of the deposit deceases with increasing depth of the deposit (Figure 3.7D and Figure 3.9). This result highlights the importance of including spatial variations of material properties in the study of breaching slope failure.

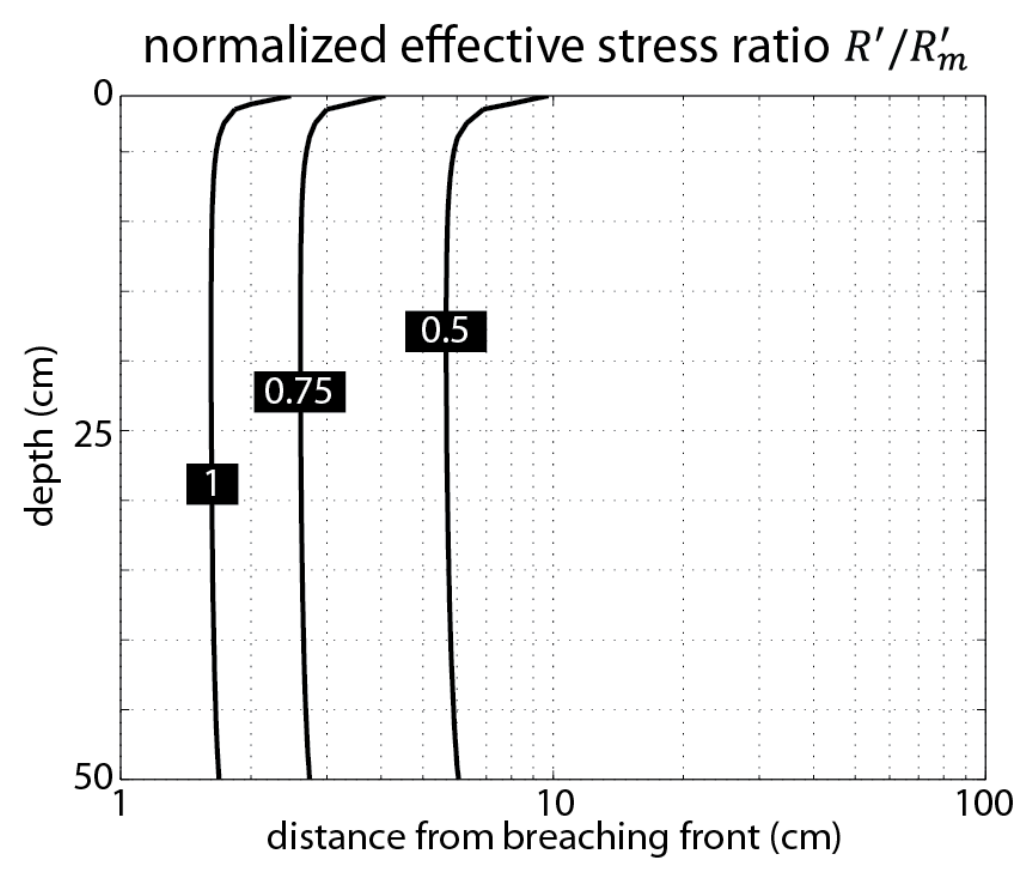

Figure 3.12: Contour of normalized effective stress ratio $R^{\prime} / R_{m}^{\prime}$ for the uniform 2D model: a 2D model with uniform dilation potential $\beta$. 
Last, I compare the excess pore pressure solution between the uniform $2 \mathrm{D}$ model (dash-dotted line, Figure 3.10) and the 1D steady state model (dashed line, Figure 3.10) to show how the vertical drainage affects the excess pore pressure solution. I find the location of the maximum pore pressure drop $\left(x_{m}\right)$ from the uniform $2 \mathrm{D}$ model is $1 \mathrm{~cm}$, or $10 \%$, less than the value predicted by the $1 \mathrm{D}$ model while the normalized excess pore

pressure at $x>x_{m}$ from the uniform 2D model is closer to hydrostatic than that from the 1D model (Figure 3.10). In the 1D model, excess pore pressure can only drain from the breaching front while in the uniform 2D model the excess pore pressure can also drain from the top surface. As a result, the excess pore pressure drains faster and is closer to the hydrostatic pressure with the addition of the vertical pore water flow component. I will show in the next section that this change accelerates erosion near the top of the breaching front.

\subsection{VARIATION OF EROSION RATE IN THE VERTICAL DIRECTION}

Here I study variation in the velocity of the breaching front at different depths with a 2D model. Previous studies and the analysis from Chapter 2 propose that the front velocity is simply controlled by the dissipation of pore pressure through the front itself (Van Rhee, 2007). The reason for this is that in order for the breaching front to retreat, sediments must be released, requiring dissipation of the negative excess pore pressure that otherwise stabilize the deposit.

I start by adopting the erosion rate model from Chapter 2, where the water flux from the failure surface into the deposit is required to compensate the pore volume increase from dilation. However, the water flux into the deposit comes from both the 
breaching front and the top surface of the deposit. Following Chapter 2 and consider both water flow from the vertical and horizontal directions, we have

$$
v(y)=-\frac{k}{E_{0} u_{m}^{*}(y)}\left(\left.\frac{\partial u^{*}}{\partial x}\right|_{(0, y)}+\left.\frac{\partial u^{*}}{\partial y}\right|_{\left(x_{m}, 0\right)}\right)
$$

where $E_{0}$ is an empirical parameter that quantifies the amount of dilation that needs to be compensated by the water flux and $\mathrm{u}_{\mathrm{m}}^{*}$ is the minimum excess pore pressure at a given depth $\mathrm{y}$. The parameter $\mathrm{E}_{0}$ is a function of the friction angle of the deposit. I choose a value for $E_{0}$ so that the average erosion rate over depth matches the observed erosion rate of $4 \mathrm{~mm} / \mathrm{s}$. Because the maximum pore pressure drop is very close to the breaching front, the horizontal flux dominates the dissipation of pore pressure near the breaching front (Figure 3.7A, 3.8A). The excess pore pressure gradient in the vertical direction at the top surface $\left.\frac{\partial u^{*}}{\partial y}\right|_{\left(x_{m}, 0\right)}$ is at least one order of magnitude smaller than the excess pore pressure gradient in the horizontal direction at the breaching front $\left.\frac{\partial u^{*}}{\partial x}\right|_{(0, y)}$. Therefore, the water flux in the vertical direction can be ignored. However, this does not mean the vertical pore pressure dissipation does not affect the erosion rate. Previous sections show that vertical dissipation of pore pressure affects the pore pressure distribution in the horizontal direction as well as the pore pressure values. In other words, vertical flow affects $\left.\frac{\partial u^{*}}{\partial x}\right|_{x=0}$ and $u_{m}^{*}(y)$. Hence the vertical flow affects the erosion rate even though the term $\left.\frac{\partial u^{*}}{\partial y}\right|_{y=0}$ can be ignored in Equation 3.18.

I couple the Equation 3.18 to the 2D pore pressure model (Equation 3.16) and solve for the erosion rate $v$. I model dilation potential as a function of the effective stresses (Equation 3.15). Solutions show that $v$ is near uniform for depths greater than $15 \mathrm{~cm}$ (changes less than 25\%) (Figure 3.13). $v$ increases near the top of breaching front. At the top of the deposit the erosion rate is $10.5 \mathrm{~mm} / \mathrm{s}, 2.5$ times faster than the average erosion rate of $4 \mathrm{~mm} / \mathrm{s}$. The erosion rate is close to uniform for $70 \%$ of the deposit 
because the coefficient of consolidation is uniform in the deposit. Chapter 2 shows that erosion is in equilibrium with the dissipation of pore pressure at steady state and erosion rate is proportional to the coefficient of consolidation. The erosion rate near the top boundary is faster because the boundary condition affects pore pressure dissipation greatly. Near the top, the pore pressure drains faster due to the closer distance to the top boundary. The faster erosion rate near the top could explain the decrease in local slope of the breaching front within the top $5 \mathrm{~cm}$ of the deposit (Figure 3.1). I argue that the faster erosion near the top does not reduce the average slope of the breaching front due to the turbidity current that sediment released during breaching generates. Erosion near the base of the deposit is strongly influenced by this plunging current (Figure 3.1). Previous studies observe active recirculation of water and sediment at the base of the deposit, potentially creating a zone of enhanced erosion (Van Rhee and Bezuijen, 1998; Eke, 2008). The erosion from the plunging current could compensate for any difference in velocity calculated from pore pressure, and in some cases erosion from the current can overcompensate and allow the base to erode faster. In conclusion, I find the erosion rate is uniform for most of the deposit and changes in slope angle of the breaching front is unlikely to occur for a deposit with a uniform coefficient of consolidation. 


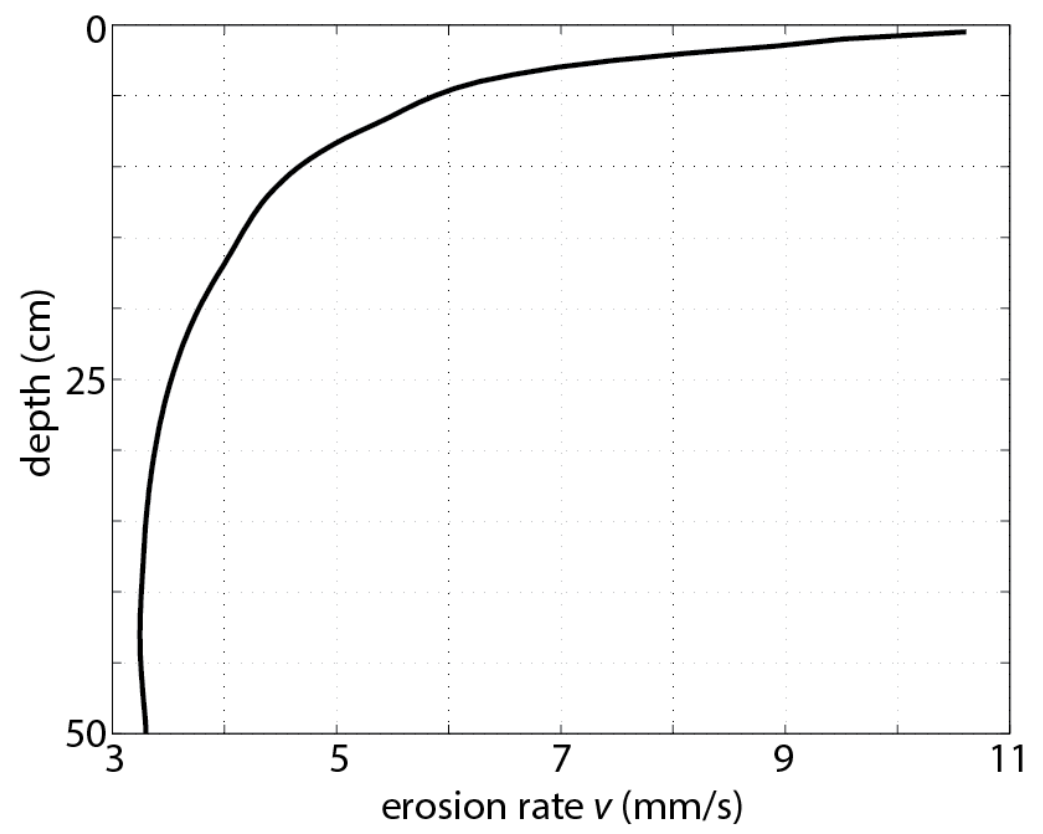

Figure 3.13: Modeled erosion rate, or velocity of the breaching front, $v$ against depth. Dilation potential is a function of stresses in this model (Equation 14).

\subsection{CONCLUSIONS AND DISCUSSION}

Breaching is a type of retrogressive submarine slope failure with a near-vertical failure surface that retreats at a slow and constant rate. During breaching the deposit dilates and generates negative excess pore pressure. In this Chapter I investigate the mechanics of breaching with 2D pore pressure and erosion rate models. I model dilation using lab experiment results. For a given depth, dilation is largest at the breaching front and decays with distance from the breaching front. As a result, the maximum pore pressure drop is close to the breaching front. Dilation decreases with increasing depth, therefore the increase of the pore pressure drop is less rapid than the increase of the magnitude of unloading with increasing depth. Consequently, the stability of the deposit associated with dilation decreases with increasing thickness of the deposit and at some depth breaching could no longer occur. 
Addition of the vertical dissipation of pore pressure results in much better fit between the model results and the observations. First, the vertical dissipation reduces the magnitude of excess pore pressure compared to 1D model, especially for the part of the deposit that is away from the breaching front. Second, the vertical dissipation moves the maximum pore pressure drop closer to the breaching front. Both changes affect the stability of the deposit because the stability of the deposit is a function of the excess pore pressure. They also affect the erosion rate because the erosion rate is a function of both the magnitude and horizontal distribution of the excess pore pressure.

I model the erosion rate of breaching in $2 \mathrm{D}$ for the first time. I couple the retreating of the breaching front to the dissipation of the negative excess pore pressure generated by breaching. Because the pore pressure drop is close to the breaching front, the sediment release is mainly controlled by dissipation of excess pore pressure in the horizontal direction. As a result, the erosion rate can be treated as a constant in the vertical direction except for the top of the deposit, suggesting the slope of the breaching front is stable during breaching. The top draining boundary accelerates the erosion near the top of the deposit, relaxing the slope of the breaching front near the top.

I only considered variation of material properties due to differences in stress in this study. Another common cause for variation of material properties in a deposit is stratification. Consider a deposit consists of interbedded sand and silty sand deposits, the coefficient of consolation and the dilation potential could be different between those two types of sediment. Future studies can use the 2D analysis presented in this chapter to find out how this type of heterogeneity affects breaching.

This and previous studies on breaching form a foundation for us to study slope failure in dilative deposits in general. Slope failures in dilative deposits should be common in the field. To assess this hypothesis I use the in situ relative density $\left(I_{D}\right)$ and 
the mean effective stress of a deposit to estimate whether natural clean sand deposits are susceptible to dilation upon their failure (Been and Jefferies, 1985; Bolton, 1986). Relative density is calculated with in situ void ratio $(e)$, maximum void ratio $\left(e_{\max }\right)$, and minimum void ratio $\left(e_{\min }\right)$, such that

$$
I_{D}=\left(e_{\max }-e\right) /\left(e_{\max }-e_{\min }\right)
$$

The maximum and minimum void ratio $\left(e_{\max }, e_{\min }\right)$ are often not measured in field studies but they can be estimated from grain size measurements (Beard and Weyl, 1973). I use this method to estimate the relative density of clean sands on the continental shelf published in literature (Table 3.2). I assume these natural deposits are less than $10 \mathrm{~m}$ thick, which corresponds to a confining stress less than $100 \mathrm{kPa}$ in the deposit. Bolton's study suggests that deposits having a relative density larger than $20 \%$ can dilate when the confining stress is less than $100 \mathrm{kPa}$ (Bolton, 1986). A majority of the published cases I found have relative densities $\left(I_{D}\right)$ larger than $20 \%$, suggesting that dilative sand is common in such environments (Breslau, 1967; Pryor, 1972; Beard and Weyl, 1973; Bennett and Stockstill, 1999; Richardson et al., 2001; Curry et al., 2004). Slope failures in dilative deposits could play a more important role in changing the morphology on the 


\begin{tabular}{|c|c|c|c|}
\hline Location & $\begin{array}{l}D_{50} \\
(\mathbf{m m})\end{array}$ & $\begin{array}{l}I_{r}: \text { relative } \\
\text { density }\end{array}$ & Reference \\
\hline $\begin{array}{l}\text { Fort Walton Beach, } \\
\text { FL }\end{array}$ & 0.42 & 1.2 & Richardson et al., 2001 \\
\hline $\begin{array}{l}\text { Fort Walton Beach, } \\
\text { FL }\end{array}$ & 0.45 & $0.5 *$ & Curry, et al., 2004 \\
\hline $\begin{array}{l}\text { Galveston, TX/New } \\
\text { Orland, LA }\end{array}$ & 0.12 & 1 & Beard and Weyl, 1973 \\
\hline Coast of Holland & 0.25 & 0.94 & $\begin{array}{l}\text { Bennett and Stockstill, } \\
1999\end{array}$ \\
\hline $\begin{array}{l}\text { Western North } \\
\text { Atlantic }\end{array}$ & $0.2-0.14$ & $0.33-1.2$ & Breslau, 1967 \\
\hline Irish Sea & 0.14 & 0.97 & Jackson, 1975 \\
\hline $\begin{array}{l}\text { Galveston, TX/New } \\
\text { Orland, LA }\end{array}$ & 0.24 & 0.13 & Beard and Weyl, 1973 \\
\hline $\begin{array}{l}\text { East Texas Gulf } \\
\text { Coast }\end{array}$ & 0.9 & -0.29 & Pryor, 1972 \\
\hline
\end{tabular}

* Curry et al. [2004] did measure maximum and minimum void ratio directly therefore the relative density is not estimation.

Table 3.2: $\quad$ Estimated relative density $\left(\mathrm{I}_{\mathrm{D}}\right)$ of clean sand deposits in published literature.

Larger values of $I_{D}$ means the deposit has smaller porosity/void ratio. $\mathrm{I}_{\mathrm{D}}>1$ means the in situ porosity is smaller than the estimated minimum value and $\mathrm{I}_{\mathrm{D}}<0$ means the in situ porosity is larger than the estimated maximum value. Assuming the deposits are less than $10 \mathrm{~m}$ thick, the condition for the deposit to dilate is $I_{d}>0.2$ according to Bolton [1986]. 


\section{Chapter 4: Dual-mode slope failure}

\subsection{INTRODUCTION}

Submarine slope failure is an important mechanism that redistributes sediments on the seascape (Piper and Normark, 2009). To accurately interpret their sedimentary records and surface morphological changes we need to know the full spectrum of possible types of slope failures. The study of submarine slope failure has emphasized liquefaction slope failure, typically in mud rich deposits. Those slope failures leave scarps that are up to a few kilometers long and have runoff distances of hundreds of kilometers (Hampton et al., 1996; McAdoo et al., 2000). As a result, they are well documented in the sedimentary records and provide us with rich information to study. Some types of slope failure, however, do not produce obvious sedimentary records and were discovered through direct observation. For example, breaching slope failure that occurs in cohesionless sand was discovered during sand mining (de Koning, 1970; Van den Berg et al., 2002). Breaching is a retrogressive slope failure where sediments are released at a slow $(\mathrm{mm} / \mathrm{s})$ and approximately constant rate from a near-vertical failure surface. Breaching generates sustained turbidity currents and leaves no discernible scarp (Van den Berg et al., 2002). Breaching could be responsible for releasing long shore drift deposits at the head of submarine canyons into their canyon axis (Mastbergen and Van den Berg, 2003; Eke et al., 2011). Because of the lack of obvious preserved geomorphic or sedimentologic features, slope failures like breaching are better suited for experimental studies, where we can understand their mechanics. In this chapter I identify a new type of slope failure that occurs in sand-rich subaqueous deposits. This style of slope failure is a 
variant of breaching that includes both the classic slow and steady release of sediment and periodic sliding.

Past studies suggest that breaching and sliding can be regarded as two endmember types of slope failure and the differences between them are due to different modes of shear deformation and their associated pore pressure responses (Meijer and van Os, 1976; Van den Berg et al., 2002). Liquefaction slope failure is characterized by dramatic slumping/sliding events with fast release of sediments. The sliding is a result of contraction of pores during shear and a rise in pore pressure. This rise in pore pressure reduces the effective stress in the deposit, which greatly weakens the deposit and leads to slope failure (Terzaghi, 1951; Hampton et al., 1996; Flemings et al., 2008). On the other hand, breaching slope failure is associated with dilation of pores during shear and a decrease in pore pressure (Meijer and van Os, 1976; Van den Berg et al., 2002). The drop in pore pressure increases the effective stress and strength of the deposit. The increase in strength keeps the deposit from sliding and only allows sediments on the failure surface to be released at a controlled rate.

Pure breaching represents a steady state, dilative slope failure. Dilative slope failure is defined by sediment that dilates under shear stress. Chapter 2 shows that during breaching the excess pore pressure is negative and reaches a steady state due to the equilibrium between slope failure and pore pressure dissipation. Chapter 2 also shows that the steady negative excess pore pressure is able to maintain a stable deposit during breaching when the dilation is more than a threshold value. However, the steady state negative excess pore pressure can fail at maintaining a stable deposit when dilation is less than the threshold value. To completely understand how sediments are released during dilative slope failure we need to understand what happens when the steady state pore pressure is not able to maintain a stable deposit. I use experiments to study this problem. 
Experimental studies are important means for us to understand the mechanics of slope failure because it is much easier to make direct measurements of parameters like pore pressure in a controlled lab environment. The knowledge we gain from the experimental study can guide us in making effective measurements in the field.

In this study I use flume experiments to identify a new type of slope failure and I define its mechanics using both pore pressure measurements and numerical pore pressure models. First, I use an ultrasonic imaging to capture the characteristic feature of this new type of slope failure, periodic alternations between breaching and sliding. Second, I combine pore pressure measurements with a numerical pore pressure model and accompanying stability analysis to examine the conditions when pore pressure drop from dilation is not enough to maintain a stable deposit during breaching, resulting in periodic sliding. I also show that sliding induces large pore pressure drops within the remaining deposit, stabilizing it and switching the mode of slope failure back to breaching. Last, I use the numerical model to discuss the conditions that could lead to this new type of slope failure instead of pure breaching in dilative deposits.

\subsection{EXPERIMENT SETUP}

I built a rectangular deposit inside a water tight flume (Figure 4.1) out of siliciclastic, well-sorted fine sand $\left(D_{50}=0.19 \mathrm{~mm}\right)$. This deposit hosting flume, referred as the inner flume, rests on the floor of a larger flume (referred as the outer flume). The inner flume is $1.2 \mathrm{~m}$ tall (vertical dimension in Figure 4.1), $0.15 \mathrm{~m}$ wide, and $0.58 \mathrm{~m}$ long (horizontal dimension in Figure 4.1) and it constrains the deposit on all sides until one narrow wall is removed as a vertical sliding gate. The inner flume is positioned in the center of the outer flume with its sliding gate more than $2 \mathrm{~m}$ away from the end of the 
outer flume. This $2 \mathrm{~m}$ distance allows sufficient space for the failed sediments to flow away from the deposit. I built each original deposit by raining sediment through the water column at a controlled rate. Because the sedimentation rate in the lab is much higher than that in the field, the deposit can have higher porosities than a deposit built with natural sedimentation rate (Vaid and Negussey, 1988). To minimize this difference I used a rubber mallet to condense the sediment by tapping on the surface of the deposit when it was at $1 / 3,2 / 3$, and full height. I also placed $23 \mathrm{~kg}$ of deadweight on top of each fully built deposit for 24 hours to facilitate further consolidation. Each constructed deposit had 6 thin $(\sim 0.01 \mathrm{~m})$, roughly evenly spaced in the vertical direction and horizontal layers of brown colored medium sand that served as marker beds so that internal deformations in the deposit could be visualized. Deposit porosity was $\sim 36 \%$, with a relative density of 85 \%; a relative density that is commonly observed in the field (e.g., Curry et al., 2004). Each final deposit was $0.58 \mathrm{~m}$ long (horizontal dimension in Figure 4.1), 0.15m wide, and depending on the experiment between $0.96 \mathrm{~m}$ to $1.0 \mathrm{~m}$ thick.

I collect three types of measurements in each experiment. First, I record the pore pressure in the deposit with gauge pressure transducers at 7 locations along the length of the deposit and at a constant depth (Figure 4.1). The transducers, whose outer diameters are $2.4 \mathrm{~cm}$, are placed outside of the outer flume and they are plumbed to the deposit with a series of thin tubes, whose outer diameters are $0.32 \mathrm{~cm}$. Using the thin tubes allows us to make measurements at higher resolution and minimize the disturbance to the deposit. The distance between the sensors and the surface of the deposit varies between $0.08 \mathrm{~m}$ to $0.12 \mathrm{~cm}$ in different experiments. I intentionally place the sensors close to the top of the deposit because the pore pressure signal in the lower portion of the deposit is complicated by the adjacent redeposition of failed sediments. The transducers records pore pressure at each location at a frequency of $1 \mathrm{~Hz}$ and an accuracy of $21 \mathrm{~Pa}$. 


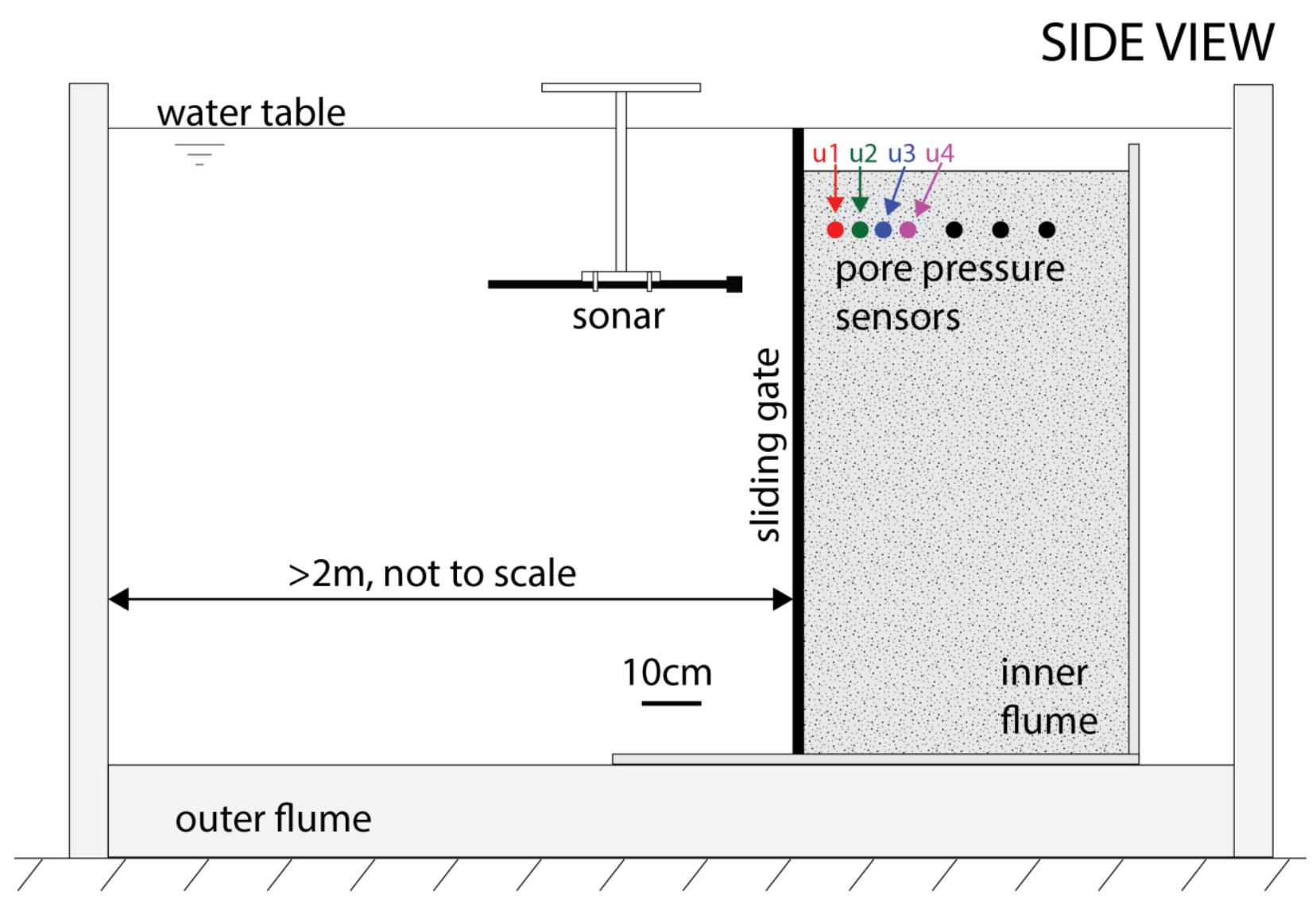

Figure 4.1: Side view of the setup of the experiment.

Second, I measure the location of the failure surface using an ultrasonic transceiver. In this study, the interface between water and the deposit has a large contrast in acoustic impedance so that the boundary is well imaged by the strong reflection of ultrasonic waves, similar to the way that distinct lithological boundaries are recorded by strong reflectors in seismic images. Because each deposit itself is relatively homogeneous in composition, the interior of each deposit appear acoustically transparent, similar to the way a homogeneous bed appears transparent in a seismic image. The transceiver collects acoustic data at a frequency of $10 \mathrm{MHz}$, and measures the distance between its head and the deposit-water interface to a resolution of $0.14 \mathrm{~mm}$ over a footprint of $1.8 \mathrm{~cm}^{2}$. 
Technical details of this measuring tool are presented in Perillo et al. (in prep.). I orient the transceiver so that it is measuring the retreat of the failure surface at a position $\sim 16 \mathrm{~cm}$ below the top of the deposit (Figure 4.1). Therefore the surface retreat measurements and the pore pressure measurements are spatially close to each other; because the tubes I use to measure pore pressure can interfere with the ultrasonic waves I am not able to measure the surface retreat at the exact depth where the pore pressure are measured. Video capturing the evolution of the entire failing deposit is also collected during each run.

\subsection{DUAL-MODE FAILURE}

I initiate slope failure by quickly pulling out the sliding gate from the inner flume. Removal of this gate takes about 2 s. The deposit does not collapse immediately after the gate is removed. Instead it maintains a vertical surface referred to as the failure front (Figure 4.2A). The failure front retreats at a relatively slow and steady rate, releasing individual grains from the otherwise stable deposit. The falling grains generate a sustained turbidity current (Figure 4.2A). All of these observations are consistent with breaching slope failure presented in Chapter 2 and previous studies (Van Rhee and Bezuijen, 1998; Van den Berg et al., 2002; Eke et al., 2011). The character of the slope failure starts to diverge from the case of pure breaching after 10s when a sliding plane oriented at $80^{\circ}$ to the horizontal forms in the deposit (Figure 4.2B). The sediment wedge positioned above this plane starts to slide downward as a relatively coherent block. As the wedge slides down, sediment on its surface, as well as sediment constituting the exposed sliding plane continues to be released at the slow and constant rate observed during the breaching interval prior to the sliding event. With continued sliding the wedge deforms and entrains water until it fully disintegrates, becoming part of the turbidity current 
generated by the slope failure. Interestingly, the onset of wedge sliding acts to stabilize the rest of the deposit. No new sliding plane forms and following collapse of the wedge a new failure front is established. In short, the slope failure diverges from breaching temporary when sliding occurs and then slope failure returns to breaching mode after the sliding event. There are multiple sliding events during an experiment, each separated by $16 \mathrm{~s}$ on average and having an average sliding duration of $4 \mathrm{~s}$. Each sliding event is preceded and followed by breaching. During each breaching interval the slope of the failure front usually steepens from $\sim 80^{\circ}$ immediately post sliding to $90^{\circ}$, sometimes even exceeding $90^{\circ}$. To summarize, the observed slope failure temporarily switches from breaching to sliding every 16 s, then switches back to breaching after $4 \mathrm{~s}$ of sliding. I call this cyclic failure process the dual-mode slope failure: breaching and sliding modes co-existing in the same slope failure event. The dual-mode also refers to the two different styles of failure front retreat: slow and steady retreat from breaching coexists with episodic fast retreat from sliding. Van Rhee and Bezuijen [1998] noted that slumping events can occur during breaching experiments but did not explore the mechanics of the slumping or study whether it represents a new type of slope failure. 

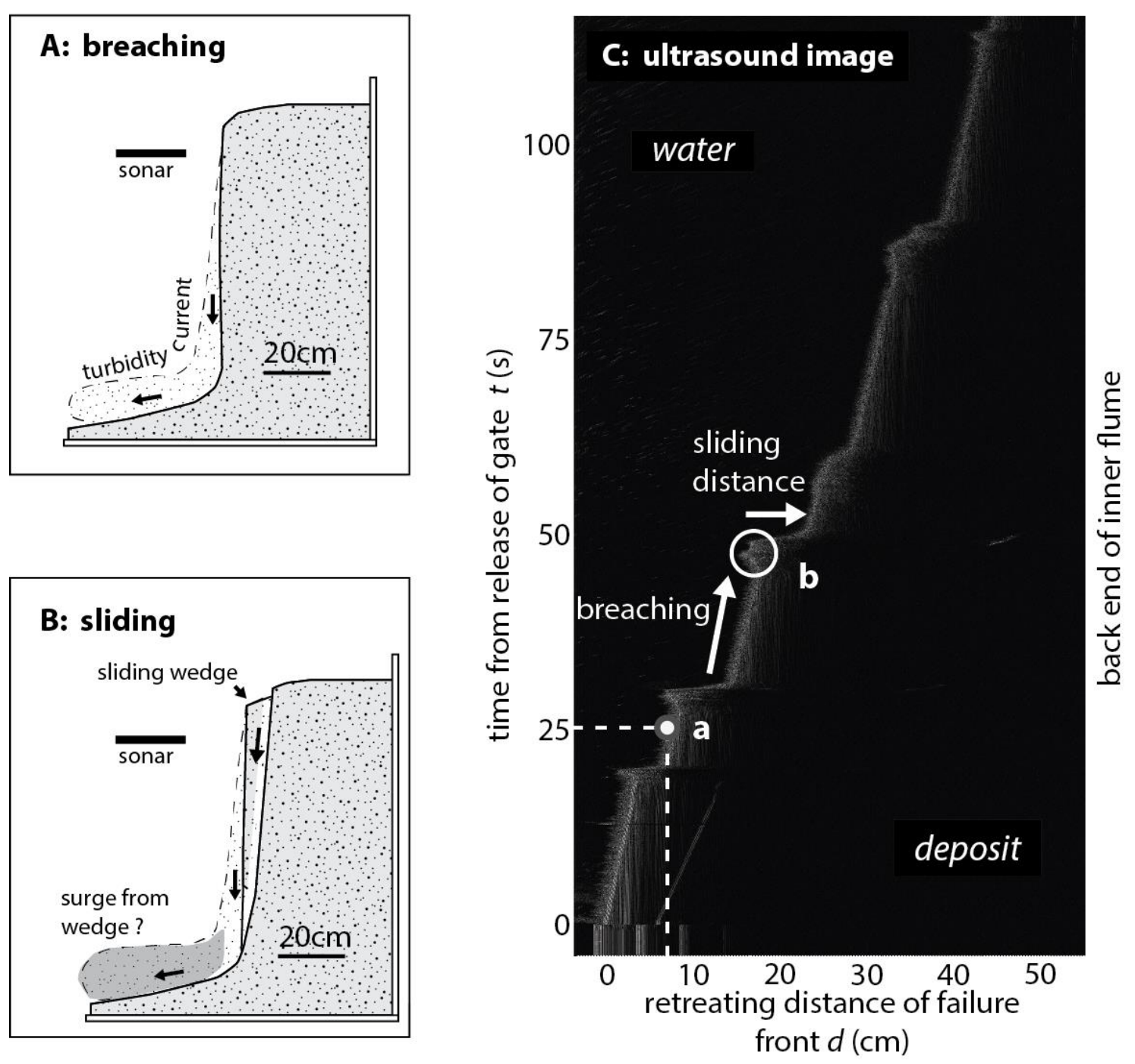

Figure 4.2: Dual-mode slope failure captured by video and sonar. A: sketch of breaching mode slope failure. B: sketch of the sliding mode slope failure as the wedge starts to slide down slope. The sliding wedge is thicker near its top therefore as it slides down the location of the failure front could temporary prograde instead of retreat (e.g., circled area in subfigure C). C: ultrasound image showing the retreating of the failure front with time. The gray scale represents the amplitude of the reflected acoustic wave; the white color represents largest amplitudes, i.e., strongest reflectors. The coordinates of the brightest reflectors (e.g., point a) represent the distance the failure front has retreated (horizontal axis, $d$ ) at a given time $t$ (vertical axis). 
I use ultrasound imaging to quantify the two styles of failure front retreat. In Figure 4.2, the position of the failure front is defined by bright reflectors on the ultrasound image. For example, point "a" in Figure 4.2C shows that the failure front has retreated $8 \mathrm{~cm}$ at $25 \mathrm{~s}$ since removal of the sliding gate. The two styles of failure front retreat are represented by two different slopes in Figure 4.2C. The steeper slopes represent the slow retreat of the failure front with time, i.e., breaching. The near horizontal slopes on the image represent fast retreat of the failure front with time, i.e., sliding. The ultrasound image shows that failure front moves forward (closer to the sonar) for a few centimeters before it suddenly retreats from sliding (circle " $b$ " in Figure 4.2C). The forward movement of the failure front is due to the passage of the sliding wedge. Because the sliding wedge is wider (size in the horizontal dimension) near its top, the water-sediment boundary temporarily moves forward as the wider part of the wedge passes through the measuring point for the sonar. I interpret that sliding starts at the time the failure front starts to move forward and ends at the time when the next breaching period (slow retreating) begins. The distance the fast retreating mode covers measures the size of the wedge and I refer to it as the sliding size. The sliding event that occurs at $62 \mathrm{~s}$ has no forward moving component for the failure front because the sliding wedge is the thickest where the sonar measurements are made.

I digitize the ultrasound image and use it to calculate the erosion rates and durations of the two modes the failure front retreats. Breaching on average has an erosion rate of $0.25 \mathrm{~cm} / \mathrm{s}$ and erodes $44 \%$ of the deposit, while sliding events have an equivalent erosion rate of $21 \mathrm{~mm} / \mathrm{s}$ and erodes $56 \%$ of the deposit. The image shows that for each breaching period, the erosion rate is a constant. The erosion rate in different breaching periods is similar, within a $\pm 0.05 \mathrm{~cm} / \mathrm{s}$ range. The sliding sizes are $6.1 \pm 1.6 \mathrm{~cm}$; there is no systematic variation of sliding size with time. . 
The dual-mode slope failure is similar to the process of episodic landslide discovered by Iverson et al. (2000). Iverson et al (2000) found that slope failure in partially saturated clay-rich soil can be episodic when the initial porosity of the soil is small. The dense soil dilates and drops pore pressure when unloaded. No displacement is observed when the pore pressure is low. Sudden displacement of the deposit along a basal slope occurs when the pore pressure rises to a certain threshold. The episodic horizontal displacement observed by Iverson et al (2000) is similar to the episodic vertical sliding I observe in this study. I show in the next section that the pore pressure measurements from this study are also similar to those from Iverson et al (2000). However, there are two major differences between the two experiments. First, I observe active retreating of the failure front between sliding events while in the experiments of Iverson et al (2000) release of sediments only occurs when sliding occurs. In other words, the experiments from Iverson et al (2000) show a pure episodic sliding behavior while this study shows breaching with episodic sliding occurring on the same slope failure. Second, Iverson et al (2000) address the stability of sediments along a pre-defined slide plane. In this study there are no pre-defined slide planes; I capture and study how these planes emerge in the deposit as it becomes unstable.

\subsection{PORE PRESSURE MEASUREMENTS}

The dual-mode retreat of the failure front produces two different signals in the pore pressure recordings. I use pore pressure recorded at the 4 sensors that are closest to the original free surface ( $\mathrm{u} 1, \mathrm{u} 2, \mathrm{u} 3$, and $\mathrm{u} 4$ in Figure 4.1) to illustrate how sliding and breaching affect the pore pressure respectively (Figure 4.3A). Before the initiation of breaching the pore pressure is at hydrostatic level and the excess pore pressure $u^{*}=0$ 
$(-10 s<t<-5 s)$. The pore pressure changes greatly when preparing the release of the gate $(-5 s<t<0 s)$. These changes are due to external forces applied on the flume and I do not consider them in this study. Immediately following the release of the sliding gate (region with yellow shading in Figure 4.3A) the pore pressure drops in all four sensors. This drop comes from both shear dilation and isotropic unloading, with majority of the drop produced by shear dilation. After the initial drop, the negative excess pore pressure starts to dissipate through pore water flow. These pore pressure changes are consistent with those observed during pure breaching as presented in Chapter 2 and other studies (Meijer and van Os, 1976). Between 18s and 20s, the pore pressure at sensors u1, u2, and $\mathrm{u} 3$ drops; the magnitude of pore pressure drop ranges from $100 \mathrm{~Pa}$ in $\mathrm{u} 3$ to $300 \mathrm{~Pa}$ in $\mathrm{u} 1$. This pore pressure drop is different from the pore pressure drop observed in pure breaching experiments, like the one in Figure 2.2 from Chapter 2. In pure breaching, the pore pressure drops in response to the slow release of sediments from the failure front. Significant pore pressure drop is limited to the deposit within $2 \mathrm{~cm}$ of the failure front. In this experiment the drops in pore pressure occurs at all 4 sensors, affecting a larger portion of the deposit than pure breaching does. 

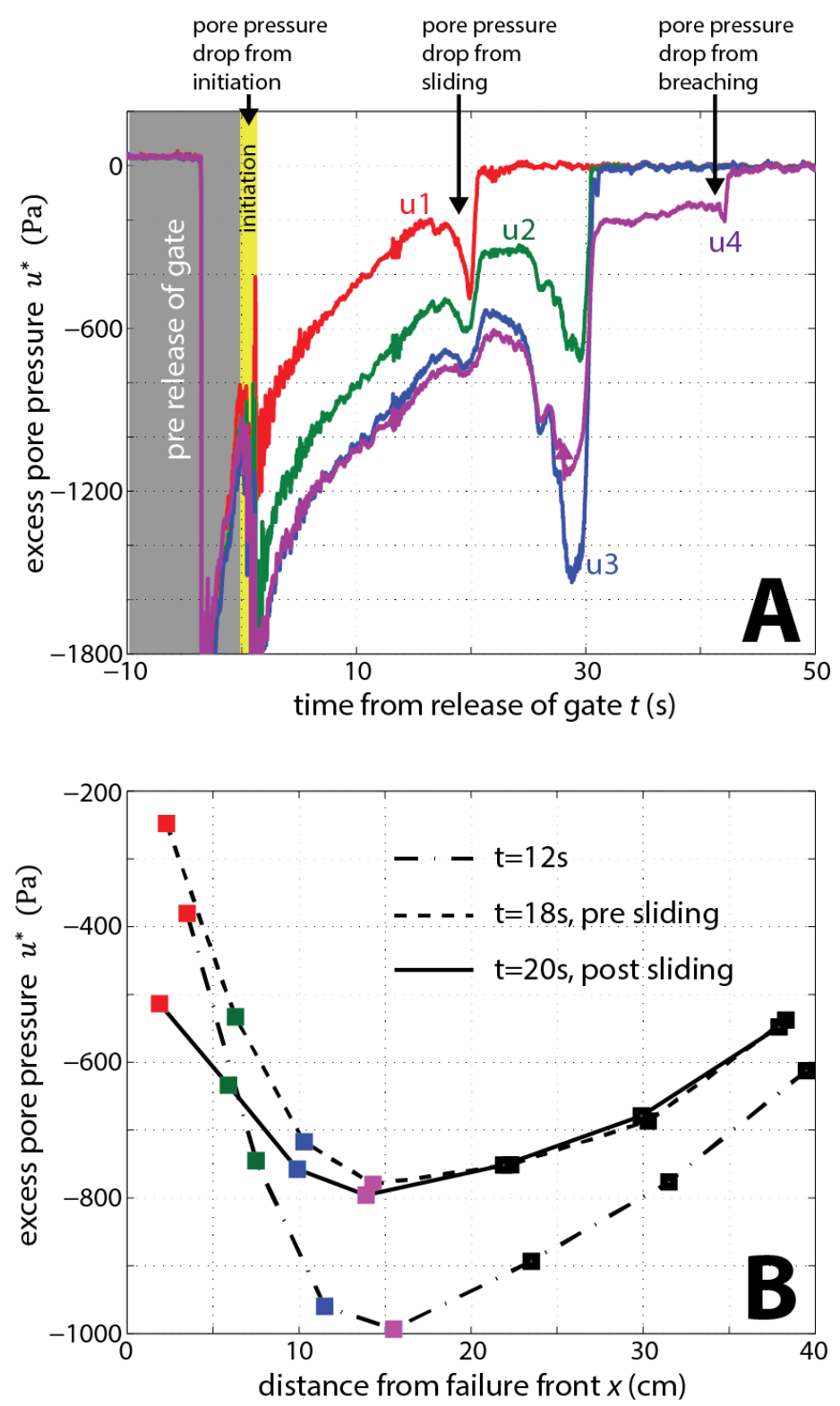

Figure 4.3: Measured excess pore pressure $u^{*}$ in the deposit. A: measured excess pore pressure at the 4 locations closest to the initial gate (labeled in different colors) against time $t$. The grey color shaded area contains measurements made before releasing the gate. The yellow color shaded area indicates the duration of initiation (pulling gate out). B: measured excess pore pressure from all the sensors (squares) against distance from failure front $(x)$ at 3 different time: $10 \mathrm{~s}$ (dash dotted line), 18s (dashed line), and 20s (solid line). $x=0$ is the failure front. 
Another way to look at the negative excess pore pressure is to plot it against distance to the failure front, i.e., plotting negative excess pore pressure in the Lagrangian reference frame whose origin retreats with the front. I study the excess pore pressure in all the sensors at $\mathrm{t}=12 \mathrm{~s}, 18 \mathrm{~s}$ (pre first sliding), and $20 \mathrm{~s}$ (post first sliding event) in Figure 4.3B. The pore pressure profiles at different times show that the spatial distribution of the negative excess pore pressure is similar at all 4 sensors. The magnitude of negative excess pore pressure increases from the failure front $(x=0)$ into the deposit $(x>0)$. The magnitude of excess pore pressure reaches its maximum value between $8 \mathrm{~cm}$ and $15 \mathrm{~cm}$ away from the failure front then it decreases with increasing distance. From $12 \mathrm{~s}$ to $18 \mathrm{~s}$ the slope failure is in breaching mode (Figure 4.2C); the magnitude of the negative excess pore pressure decreases as the excess pore pressure dissipates everywhere in the deposit. At $t=18 \mathrm{~s}$, the first sliding event occurs (Figure 4.2C) and it finishes at $t=20 \mathrm{~s}$. The excess pore pressure drops significantly for $x<10 \mathrm{~cm}$ between $18 \mathrm{~s}$ and 20s. After the sliding $t>20 \mathrm{~s}$ the magnitude of the negative excess pore pressure decreases as the excess pore pressure dissipates, until the next sliding occurs at $25 \mathrm{~s}$.

Each sliding event is associated with a sudden drop in excess pore pressure except for the sliding at $62 \mathrm{~s}$ (Figure 4.4). The top of the sliding wedge at $t=62 \mathrm{~s}$ is below where the pressure sensors are located and this could be the reason why no pore pressure drop is recorded at this time. On the other hand, pore pressure drop due to mechanisms like breaching (e.g., point "a" in Figure 4.4) is not associated with any sliding events and the magnitude of those drops is much smaller than the drops from sliding. The slope failure switches back to breaching mode after the pore pressure drops from sliding, suggesting that the deposit is stable after sliding. The excess pore pressure rises after each sliding. The excess pore pressure at a fixed point can drop at a rate slower than that during sliding before the next sliding happens, e.g., $t \in[30 s, 45 s]$ in Figure 4.4. This 
type of small pore pressure drop could be due to spatial variation of the excess pore pressure. The failure front moves closers to the sensors with time and the magnitude of negative excess pore pressure is larger nearer to the failure front.

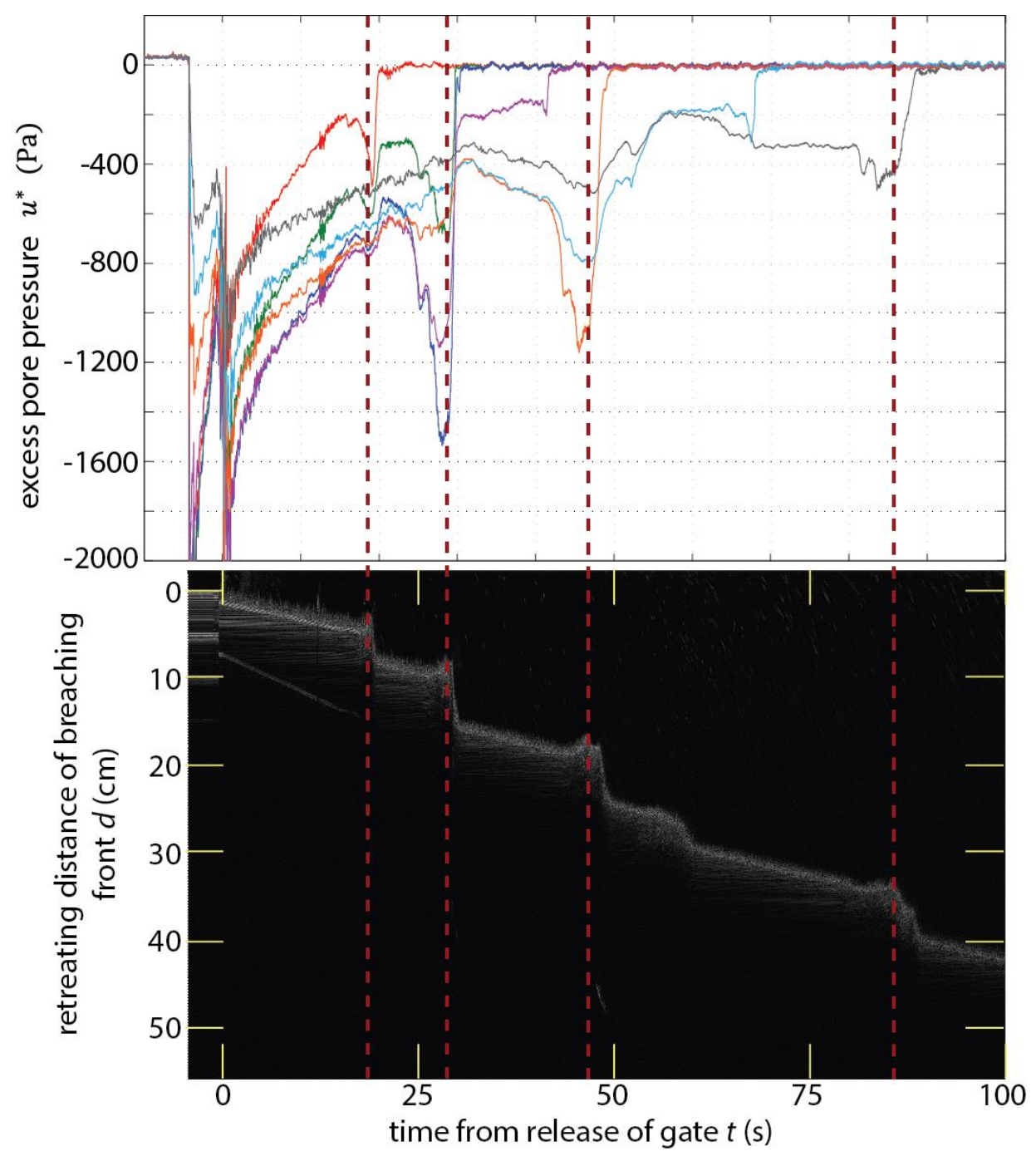

Figure 4.4: Excess pore pressure measurements for all the sensors against time (top figure) compared to the position of the slope failure surface against time (bottom figure, it is Figure 4.2C viewed in a different orientation). The two time series are aligned at the moment the gate starts to slide $(t=0)$. The red dashed lines mark the time when the excess pore pressure $\left(u^{*}\right)$ suddenly drops in the top figure. 
The periodic fluctuation in the excess pore pressure means that it never reaches a steady state in dual-mode slope failure. During pure breaching the excess pore pressure rises after the initiation but ultimately reaches a steady state value. Chapter 2 shows that during pure breaching the steady state pore pressure for the deposit is able to maintain the stability of the deposit therefore no sliding occurs. I hypothesize that as the excess pore pressure rises toward its steady state the stability of the deposit decreases; the deposit becomes unstable before the pore pressure reaches its steady state in dual-mode slope failure. I use a 2D model to test the hypotheses in the next section by studying how the stability of the deposit changes as the pore pressure evolves during dual-mode slope failure.

\subsection{D TRANSIENT PORE PRESSURE MODEL}

In this section I build a $2 \mathrm{D}$ pore pressure model to simulate the transient pore pressure during dual-mode slope failure. In the next section I use the pore pressure solutions in stability analysis to test whether the stability of the deposit does indeed decrease as the excess pore pressure rises. Because the changes in pore pressure are cyclic I only need to simulate one cycle of pore pressure changes. Specifically I model the rise of excess pore pressure from initiation until the beginning of the first sliding event, i.e., when the deposit is first unstable. In this period of time the slope failure is in breaching mode. Therefore the pore pressure changes in response to two factors (Meijer and van Os, 1976). First, the slow release of sediments from breaching generates negative excess pore pressure, or pore pressure drops. Second, pore water flow dissipates the negative excess pore pressure, i.e., decreases the magnitude of the negative excess pore pressure. Following Chapter 3, I model the changes in the excess pore pressure $u^{*}$ as a 
combination of pore pressure dissipation due to pore water flow and pore pressure generation due to changes in the horizontal stress $\sigma_{h}$. In the Lagrangian reference frame whose origin moves with the failure front, the changes in excess pore pressure with time $\frac{\partial u^{*}}{\partial t}$ in a deposit with infinite length follows,

$$
\frac{\partial u^{*}}{\partial t}=C_{v x} \frac{\partial^{2} u^{*}}{\partial x^{2}}+C_{v y} \frac{\partial^{2} u^{*}}{\partial y^{2}}+v \frac{\partial u^{*}}{\partial x}-v \beta \frac{\partial \sigma_{h}}{\partial x}, \text { for } 0<\mathrm{x}<\infty \text { and } 0<\mathrm{y}<\mathrm{H} .
$$

where $c_{v x}$ and $c_{v y}$ are the coefficient of consolidation of the deposit in the horizontal (x) and vertical (y) directions (unit is $m^{2} s^{-1}$ ), $v$ is the erosion rate of breaching (unit is $m s^{-1}$ ), $\beta$ is the dilation potential (dimensionless), and $\mathrm{H}$ is the total height (unit is $m$ ). Dilation potential $\beta$ quantifies how much more pore pressure drop comes from dilation than from isotropic unloading; larger $\beta$ means there is more dilation and larger pore pressure drops. The first two terms on the right hand side of Equation 4.1, $C_{v x} \frac{\partial^{2} u^{*}}{\partial x^{2}}+C_{v y} \frac{\partial^{2} u^{*}}{\partial y^{2}}$, represent the pore pressure dissipation due to pore water flow. The third term $v \frac{\partial u^{*}}{\partial x}$ represents the pore pressure changes due to the retreating failure front. The last term $v \beta \frac{\partial \sigma_{h}}{\partial x}$ is the source for pore pressure drop; it is can be viewed as the changes in horizontal stress in the Lagrangian reference frame $v \partial \sigma_{h} / \partial x$ amplified by the dilation potential $\beta$.

I apply the boundary conditions

$$
\begin{aligned}
& u^{*}(0, y)=0, u^{*}(x, 0)=0, \\
& \left.\frac{\partial u^{*}}{\partial x}\right|_{(\infty, y)}=0,\left.\frac{\partial u^{*}}{\partial y}\right|_{(x, H)}=0,
\end{aligned}
$$

and the initial condition

$$
u^{*}(t=0)=\frac{y u_{0}}{h_{0}}
$$

where $u_{0}$ is the measured excess pore pressure (unit is $P a$ ) at $t=2 \mathrm{~s}$ and $h_{0}=10 \mathrm{~cm}$, the depth at which the measurements are made. Those conditions are the same as the ones 
in Chapter 3. I model the horizontal stress $\sigma_{h}$ as an exponential function with distance from the failure front, same as in Chapter 2 and Chapter 3.

$$
\frac{\partial \sigma_{h}}{\partial x}=k_{0} \rho_{s} g y e^{-\eta x}
$$

where $\mathrm{k}_{0}$ is the ratio between the horizontal and vertical stress in the far field (dimensionless), $\rho_{\mathrm{s}}$ is the density of the submerged sediment (unit is $\mathrm{kgm}^{-3}$ ), $\mathrm{g}$ is the gravitational acceleration (unit is $m s^{-2}$ ), and $\eta$ is a constant that describes the decay of unloading with distance to the failure front (unit is $\mathrm{m}^{-1}$ ). The ultrasound image shows that the erosion rate for breaching $v$ is steady with time and Chapter 3 shows that $v$ can be considered uniform in the vertical direction, therefore I consider $v$ as a constant in this model and $v=2.5 \mathrm{~mm} / \mathrm{s}$ according to the ultrasound image.

I use the same modeling parameters from Chapter 3 since the composition and relative density of the sediments are the same in both studies. I set the total thickness of the deposit $H$ to be $100 \mathrm{~cm}$ to match the average thickness in the experiment. It is impractical to have a deposit with infinite length in a numerical model; I set the model length $L=100 \mathrm{~cm}$. The solution shows the excess pore pressure does not change significantly at $x=100 \mathrm{~cm}$ therefore the solution can be used as an approximation to the solution from a deposit with infinite length. I use the finite difference method with fully implicit time stepping method in solving for the excess pore pressure. The spatial grid size is $1 \mathrm{~cm}\left(50 \times D_{50}\right.$ of the sediment $)$ and the time step size is $0.1 \mathrm{~s}$. Because $\beta$ is a function of the excess pore pressure the governing equation (Equation 4.1) is nonlinear. I use single point iterative method to solve for $\beta$ and $u^{*}$ at the same time.

I compare the excess pore pressure measured from ul (solid line in Figure 4.5), the sensor that is closest to the initiation position of the sliding gate (Figure 4.1), with the model solution at the same location (dash dotted line in Figure 4.5) to demonstrate the changes of the pore pressure solution with time. The modeled pore pressure follows the 
same trend as the measured pore pressure with time: the magnitude of the excess pore pressure decreases with time as the pore pressure dissipates. However, the modeled pore pressure dissipates at a much faster rate than the measured pore pressure. To match the observed rate of pore pressure dissipation, the coefficient of consolidation for the deposit $C_{v}$ has to be 5 times smaller than the original input $C_{v 0}$ (dashed line in Figure 4.5). In this study I focus on explaining the mechanics of how the slope failure switches between the two modes. I show in the next section that this switch depends on the dissipation of excess pore pressure and that the switching mechanism is independent of the rate of pore pressure dissipation. The frequency of the switching does depend on the rate of pore pressure dissipation, as explained it in the next section.

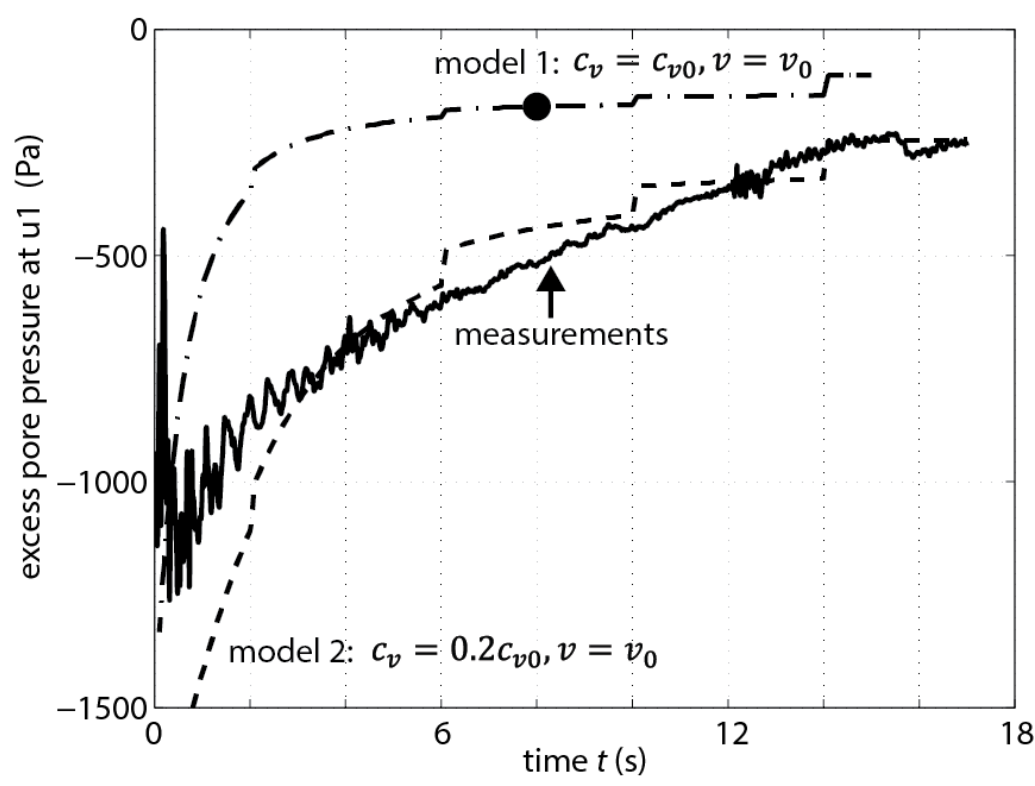

Figure 4.5: Dissipation of the excess pore pressure with time from the sensor closest to the initial position of the gate (solid line, $\mathrm{u} 1$ in Figure 4.1 and 3A), numerical solution for pore pressure at the location of $\mathrm{u} 1$ with default modeling parameters (dashed line), and numerical model solution for pore pressure at the location of ul with a coefficient of consolidation $C_{v}$ that is 10 times smaller than the default value (dash-dotted line). 


\subsection{STABILITY ANALYSIS}

I apply Coulomb's method of wedge analysis (Nedderman, 1992) to the pore pressure solution at each time step in order to determine if the deposit is stable. In this analysis I compare the driving forces that act in the downslope direction for a given slope $\theta$ to the resistance forces that act in the upslope direction (Figure 4.6A). The friction force is $\mathrm{T}=\left(\mathrm{W} \cos \theta+\mathrm{F}_{\mathrm{h}} \sin \theta-\mathrm{P}\right) \tan \phi$, where $\phi$ is the internal friction angle, $W$ is the gravitational force on the wedge, $F_{h}$ is the horizontal intergranular force, and $P$ is the force from pore pressure acting on the slope. $F_{h}$ and $P$ are calculated by integrating the horizontal stress $\left(\sigma_{3}\right)$ and excess pore pressure $\left(u^{*}\right)$ along the slope $\theta$,
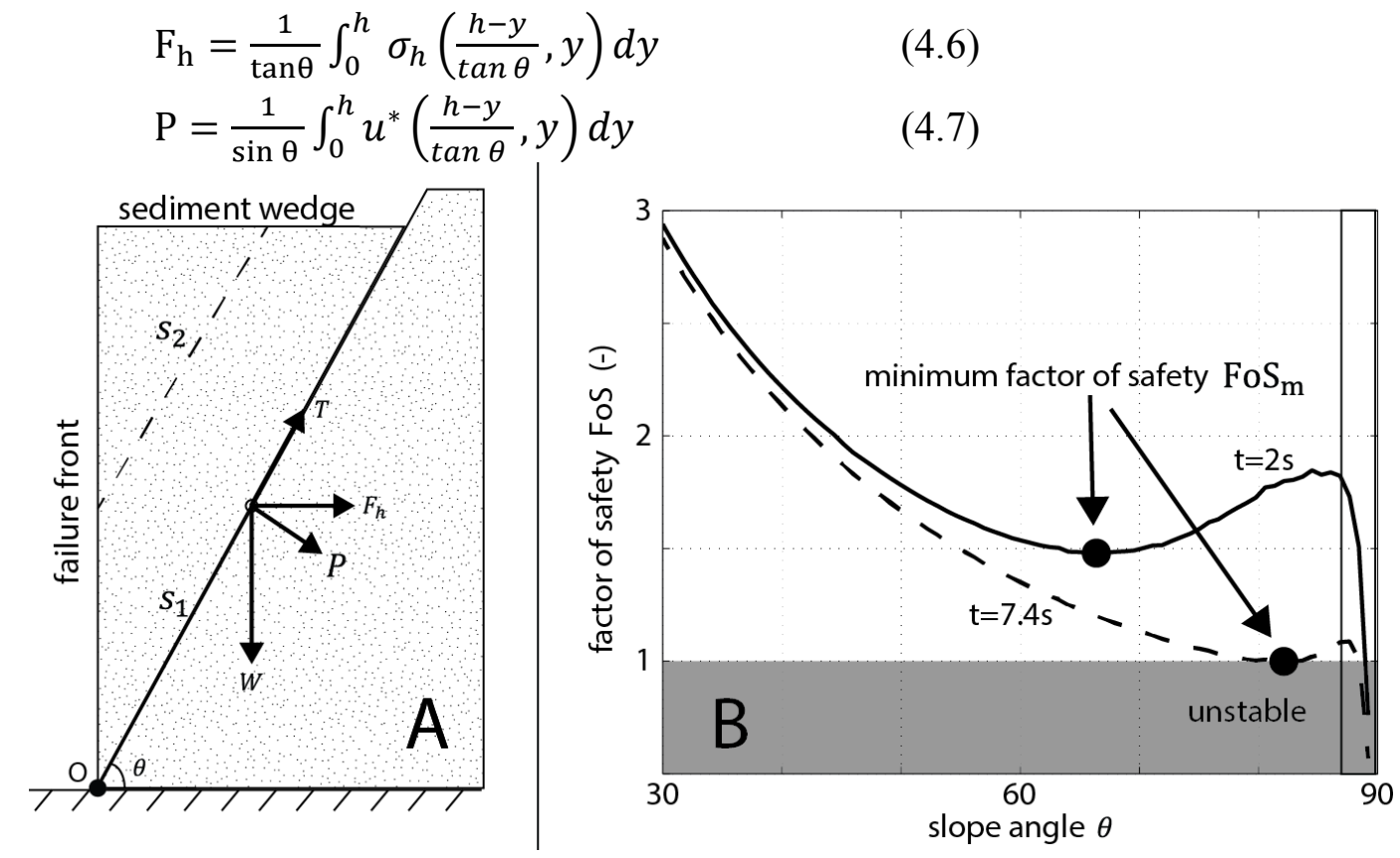

Figure 4.6: Sketch of the stability analysis and an example of the results. A: sketch of the stability analysis. I consider slope angle $\theta \in\left[30^{\circ}, 90^{\circ}\right]$ in this analysis and slopes extends to the bottom of the failure front (point "O"), e.g., slope $s_{1}$. B: factor of safety, FoS, (Equation 4.8) for different slope angles at $t=2 \mathrm{~s}$ (solid line) and 7.4s (dashed line) in the numerical model. The grey shaded area has $\mathrm{FoS}<1$ and slopes in this area are unstable. Model results for $\theta>86^{\circ}$ are considered spurious for reasons discussed in the text.

Neglecting these high values of $\theta$ it is clear that for this particular case all surfaces are stable and $\mathrm{FoS}_{\mathrm{m}}$ at $\theta=65^{\circ}$ is the least stable of these slopes. 
I use factor of safety, FoS, to evaluate the stability of the deposit, where

$$
\mathrm{FoS}=\frac{\tan \phi\left(\mathrm{W} \cos \theta+\mathrm{F}_{\mathrm{h}} \sin \theta-\mathrm{P}\right)+\mathrm{F}_{\mathrm{h}} \cos \theta}{\mathrm{W} \sin \theta}
$$

When $\mathrm{FoS}<1$ for a certain slope, the driven force $W \sin \theta$ is larger than the resistance force on the the slope and the deposit will start to slide along that surface. This stability condition shows that when the pore pressure drops, i.e., the excess pore pressure $u^{*}$ is more negative, the factor of safety FoS is larger and the deposit is more stable. As the magnitude of the negative excess pore pressure dissipates, FoS becomes smaller and the deposit could become less stable. I assume the peak friction angle $\phi=42^{\circ}$ is a constant in the model; the value for $\phi$ is calculated using triaxial shear test results presented in Chapter 3.

To demonstrate the stability analysis, I substitute the modeled pore pressure at $t=2 s$ into Equation 4.8 and calculate the FoS for slopes between $30^{\circ}$ and $89^{\circ}$; slopes larger than $89^{\circ}$ are indistinguishable from $90^{\circ}$ because the grid size is coarse. I only consider surfaces that extend all the way down to the bottom of the failure front (i.e., slopes like $s_{1}$ but not slopes like $s_{2}$ in Figure 4.6A). Model results beginning at $\theta=30^{\circ}$ show FoS decreasing as slope angle increases until a local minimum value is reached at $\theta=65^{\circ}$ (Figure 4.6B) and then FoS increases with increasing slope angle for $\theta \in\left[79^{\circ}, 86^{\circ}\right]$. FoS is calculated to rapidly decrease for surfaces with $\theta>86^{\circ}$, to the point where $\mathrm{FoS}<1$ at $\theta=88^{\circ}$ (Figure 4.6B), suggesting that slopes steeper than $88^{\circ}$ are unstable. However, such high sliding slope angles never appeared in the experiment. There are two possible reasons for this discrepancy. First, due to limitations of the computational grid size, FoS for slopes larger than $86^{\circ}$ are underestimated by the model. I find that by reducing the grid size the FoS for slopes steeper than $86^{\circ}$ increases and slopes higher than $88^{\circ}$ become stable. Second, the steeper slopes could have larger friction angles associated with them. The peak friction angle for sand increases with 
decreasing mean effective stress (Been and Jefferies, 1985; Bolton, 1986). High angle slopes are located nearer to the failure front, where the mean effective stresses is smaller. Therefore the steeper slopes have higher friction angles and are more stable than predicted by the stability analysis with constant friction angle. In the following analysis I exclude the slopes larger than $86^{\circ}$ because of these two reasons.

The modeled minimum values for factor of safety, $\mathrm{FoS}_{\mathrm{m}}$, decrease with time. Therefore, the deposit becomes less stable with time. The decrease of FoS $\mathrm{m}_{\mathrm{m}}$ with time is due to the decrease of the magnitude of the negative excess pore pressure with time (Equation 4.8 and Figure 4.7). The model calculates a $\mathrm{FoS}_{\mathrm{m}}<1$ at $7.4 \mathrm{~s}$ along the slope $\theta=81^{\circ}$ (Figure 4.6, dashed line). As a result, the wedge above the slope $\theta=81^{\circ}$ is predicted to start sliding. This prediction matches the experimental observation reasonably well. The model also predicts the slope becoming unstable $7.4 \mathrm{~s}$ after initiation, before the excess pore pressure reaches its steady state. However, this duration is 2.6 times shorter than the observed duration between initiation and first sliding event in the laboratory (18s, Figure 4.2C). The discrepancy is most likely due to the overestimation of the pore pressure dissipation rate in the model as discussed in the last section (Figure 4.5). The model also predicts a much smaller value for $u_{10}^{*}$ when sliding occurs $(-220 \mathrm{~Pa}$, Figure 4.7$)$ than what is measured in the lab $(-780 \mathrm{~Pa})$. This discrepancy could be due to the assumption that the deposit is a perfect rectangle. In the experiment the failure front can take on a slope angle larger than $90^{\circ}$, i.e., the slope is overhanging. Overhanging of the deposit reduces its stability, causing slope failure to occur at more negative excess pore pressures. 


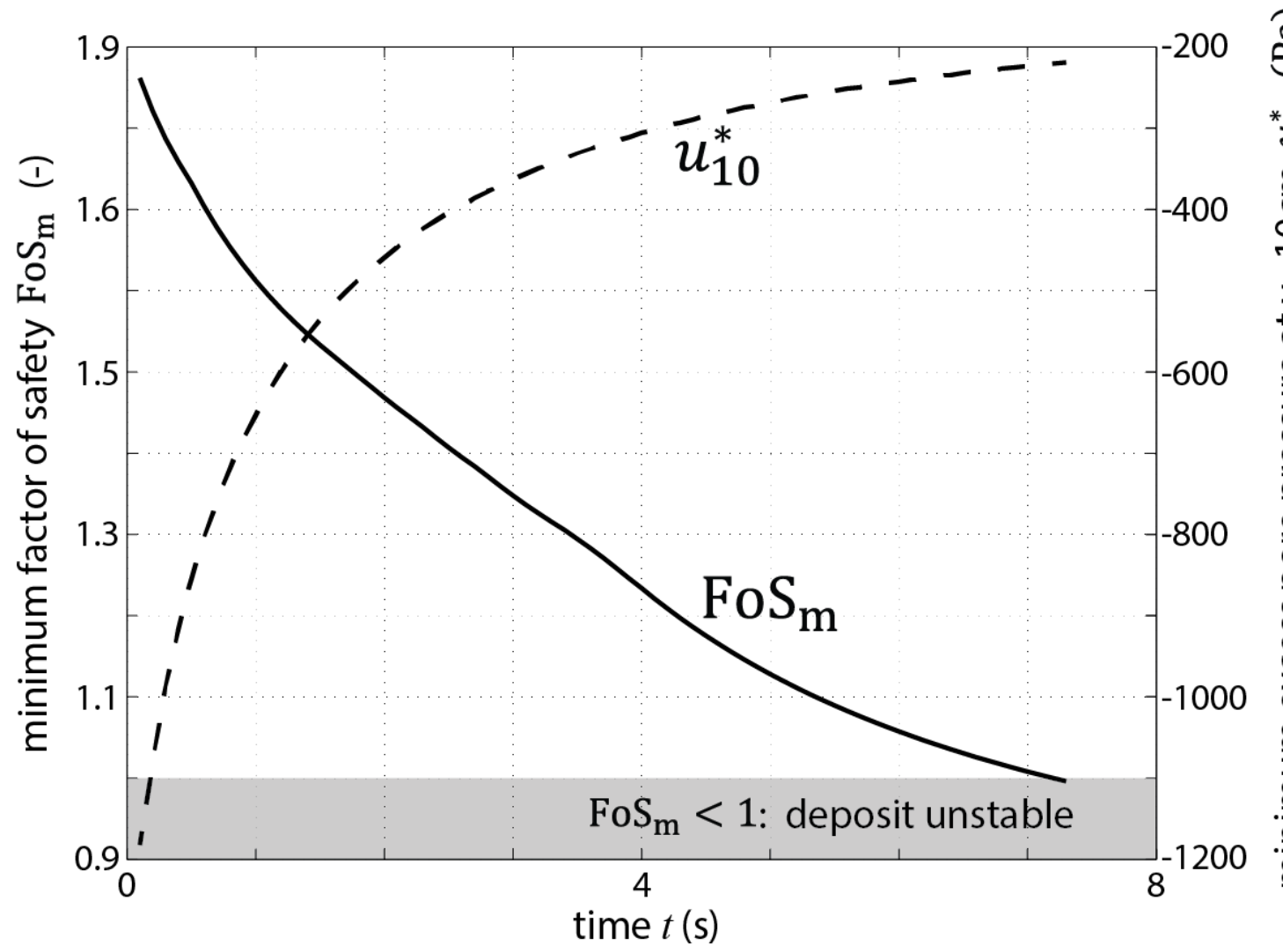

Figure 4.7: Modeled minimum factor of safety, $\mathrm{FoS}_{\mathrm{m}}$ (solid line), and minimum excess pore pressure at $y=10 \mathrm{~cm}, u_{10}^{*}$ (dashed line), against time, $t$. I choose $u_{10}^{*}$ against time to represent the trends of excess pore pressure in the deposit. When $\mathrm{FoS}_{\mathrm{m}}<1$ (at $t=7.4 s$ ), the deposit becomes unstable and sliding occurs.

\subsection{MECHANICS OF DUAL-MODE SLOPE FAILURE}

The stability analysis shows that dissipation of the excess pore pressure during breaching weakens the deposit and leads to instability, i.e., sliding. Therefore the rate of pore pressure dissipation determines the release interval for slides. The rate of pore pressure dissipation is proportional to the coefficient of consolidation $C_{v}$ (Equation 4.1). The pore pressure dissipates faster when $C_{v}$ is larger. As a result, the time it takes for the 
pore pressure to reach the critical state where the deposit is no longer stable is shorter. In other words, larger $C_{v}$ corresponds to shorter sliding period, $t_{s}$, or a higher sliding frequency, $f_{s}$. I study the sensitivity in the time it takes for the deposit to become unstable, the sliding period, $t_{s}$, by changing the values of permeability $k$ in the numerical model input. Numerical results show that $t_{s} \propto 1 / C_{v}$. To show the physical meaning of the relationship between $C_{v}$ and $t_{s}$, I simplify the transient pore pressure model so an analytical form of the transient pore pressure solution can be obtained. I simplify the model by considering only the horizontal pore pressure dissipation. Hence,

$$
\frac{\partial u^{*}}{\partial t}=C_{v} \frac{\partial^{2} u^{*}}{\partial x^{2}}+v \frac{\partial u^{*}}{\partial x}-v \eta \beta s_{0} e^{-\eta x}
$$

with the initial condition

$$
u^{*}(t=0)=u_{0}
$$

Chapter 3 shows that horizontal pore pressure dissipation dominates the changes in the pore pressure during breaching, therefore we can use the $1 \mathrm{D}$ model to study the mechanics of dual-mode slope failure. I define $\left\langle u_{0}\right\rangle=\frac{u_{0}}{\beta s_{0}},\left\langle u_{t}\right\rangle=\frac{u^{*}}{\beta s_{0}}$, and $\langle t\rangle=\frac{t v^{2}}{C_{v}}$. Then the transient pore pressure equation can be transformed into the dimensionless form

$$
\frac{\partial\left\langle u_{t}\right\rangle}{\partial\langle t\rangle}=\frac{\partial^{2}\left\langle u_{t}\right\rangle}{\partial\langle x\rangle^{2}}+\frac{\partial\left\langle u_{t}\right\rangle}{\partial\langle x\rangle}-\xi e^{-\xi\langle x\rangle}
$$

where $\xi=\frac{\eta C_{v}}{v}$ is the controlling parameter for the steady state solution (Chapter 2). I assume the solution to the excess pore pressure $\left\langle u_{t}\right\rangle$ can be separated as the sum of a transient component $\left\langle u_{1}\right\rangle(\langle x\rangle,\langle t\rangle)$ and a steady state component $\left\langle u_{2}\right\rangle(\langle x\rangle)$, i.e., $\left\langle u_{t}\right\rangle=\left\langle u_{1}\right\rangle+\left\langle u_{2}\right\rangle$. Observation shows that $\frac{\mathrm{d} v}{\mathrm{~d} t}=0$, therefore Equation 4.11 can be decomposed into the following two equations

$$
\begin{aligned}
& \frac{\partial\left\langle u_{1}\right\rangle}{\partial\langle t\rangle}=\frac{\partial^{2}\left\langle u_{1}\right\rangle}{\partial\langle x\rangle^{2}}+\frac{\partial\left\langle u_{1}\right\rangle}{\partial\langle x\rangle} \\
& 0=\frac{\mathrm{d}^{2}\left\langle u_{2}\right\rangle}{\mathrm{d}\langle x\rangle^{2}}+\frac{\mathrm{d}\left\langle u_{2}\right\rangle}{\mathrm{d}\langle x\rangle}-\xi e^{-\xi\langle x\rangle}
\end{aligned}
$$

Equation 4.13 is the same as the 1D steady state pore pressure model (Equations 2.1-2.3), therefore $\left\langle u_{2}\right\rangle=\frac{\exp (-\xi\langle x\rangle)-\exp (-\langle x\rangle)}{\xi-1}$ (Equation 2.6) and $v=\delta \eta C_{v}$ (Equation 2.4). With 
Equation 4.12, the initial condition Equation 4.10, and the fact that $\lim _{\langle t\rangle \rightarrow \infty}\left\langle u_{1}\right\rangle=0$ (the transient pore pressure ultimately disappears), we have

$$
\left\langle u_{1}\right\rangle=e^{-\lambda\langle t\rangle}\left(\left\langle u_{0}\right\rangle-\left\langle u_{2}\right\rangle\right)
$$

where $\lambda$ is a constant and does not depend on $\langle x\rangle$ or $\langle t\rangle$. Therefore

$$
\left\langle u_{t}\right\rangle=e^{-\lambda\langle t\rangle}\left(\left\langle u_{0}\right\rangle-\left\langle u_{2}\right\rangle\right)+\left\langle u_{2}\right\rangle
$$

The solution shows that the transient component of the pore pressure $e^{-\lambda\langle t\rangle}\left(\left\langle u_{0}\right\rangle-\left\langle u_{2}\right\rangle\right)$ is the dissipation of the difference between the initial excess pore pressure and the steady state excess pore pressure. Rearranging the equation

$$
\frac{\left\langle u_{t}\right\rangle-\left\langle u_{2}\right\rangle}{\left\langle u_{0}\right\rangle-\left\langle u_{2}\right\rangle}=e^{-\lambda\langle t\rangle}
$$

Therefore,

$$
\log \left(\frac{\left\langle u_{t}\right\rangle-\left\langle u_{2}\right\rangle}{\left\langle u_{0}\right\rangle-\left\langle u_{2}\right\rangle}\right)=-\lambda\langle t\rangle
$$

Transforming equation into the dimensional form

$$
\log \left(\frac{u^{*}-u_{s}^{*}}{u_{0}^{*}-u_{s}^{*}}\right)=-\frac{\lambda v^{2}}{C_{v}} t
$$

where $u_{s}^{*}=\left\langle u_{2}\right\rangle \beta s_{0}$. Substitute in the steady state solution that $v=\delta \eta C_{v}$ (Equation 2.4). The solution is reduced to

$$
\log \left(\frac{u^{*}-u_{s}^{*}}{u_{0}^{*}-u_{s}^{*}}\right)=-\lambda \delta \eta(v t)
$$

The dimensionless transient excess pore pressure solution shows that the time it takes for the excess pore pressure to reach a given value $u^{*}$ from its initial value $u_{0}^{*}$ is proportional to $1 / v$, hence $1 / C_{v}$. Sliding occurs when the pore pressure reaches a critical value $u_{c}^{*}$ defined by the friction angle and stresses on the deposit, shown in the stability analysis (Figure 4.7). Therefore, the time it takes for sliding to reoccur is the same time it takes for the pore pressure to dissipate from its value post sliding, $u_{0}^{*}$, to the critical value $u_{c}^{*}$. Hence the period between two sliding events $\left(t_{s}\right)$ is proportional to $1 / C_{v}$, or the sliding frequency $f_{s}$ (defined as $\frac{1}{t_{s}}$ ) is proportional to $C_{v}$. 
The dimensionless transient excess pore pressure solution (Equation 4.18) also shows that the distance between two sliding events is a constant. The distance between two sliding events $x_{s}$ is defined by the velocity of the failure front during this period (i.e., breaching period) multiplied to the time, therefore $x_{s}=v t_{s}$. Because $v \propto C_{v}$ (solution from Equations 4.13 and 2.3) and $t_{s} \propto 1 / C_{v}, x_{s}$ should be insensitive to $C_{v}$. Equation 4.18 shows that $x_{s}$ equals $\frac{-\log \left(\frac{u_{c}^{*}-u_{s}^{*}}{u_{0}^{*}-u_{s}^{*}}\right)}{\lambda \delta \eta}$, and is indeed not dependent on $C_{v}$. The sliding frequency and spatial separation are important parameters in studying how sediments are released from dual-mode slope failure. Future experiments with different coefficient of consolidation values are needed to test this result (more discussions are presented in Chapter 6).

Pore pressure measurements show pore pressure drops after sliding (Figure 4.4). I hypothesize that sliding drops the pore pressure by suddenly unloading the sediment. Because a larger sliding wedge will generate a larger unloading, the magnitude of pore pressure drop from sliding should depend on the size of the sliding wedge (Figure 4.2C). I test this hypothesis by comparing the sliding wedge size against the magnitude of associated pore pressure drop from measurements (Table 4.1). The number of sliding events is small in any one experiment but the data support the hypothesis that larger sliding size corresponds to larger pore pressure drops. The 4th sliding event in Table 4.1 is an exception: its sliding size is larger than that of the first event, but the corresponding pore pressure drop is smaller. One possible reason is that the 4th sliding event lasts longer than other events (Figure 4.2C). As a result, the pore pressure drop has more time to dissipate and results in an apparent smaller pore pressure drop at the end of the sliding event. I find the positive trend between sliding size and magnitude of pore pressure drop 
exists for every individual experiment. I conclude that sliding causes the pore pressure to drop.

\begin{tabular}{|l|l|l|l|l|}
\hline Sliding event \# & 1 & 2 & 3 & 4 \\
\hline $\begin{array}{l}\text { Size of sliding } \\
\text { wedge (cm) }\end{array}$ & 4.3 & 7.2 & 7.4 & 4.5 \\
\hline $\begin{array}{l}\text { Magnitude of } \\
\text { pore pressure } \\
\text { drop }(\mathrm{Pa})\end{array}$ & 342 & 823 & 856 & 150 \\
\hline
\end{tabular}

Table 4.1. Size of the 4 sliding wedges compared to the associated magnitude of pore pressure drop. The number of the sliding events is according to the order they occur in time (Figure 4.4).

According to Equation 4.9, the factor of safety FoS decreases when the magnitude of the negative excess pore pressure diminishes. The stability analysis shows that when sliding occurs only the minimum FoS is slightly less than 1 (Figure 4.7). As a result, FoS is $>1$ for all slopes immediately after sliding produces additional negative excess pore pressures. After the deposit becomes stable, the slope failure switches back to breaching mode. To sum up, the cyclic switching between breaching and sliding in dual-mode slope failure is due to the evolution of excess pore pressure. Dissipation of the excess pore pressure during breaching leads to the emergence of a single unstable slope; sliding occurs along this slope. Sliding drops the pore pressure and switches the slope failure mode back to breaching. This switching mechanism is similar to the one that controls the episodic landslide observed in Iverson et al (2000). 


\subsection{CONDITIONS FOR DUAL-MODE SLOPE FAILURE TO OCCUR}

I propose that a necessary condition for dual-mode slope failure to occur is that the deposit has to become unstable before the pore pressure field reaches its steady state associated with pure breaching. The instability occurs due to dissipation of the negative excess pore pressure generated by the initial failure. If the deposit is stable at the steady state pore pressure, sliding would never occur and the slope failure will simply continue as pure breaching (like the case in Chapter 2). I explore the conditions that could lead to sliding by studying how the stability of the deposit changes with friction angle $\phi$ and different dilation potentials $\beta$ (Equation 4.1).

Studies show that the peak friction angle of sand increases at smaller mean effective stress. Therefore, deposit located near the top surface of the sediment accumulation has a larger peak friction angle than the rest of the deposit; a thinner deposit will also has a larger overall peak friction angle than a thicker deposit. Peak friction angles at mean effective stresses less than $10 \mathrm{kPa}$ (which is common in a deposit that is less than $1 \mathrm{~m}$ thick) are difficult to measure. Sture et al. (1998) find the friction angle of sand can be higher than $50^{\circ}$ for a mean effective stress of $1.3 \mathrm{kPa}$. I setup a numerical model with $50 \mathrm{~cm}$ total deposit thickness and $\phi=50^{\circ}$ to study the sensitivity of the stability analysis results to changes in $\phi$. Model results show that the minimum factor of safety $\mathrm{FoS}_{\mathrm{m}}$ from the thinner deposit-higher $\phi$ model is greater than that from the model with $1 \mathrm{~m}$ thickness, even when the pore pressure values are the same (Figure 4.8). The thinner deposit is always stable because $\mathrm{FoS}_{\mathrm{m}}>1$ even after the pore pressure reaches its steady state (marked by the star in Figure 4.8). This result explains why pure breaching can occur in the same sand used in this study (Chapter 2). 


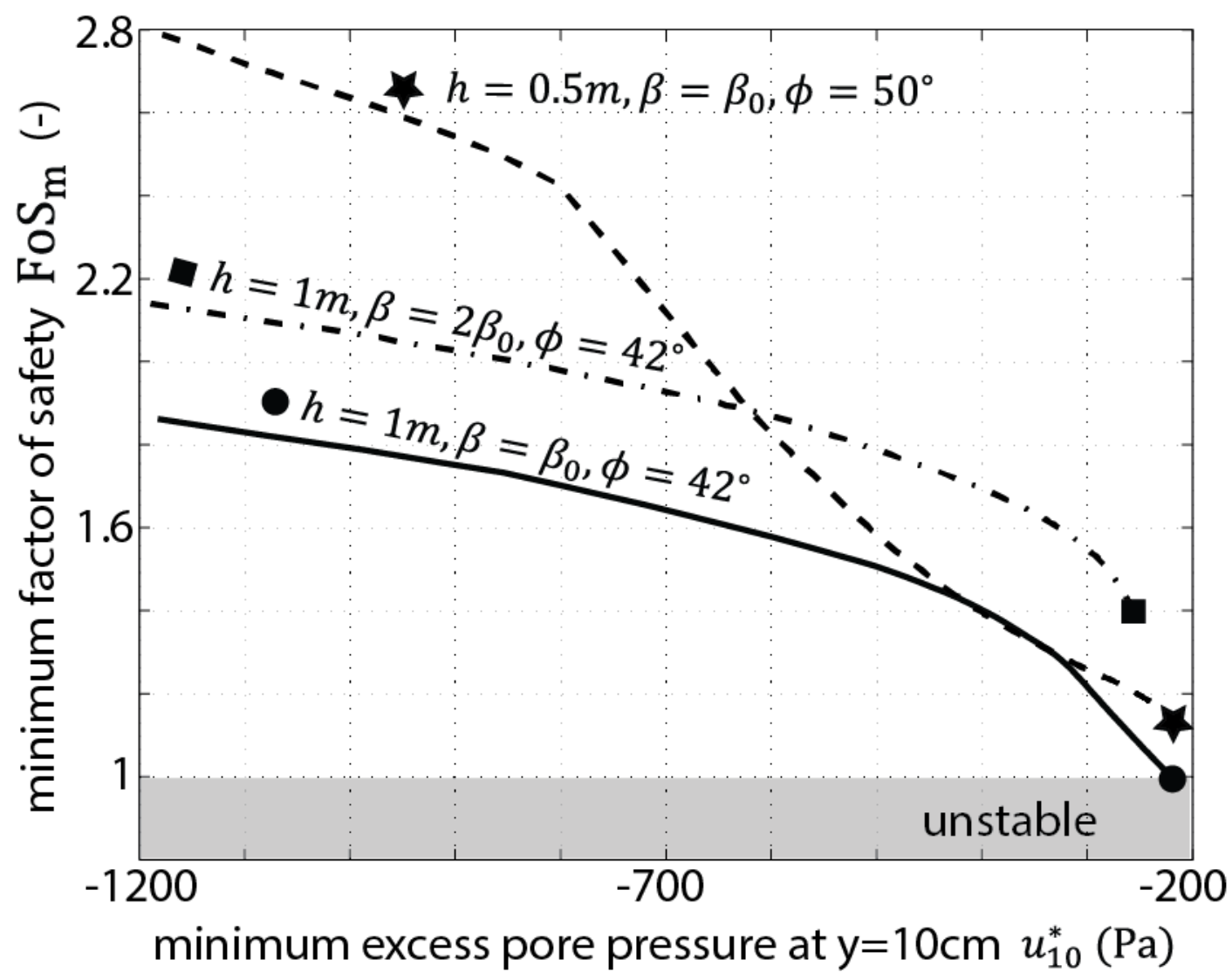

Figure 4.8: Minimum factor of safety against the minimum excess pore pressure at $y=10 \mathrm{~cm}$, which represents the pore pressure in the deposit. The solid line with circle at the right end marks the model for the deposit in the experiment, referred as the base model. The dashed dotted line with square in the right end (most of the line covered by the solid line) marks a model that is the same as the base model except the dilation potential is increased by 2 times. The dashed line with star in the right end marks a model with $0.5 \mathrm{~m}$ thickness, same dilation potential as base model, and higher friction angle than the base model.

Sensitivity study shows that the stability of the deposit also depends on the dilation potential $\beta$. I setup a new numerical model in which the value of $\beta$ is double the original input (dash dotted line in Figure 4.8). With larger $\beta$ the pore pressure drop increases and as a result, the minimum factor of safety $\mathrm{FoS}_{\mathrm{m}}$ increases in value compared 
to the base case $\left(H=1 m, \beta=\beta_{0}\right)$. This results in $\mathrm{FoS}_{\mathrm{m}}>1$ after the pore pressure reaches its steady state (filled square in Figure 4.8). Simply put, more dilation leads to a more stable deposit and less dilation can lead to sliding. Previous studies show that a deposit with larger porosity dilates less than the same sediment with smaller porosity (Been and Jefferies, 1985; Bolton, 1986). Therefore dilative deposits with a larger porosity are more likely to generate dual-mode slope failure than a deposit of the same sediment with a smaller porosity.

I propose that dual-mode slope failure cannot occur in contractive deposits, i.e., the pore volume in the sediment deposit cannot decrease under shear. This would limit dual-mode slope failure to deposits that experience no volumetric strain under shear and the deposits that dilate under shear. This condition ensures that sliding drops the pore pressure and the negative excess pore pressure act to maintain the stability of the deposit.

\subsection{POTENTIAL FIELD SITES FOR DILATIVE SLOPE FAILURE}

I argue that dual-mode slope failure and pure breaching slope failure captures the full range of failure styles in dilative deposits (Figure 4.9). Any slope failure initiation mechanism, like releasing the gate in this study, increases the shear in the deposit. Dilative deposits generate pore pressure drops with increases in shear. The pore pressure drop from dilation keeps the deposit stable temporary and the slope failure is in breaching mode (step 2 in Figure 4.9). As the negative excess pore pressure dissipates the slope failure can potentially evolve along two different paths. One type of slope failure has the

deposit becoming unstable before the excess pore pressure becomes steady (step $3 \mathrm{~b}$ in Figure 4.9). In this case the slope failure then switches to the sliding mode and dual-mode 
slope failure follows. Pure breaching slope failure occurs if the deposit is stable even after the excess pore pressure reaches its steady state (step 3a in Figure 4.9).

Dilative slope failure should be common in the field. Dilative slope failure requires sandy deposits that can dilate. Sand-rich deposits are common at locations on the continental shelf with strong long-shore currents. These long-shore currents tend to entrain sediments finer than sand, removing them from long-shore drift deposits and producing deposits with relatively narrow distributions of grain sizes (Dill, 1964; Visher and Part, 1967; Limber et al., 2008). Sandy deposits in such regions are likely to be dilative for two reasons. First, studies show that relatively well-sorted sand deposits tend to have dense, i.e., dilative, packing. For example, numerous experiments show that simply depositing uniform grains by pouring them into a container produces deposits with relative densities (Equation 3.19) of above 40\% (Smith et al., 1929; Onoda and Liniger, 1990; Radin, 2008), well above the dilation limit of $20 \%$ for $1 \mathrm{~m}$ thick deposits (Bolton, 1986). Second, experiments show that external energy input like tapping condenses sediment deposits (Rutgers, 1962; Scott et al., 1964); waves in the ocean can provide such energy. In summary, long-shore drift and wave-reworked deposits favor the production of dilative deposits. Measurements presented in Dill (1964) show that the long shore drift deposits at the head of Scripps Submarine Canyon are indeed dilative. More systematic studies are required to fully assess how common dilative deposits are in the field and I discuss this in the Chapter 6: Future Research.

One process that can lead to the initiation of dilative slope failure is focused bed erosion during storms on the continental shelf (Figure 4.10). Here I use Scripps Submarine Canyon as an example of where storms cause for release of sediments accumulated at the canyon head. Studies show that long shore drift deposits at this site disappear during storms while turbidty currents are observed moving down the canyon 
(Chamberlain, 1964; Dill, 1964; Shepard and Marshall, 1973). The disappearance of these canyon-head deposits cannot be a product of liquefaction slope failure because these deposits actually dilate instead of contract under shear (Dill, 1964). Dilative slope failure is the more likely candidate responsible for delivering those sediments into the deep ocean. The proposed focused erosion by currents need only create a surface slope that is more than the angle of repose for those sediments to initiate slope failure (Figure 4.10). The initial unstable slope angle does not have to be $90^{\circ}$, as is the case in these experiments. I observe that during dual-mode slope failure (this chapter) and pure breaching (Figure 2.3), the failure front steepens with time. As a result, any initially unstable slope can evolve into a nearly vertical failure surface. 


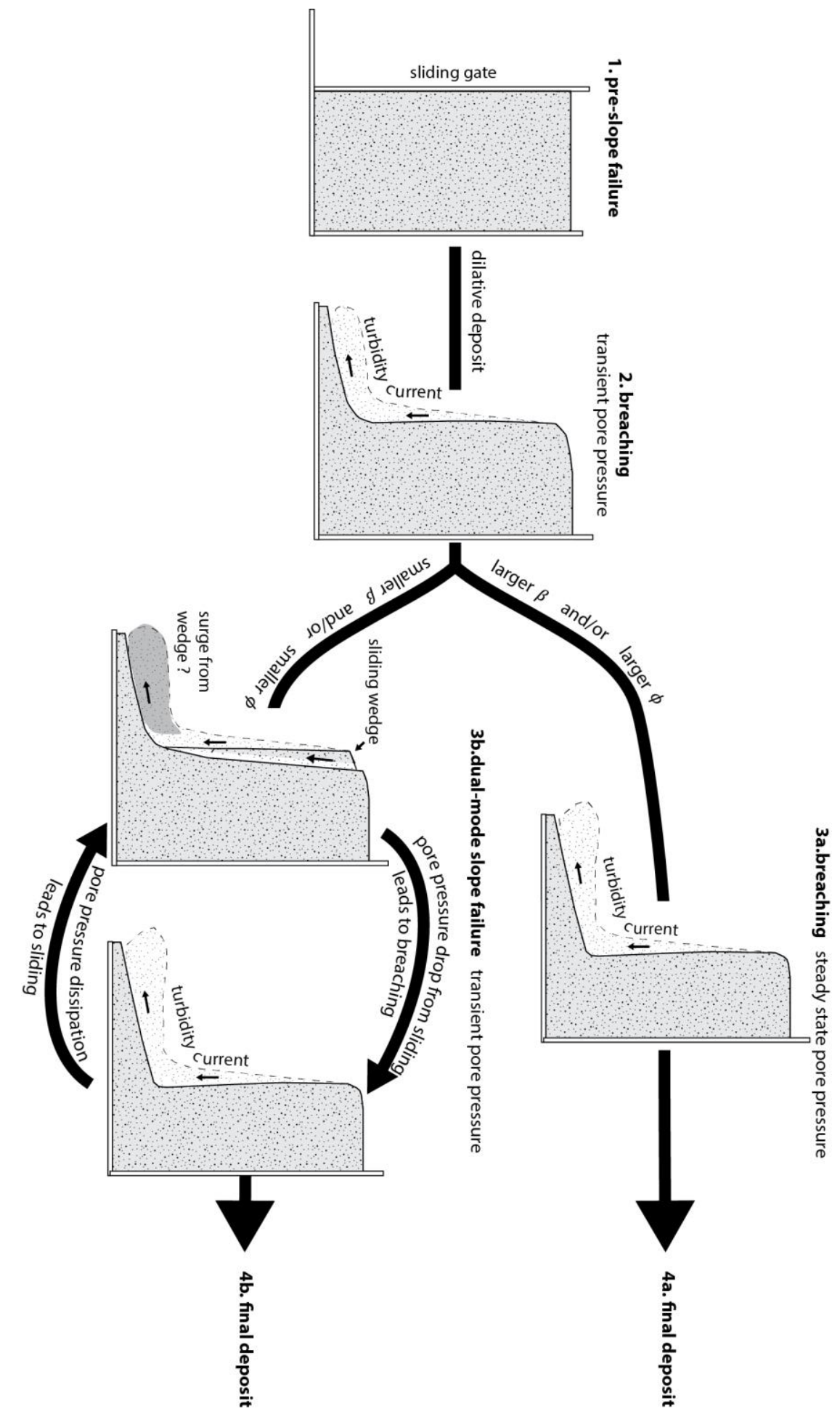

Figure 4.9: Summary sketch of the evolution and possible styles of dilative slope failure. 


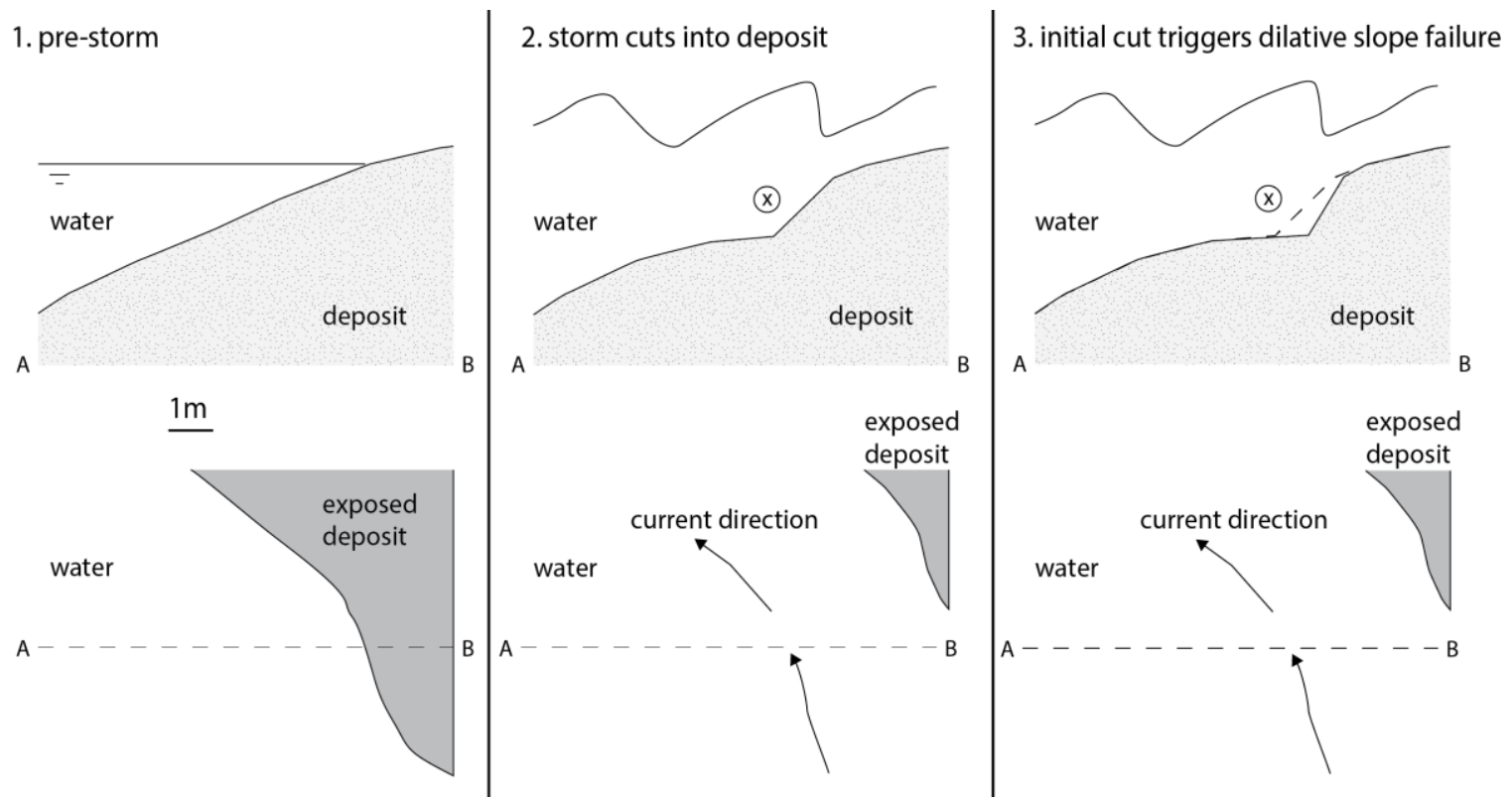

Figure 4.10: Sketch of how a storm could generate dilative slope failure. The top figures are cross sections from the locations marked as dashed lines on the associated regional maps positioned underneath each section. 1. pre-storm. 2. storm enhanced or generated currents (arrows) cut into the deposit. 3. the cut initiates slope failure and the failure front retreats toward the right-hand side of the figure.

\subsection{CONCLUSIONS AND DISCUSSION}

I introduce a new type of submarine slope failure called the dual-mode slope failure and I investigate its mechanics with experiments and a numerical pore pressure model. The slope failure is characterized by periodic switching between a breaching slope failure mode and a sliding slope failure mode. Pore pressure measurements and numerical model results show that the switching mechanism for the slope failure modes is the evolution of excess pore pressure field. Negative excess pore pressure dissipates towards its steady state during breaching mode; dissipation of the negative excess pore pressure weakens the deposit and ultimately switches the slope failure to sliding mode if 
the deposit becomes unstable. Sliding increases the magnitude of the negative excess pore pressure; this strengthens the deposit and switches the slope failure back to the breaching mode.

I further describe the sensitivity of the dual-mode slope failure using a theoretical stability analysis. I find that sliding occurs in deposits with small dilation potentials or small friction angles. However, the stability analysis only considers those slopes that intersect the bottom of the failure front. Future studies are needed to consider all possible sliding planes (e.g., surface $s_{2}$ in Figure 4.6A). We also need a better understanding of how the friction angle of sand varies in low stress conditions to properly assess the stability of slopes in a sand deposit at Earth's submarine and terrestrial surface. Nonetheless, the conclusion that dissipation of the negative excess pore pressure leads to sliding should still hold.

This study shows that sediments can be released at two drastically different rates during a single slope failure event. The dual-mode of sediment release could affect the characteristics of the turbidity current that the slope failure generates. For example, the faster sediment release from sliding could generate a sudden increase in sediment concentration and current velocity. The two modes of sediment release could also generate different sedimentary records. Future study on these topics is needed for us to accurately interpret sedimentary records and morphological changes on Earth. 


\section{Chapter 5: Conclusions}

This study investigates the mechanics of dilative slope failure by combining lab experiments with mathematical models. There are two types of dilative slope failure. One type is pure breaching; it is characterized by a slow $(\mathrm{mm} / \mathrm{s})$ and steady retreat of a nearvertical failure front that releases sediments only from its surface. Breaching is associated with negative excess pore pressure and the pore pressure reaches a steady state during breaching. The other type is dual-mode slope failure; it is a combination of breaching style sediment release with episodic sliding events when a triangular wedge of sediment falls all in once. Dual-mode slope failure is associated with periodic excess pore pressure fluctuations: the excess pore pressure drops with sliding events and rises during breaching periods.

All dilative slope failure requires the sediment to dilate under shear stress and consequently release sediments down-slope. In chapter 1 and 3, I show that a dilative deposit is common for clean sand and silty sand deposits in the field. Therefore, dilative slope failure should be common in the field, and it is potentially an important mechanism that delivers sand and silt into deep sea through the turbidity current it generates. The analysis of the sediment release rate in this study provides process based boundary conditions on sediment input for turbidity current models. These findings can improve our interpretations on sedimentary records produced by dilative slope failure.

Dilation potential, a new material parameter, controls whether pure breaching occurs or dual-mode slope failure occurs. Pure breaching requires large dilation potential so that the pore pressure drop from breaching is large enough to keep the deposit stable; the pore pressure reaches a steady state in this case. When the pore pressure drop from breaching is not large enough to keep the deposit stable, periodic sliding occurs. Sliding 
drops the pore pressure more than breaching and generates a transient negative excess pore pressure. The transient pore pressure stabilizes the deposit temporarily so that the slope failure returns to breaching mode again. The transient pore pressure dissipates during breaching period and sliding occurs again when the transient pore pressure is not able to keep the deposit stable.

This study finds that spatial variations of dilation potential and other mechanical properties of the deposit affect the pore pressure distribution in the deposit and the mechanics of slope failure. The stability analysis in Chapter 4 shows that because the dilation potential and friction angle decreases with thickness of a deposit pure breaching on the sand used in this study is limited to short deposits less than $1 \mathrm{~m}$. This study only considers the variation of dilation potential as a function of stresses. However, the dilation potential and other material properties can also change due to stratification of the sediments. For example, an inter-bedded sand and silty deposit has different material properties in each of the two types of beds. Additional study is required to determine how variation of material properties due to stratification affects the mechanics of dilative slope failure. The analytical methods established in Chapter 3 and Chapter 4 can be used as a foundation for this type of future study.

The two types of dilative slope failure release sediments in two different ways. Breaching releases sediments at a constant rate; the rate is proportional to the coefficient of consolidation of the deposit because the rate of pore pressure generated is in equilibrium with the pore pressure dissipation during breaching. Sliding releases sediments in two ways. During breaching the sediments are released at a constant and slow rate and during sliding a wedge of sediment is released all at once. In other words, dual-mode slope failure releases sediments with a constant rate with periodic surges; the frequency of the surge is proportional to the coefficient of consolidation, i.e., the rate of 
pore pressure dissipation, of the deposit. Future study is needed to assess how the different ways of sediment release affects the turbidity current the two types of slope failure generates. 


\section{Chapter 6: Future Research}

This dissertation describes the framework for studying dilative subaqueous slope failure and slope failures in general. The observations and model results opens up new questions. Models in this study show that two material properties, the dilation potential $\beta$ and the coefficient of consolidation $C_{v}$, control the type of slope failure to be expected and the rate of sediment release from the slope failure. These results open doors to two areas for future research. First, future studies on systems with a wide range of $\beta$ and $C_{v}$ are needed to test these results. Second, field studies are needed to map the values for these two material properties in the field so we can properly assess the potential of dilative slope failure in the field. Below I recommend 5 research projects in these two areas. These projects will enhance our understanding of the mechanics of dilative slope failure and will help us to better understand how slope failures and ensuing turbidity currents are initiated in the field.

\subsection{STUDY DILATIVE SLOPE FAILURE WITH CENTRIFUGE MODELS}

The flume experiment presented in this study is a 1:1 scale of prototypes in the nature, i.e., a $1-\mathrm{m}$ thick deposit in the flume represents a $1 \mathrm{~m}$ thick deposit in the nature. As a result, the size of the facility limits the size of prototypes I can study in the lab. Centrifuge models can greatly reduce the sizes of the deposit required in lab experiments and enable us to explore prototype deposits that are tens of meters thick with model deposits that are only tens of centimeters tall (Pahwa et al., 1987). In a centrifuge model, the radial direction models the vertical direction in its prototype, i.e., the force in the radial direction in a centrifuge models the gravity in an actual deposit and the length of 
deposit in the radial direction of the centrifuge characterizes the height of the prototype deposit. A centrifuge applies a centrifugal acceleration to the model that is much greater than $1 \mathrm{~g}$. As a result, the centrifuge deposit can model a prototype deposit with a thickness that is much larger (e.g., 150 times larger, Pahwa et al., 1987) than that of the centrifuge deposit. For example, Pahwa et al. (1987) studies slope stability with a centrifuge deposit that is $10 \mathrm{~cm}$ long, and it models a prototype deposit that is $15 \mathrm{~m}$ thick.

Reducing the model size has a few other benefits besides allowing us to study thicker prototype deposits. First, because a centrifuge model needs much less sediments it is easier to use rigorous vacuum saturation procedures to ensure a fully de-aired deposit (Pahwa et al., 1987). The vacuum saturation methods are impractical for a flume experiment. Second, because the deposit can be prepared dry before saturation it is easier to build a homogeneous deposit, especially when using sediments with a wide range of grain sizes. For sediments with a wide distribution of grain sizes the sedimentation method used in this study (raining dry sediments through water column) would cause sorting in the deposit due to different settling velocities of the grains. Third, because a centrifuge model is much smaller than a 1:1 flume model, it greatly reduces the time required to prepare a deposit. This is very important for studying sediments that have small coefficients of consolidation, $C_{v}$, like deposits with significant amounts of silt or clay. Abnormal pressure can build up when preparing a deposit with those sediments. The abnormal pressure can come from the pressure gradient applied to saturate the deposit if the deposit is settled dry or from sedimentation if the deposit is settled wet. The characteristic time scale for pore pressure dissipation is $L^{2} / C_{v}$, where $L$ is the size of 
the deposit. Therefore, reducing the size of the deposit greatly reduces the time needed for the abnormal pore pressure generated from preparation to dissipate.

There are well established methods to map experimental results from centrifuge models to prototypes (Pahwa et al., 1987). But there are two possible roadblocks that may require careful investigation. First, the time it takes for pore pressure dissipation in a centrifuge model scales differently from time related to other quantities, like the velocity of the breaching front (Pahwa et al., 1987). This is because the characteristic time for pore pressure dissipation is $L^{2} / C_{v}$, which scales to the square of the length. However, the characteristic time for the breaching front to travel a given distance $L$ scales linearly with the distance itself. This difference in effect reduces the viscosity of the pore fluid (Pahwa et al., 1987). Second, the centrifuge model in effect magnifies the length scale of the model to represent a much larger prototype; therefore grain size is increased when using centrifuge models. With a model like the one used by Pahwa et al. (1987), one grain in the centrifuge model can represent a centimeter of deposit in the prototype The change in grain size could affect the distribution of stresses in a granular deposit and the erosion process. It is important to find out how this issue and the different scaling for pore pressure dissipation time affect the dynamics of the dilative slope failure and the interpretation of centrifuge model results.

\subsection{VARYING $C_{v}$}

This study shows that the coefficient of consolidation $C_{v}$ controls the release of sediments during slope failure. But there is a lack of experimental results to support this result. Testing whether $C_{v}$ controls the rate of sediment release as shown in this study 
requires experiments with different $C_{v} . C_{v}$ is a function of the mechanical properties of the deposit (permeability $k$ and compressibility $m_{u}$ ) and the viscosity of the liquid $\mu$. To change $C_{v}$ one can either use different types of sediments that have different mechanical properties and/or different types of fluid that have different $\mu$.

Both the compressibility and the permeability are difficult to quantify and to accurately adjust to desired values. Therefore it is not easy to control $C_{v}$ accurately by using different types of sediments. The viscosity $\mu$ is easier to control. This is usually done by mixing water with a water soluble fluid that has a much higher viscosity, like glycol or glycerol ( $\mu$ at least 2 orders of magnitude larger than $\mu$ of water). The viscosity of the mixtures can be accurately determined from the proportions of each fluid and the ambient temperature (Bohne et al., 1984). I propose a series of experimental studies using different mixtures of water and glycol or glycerol to test the relationship between $C_{v}$ and erosion rate for breaching as well as the relationship between $C_{v}$ and the sliding frequency. This study is best carried out in a centrifuge or with a small flume, where only a small quantity of the fluid is required and the temperature of the fluid can be easily controlled. In this proposed study, both the erosion rate for breaching and the sliding frequency can be measured using an ultrasonic transceiver, as developed in Chapter 4.

\subsection{DEVELOP BETTER MODELS FOR MATERIAL PROPERTIES}

There are a few discrepancies between the model and the observations, for example the model overestimates the erosion rate. I showed that some of the 
discrepancies can be explained by an underestimation of the compressibility for the fine sand and/or an overestimation of the compressibility for the silty sand. One possible source for the mismatch of compressibility is that the stress path in the isotropic unloading test (where $m_{u}$ is measured) is different from the stress path in the flume experiments. In the isotropic test, there is no differential stress acting on the sediment while the mean stress decreases. However, in the flume experiment the differential stress increases as the sediment is close to the failure front (Figure 3.9). This difference in the differential stress could result in different values for the compressibility.

Future studies are needed to understand how differential stress affects the compressibility of granular materials like sand. One possible approach is to run isotropic unloading tests with different differential stresses. In each of these tests the differential stress would be kept constant while the mean stress decreases gradually. The isotropic unloading test presented in Chapter 3 represents the case where the differential stress is 0 . Future tests can utilize the vertical load cell in a triaxial shearing device (Figure 3.2) to provide a nonzero differential stress.

\subsection{EXPERIMENT WITH DIFFERENT INITIAL SLOPE ANGLES}

All the experiments in this study have a $90^{\circ}$ slope as the initial failure front (Figure 2.3 and Figure 4.1). While this slope angle does not necessarily represent the conditions in the field, it simplifies the problem so I was able to find the material parameters that control dilative slope failure. I argue that the initial failure front slope angle does not change the mechanics of dilative slope failure. In the dual-mode experiment the slope angle for the failure front is reduced to $80^{\circ}$ after sliding, and this 
slope angle increases during the subsequent breaching period. In some cases, the slope angle of the failure front can increase beyond $90^{\circ}$. This observation suggests that the slope angle for the failure front self-adjusts to around $90^{\circ}$. We need to know whether this self-adjustment can happen for any unstable initial slope angle, e.g., can the slope steepen from $60^{\circ}$ to around $90^{\circ}$, to better understand how initial conditions controls the mechanics of dilative slope failure. Future studies with initial slope angles of the failure front less than $90^{\circ}$ are needed for this analysis. The results are important not only in understanding how the initial condition affects the mechanics of slope failure, but also in assessing the potential of dilative slope failure in the field.

\subsection{STUDY HOW COMMON DILATION IS IN THE FIELD}

This study argues that dilative slope failure should be common on the continental shelf, especially in long shore drift deposits (Conclusions and Discussion section in Chapter 4). Unfortunately there are no systematic studies on the packing of natural deposits to directly test this argument. Studies on the packing of natural deposits are needed for us to predict where dilative slope failure occurs; they can also help engineer and geophysics communities in understanding the mechanical properties of deposits in different depositional environments.

I propose a series of field campaigns and accompanying experimental studies to understand the packing of natural deposits. The field component needs to focus on a small number of representative depositional environments on the continental shelf. A key environment to include is the head of submarine canyons where long shore drift deposits are accumulated, like the head of Scripps Submarine Canyon. A number of previous 
studies noticed "grain flow" in those regions (Dill, 1964); some studies speculated those regions are potential sites for breaching slope failure to occur (Van den Berg et al., 2002; Mastbergen and Van den Berg, 2003; Eke et al., 2011). The field part of the study should collect at least three types of data: the in situ porosity, grain size distribution, and the thickness of the deposits. The study should also collect sediment samples for lab analysis and experiments. In situ porosity can be measured using a resistivity tool, following the well-established methods (Curry et al., 2004). Grain size distribution can be measured from sediment samples taken from the field.

The experimental studies should include at least two components. First, we need to measure the maximum and minimum void ratios for the sediment samples collected from the field. Those two lab measurements and the in situ porosity measurements can tell us the relative density of the sediments in the field and determine whether the deposits are dilative (Bolton, 1986). Second, we should study how depositional procedures affect the porosity of deposits. For example, how is the porosity related to the sedimentation rate? Or how can waves consolidate a deposit. This type of study can help us better predict the porosity and mechanical properties of deposits in the field. 


\section{Appendix A: Supplementary material for Chapter 2}

\section{A.1 Pore PRessure Measurements from all 9 LOCATIONS}

The pore pressure is monitored at 9 locations (Figure A.1). The first 5 (counting from left) of the 9 pore pressure profiles are similar to each other, including the two (colored blue and red) described in detail in Chapter 2. The other 4 sensors recorded the pore pressure drop in response to the initiation, but did not record the pore pressure response to slope failure. This is due to the shortening of the breaching front through time; the locations of the other 4 sensors were below the bottom of the breaching front when the front is close by. As a consequence, the horizontal unloading from slope failure did not affect those locations and the sensors do not record any significant pore pressure drop.

At around 100s and 160s, when the blue and red sensor recorded the second pore pressure drop (in response to retrogressive slope failure), the next sensor (red sensor at $100 \mathrm{~s}$ and green sensor at $160 \mathrm{~s}$ ) seem to have recorded some changes in pore pressure. This may have been caused by the presence of the tubes in the deposit. When the erosion occurs around the tube small slumps are generated sometimes and can cause observable pore pressure change at the next sensor location.

\section{A.2 ESTIMATE THE MODELING PARAMETER $\boldsymbol{\eta}$ AND $s_{0}$}

I use the initial pore pressure response (pore pressure immediately after initiation) to fit the two parameters. Because the largest pore pressure drop occurs very close to the normal pore pressure boundary (the breaching front) and the permeability of the silty 
sand is large we can not consider the initial response as undrained. Instead I use a numerical model to simulate the pore pressure response to the initiation.

In this model I use the following equation,

$$
\frac{\partial \widehat{u}}{\partial t}=C_{v} \frac{\partial^{2} \widehat{u}^{*}}{\partial \hat{x}^{2}}+\beta a_{0}
$$

where $a_{0}$ is the rate of stress change at the breaching front. This stress distribution model is consistent with what I use for the breaching model (Equation 2.2 in Chapter 2). I assume that the stress change at the breaching front is at a constant rate during the lifting of the restraining plate. The time for removal of plate is $0.5 \mathrm{~s}$ based on observation, then $a_{0}=2 s_{0}$. The total simulation time is $0.5 \mathrm{~s}$. The spatial distribution of the initial pore pressure response is only sensitive to $\eta$ and the magnitude of the initial pore pressure response depends on $s_{0}$. Therefore I can use the recorded initial pore pressure distribution and magnitude to constrain those two parameters.

\section{A.3 ESTIMATE THE DILATION POTENTIAL OF SAND AT SCRIPPS CANYON FROM PUBLISHED SIMPLE SHEAR TEST RESULTS}

I estimate the dilation potential $\beta$ for sand at Scripps Canyon head from published simple shear tests results on the sediment specimen collected from the region (Dill, 1964). First, I estimate the mean effective stress $p^{\prime}$ and differential stress $q$ of the specimen during the test. I assume the measured stresses are at critical state where the stress Mohr circle of the specimen is tangential to the failure envelope (Figure A.2).

The geometric relationships suggests that (Figure A.2)

$$
\begin{aligned}
& q=\frac{\tau}{\cos \phi} \\
& p=\sigma_{\mathrm{n}}+\tau \tan \phi
\end{aligned}
$$


where $\phi$ is the internal friction angle of the deposit and I assume it to be $30^{\circ}$ for the analysis in Chapter 2.

Since the test is done in a drained condition, i.e., no excess pore pressure, the mean effective stress $p^{\prime}$ is the same as the mean stress $p$. I assume the measured volumetric strain $\varepsilon_{v}$ is a combination of the volumetric strain due to $p^{\prime}$ and $q$,

$$
\varepsilon_{v}=-m_{u} p^{\prime}+m_{q} q
$$

Both $m_{u}$ and $m_{q}$ for the specimen are unknown. Due to lack of additional test data, I assume a typical compressiblity value of $10^{-8} \mathrm{~Pa}^{-1}$ for the specimen. Then I calculate the value for $m_{q}$ from Equation A.4 and the dilation potential with

$$
\beta=\frac{1}{2}+\frac{m_{q}}{2 m_{u}} .
$$




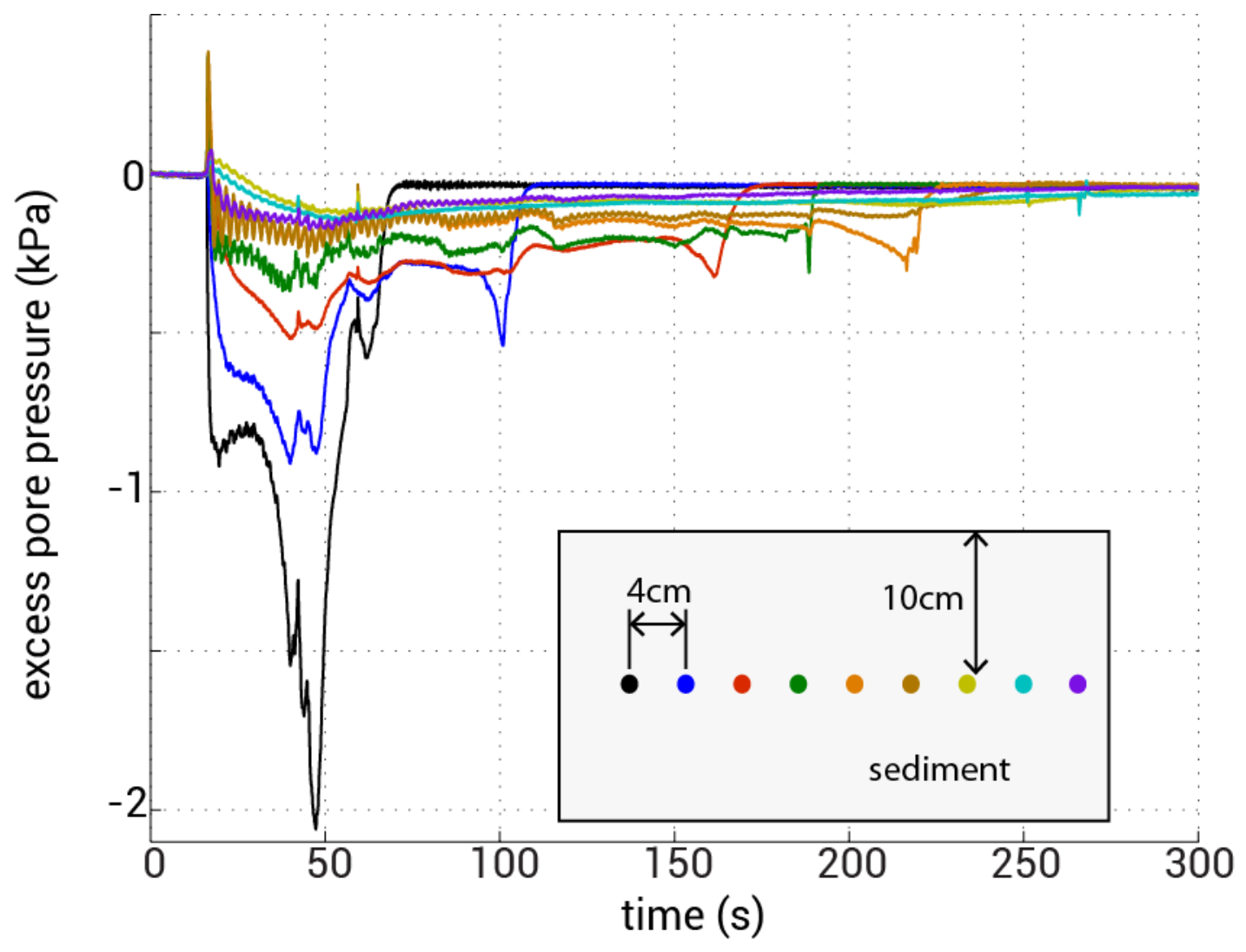

Figure A.1: Excess pore pressure measured at 9 locations during one breaching experiment. The two lines colored blue and red are the two sensors presented in Chapter 2. 


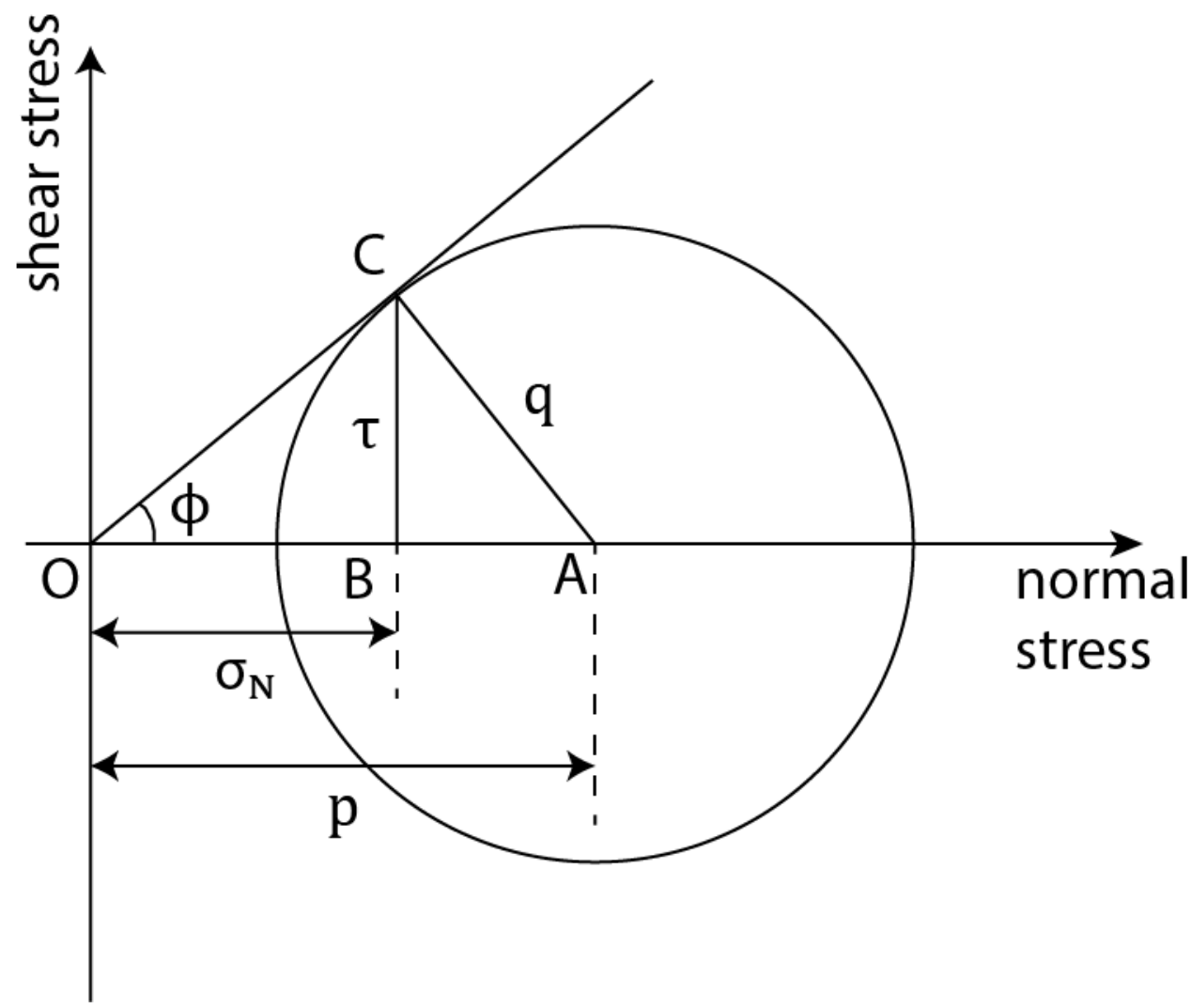

Figure A.2: Stress Mohr circle for the testing specimen at critical state. Measured normal stress $\sigma_{N}$ is $\mathrm{OB}$, measured shear stress $\tau$ is $\mathrm{BC}$. The mean stress $p$ is $\mathrm{OA}$, and the differential stress $q$ is $\mathrm{AC}$. Line $\mathrm{OC}$ is the failure envelope and the angle $\mathrm{AOC}$ is the internal friction angle $\phi$ 


\section{Appendix B: Additional steps in processing triaxial test data}

Because sediment failure occurs when the differential stress reaches its maximum value I only consider the part of the data before the differential stress $q$ reaches its maximum value (from point $\mathrm{A}$ to point $\mathrm{B}$ in Figure B.1). By definition, $m_{t}$ is the local slope between the volumetric strain $\varepsilon_{v}$ and the differential stress. Due to noise in the stress measurements the local slope between $\varepsilon_{v}$ and $q$ has large uncertainties (e.g., point $\mathrm{C}$ in Figure B.1). To avoid the uncertainties I first calculate the average slope between $\varepsilon_{v}$ and $q$, denoted as $\overline{m_{t}}$ (e.g., slope AC in Figure B.1), where

$$
\overline{m_{t}}=\frac{\varepsilon_{v}}{q}
$$

$\overline{m_{t}}$ is converted into $m_{t}$ with the following,

$$
m_{t}=\frac{\partial\left(q \overline{m_{t}}\right)}{\partial q}=\overline{m_{t}}+q \frac{\partial \overline{m_{t}}}{\partial q}
$$

$\overline{m_{t}}$ and the differential stress $q$ satisfies the power law relationship (Figure B.2), $\frac{\overline{m_{t}}}{\overline{\bar{M}_{t}}}=\left(\frac{q}{q_{\max }}\right)^{4.8}$

where $q_{\max }$ is the maximum differential stress and $\overline{M_{t}}$ is the $\overline{m_{t}}$ at maximum differential stress; it is also the maximum $\overline{m_{t}}$. From Equations B.2 and B.3,

$$
m_{t}=5.8 \overline{m_{t}}
$$




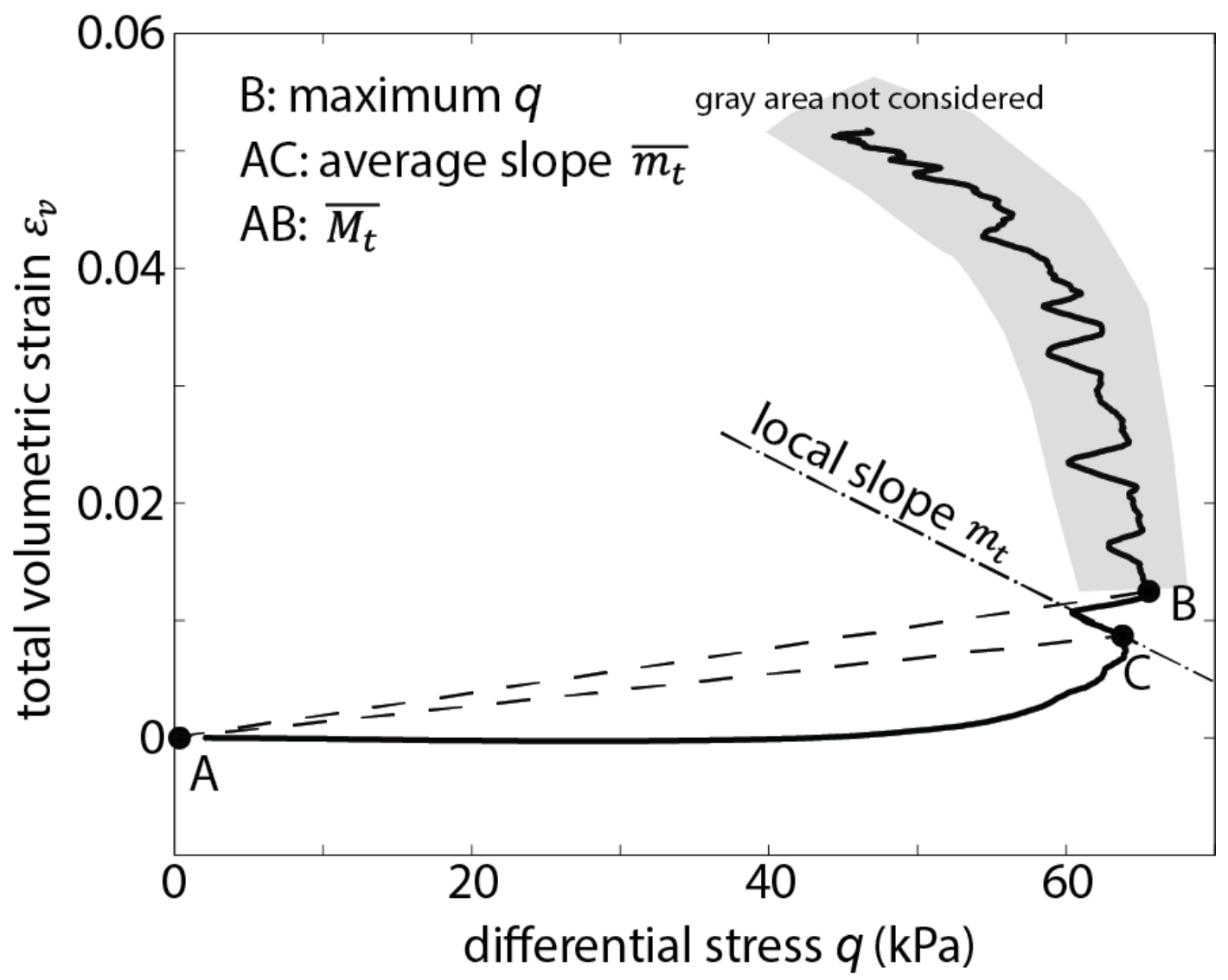

Figure B.1: Total volumetric strain $\varepsilon_{v}$ against differential stress $q$ from a triaxial shear test with an initial mean effective stress of $14 \mathrm{kPa}$. Point A marks the start of the shear. Point B marks the maximum differential stress; it also represents the point of shear failure of the specimen. 


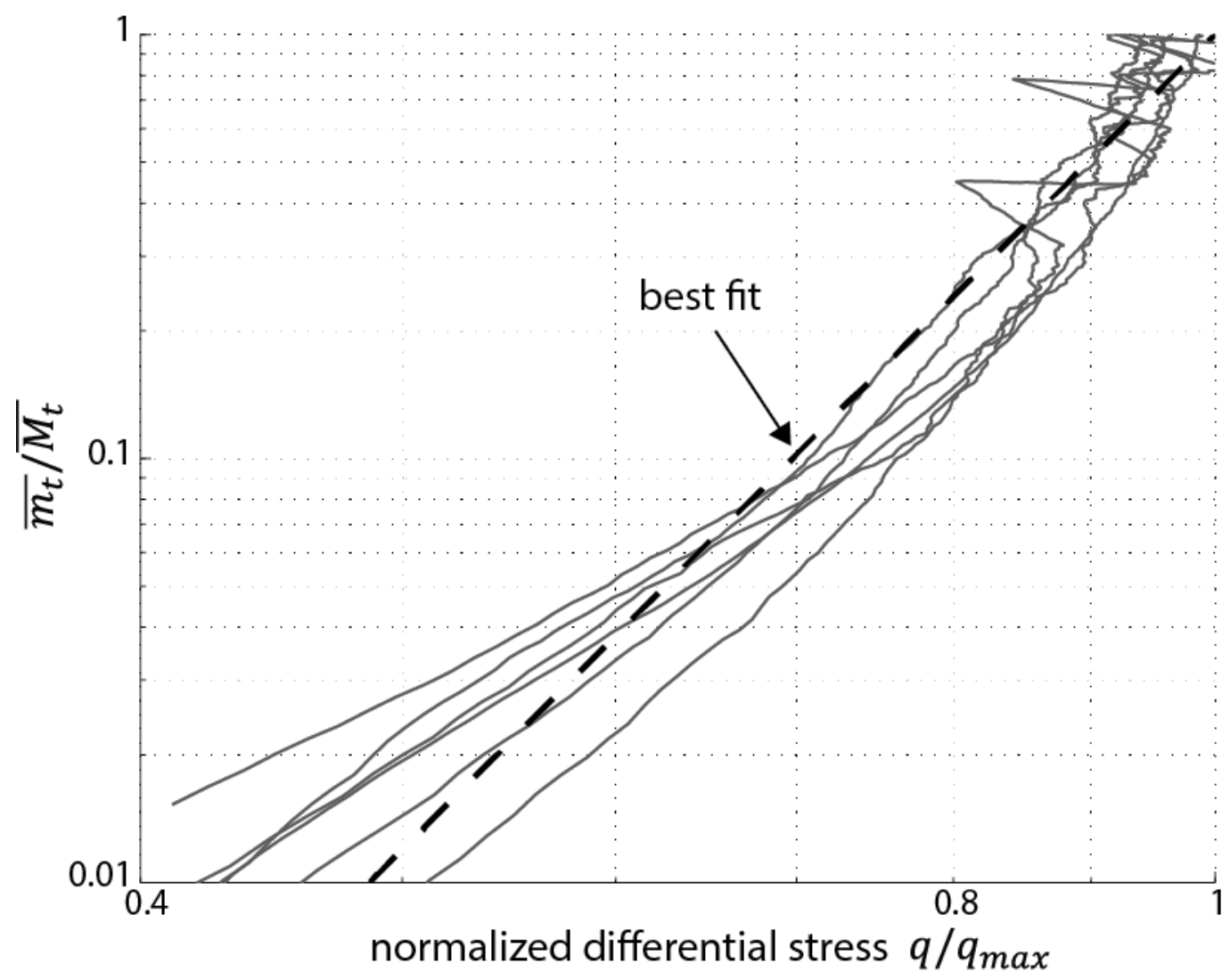

Figure B.2: Normalized $\overline{m_{t}}$ (definition in Equation B.1) against normalized differential stress. Each solid line represents results from one test. The dashed line is the best fit power-law relationship for all the test results (Equation B.3). 


\section{Appendix C: Procedure for measuring pore pressure in the flume}

I measure pore pressure with Measurement Specialties LM series gauge pressure transducer. The transducer measures pore pressure over a circular 0.5 inch diameter diaphragm. There are two drawbacks in installing the transducers in the deposit and measuring pore pressure directly over the diaphragm. First, data resolution would equal the diaphragm size. Previous studies show that the pore pressure can change dramatically over a few centimeters (Meijer and van Os, 1976; Van Rhee and Bezuijen, 1998). Therefore pore pressure needs to be measured at sub-centimeter resolution, which is less than the diameter of the diaphragm. Second, the transducer can disturb surrounding sediment, which could lead to misleading measurements that does not represent undisturbed deposits. For example, because the transducer is rigid sediments around it could have less volumetric strain and pore pressure changes with changes in stress. To avoid those two issues I connect the transducer to the interior of the deposit using a series of thin tubes (1/8 inch outer diameter and 1/16 inch inner diameter) and tube fittings (Figure C.1). This system allows pore pressure to be measured with a much higher resolution at 1/16 inch. This setup also reduces the amount of deposit that is disturbed.

The tubing system is composed of two parts, one part attached to the inner flume and the other part attached to pressure transducers. Those two parts are hydraulically connected by a piece of nylon tube. The part attached to the inner flume consists of a tube connector that connects the nylon tube on the outside of the inner flume and a piece of stainless steel tube on the inside of the inner flume (Figure C.1A). The steel tube is used to control the position of the measuring point. The part attached to the transducer consists of a plastic cap that encapsulates the diaphragm of the transducer in a water tight chamber; this chamber is connected to the nylon tube through a piece of tube fitting on 
the cap (Figure C.1B). Once the tubes and the cap are filled with water the pressure at the end of the steel tube equals the pressure in the cap, which is monitored by the transducer.

I record the voltage output from the transducers with a $1 \mathrm{kHz}$ data logger (records data once every 0.001 second for each transducer). With the high recording frequency sharp drops of pore pressure are easily captured and the values of the minimum pore pressure can be accurately recovered. The transducer records pore pressure with an accuracy of $21 \mathrm{~Pa}$ and can record a maximum pore pressure of $7000 \mathrm{~Pa}$.

In the following sections I describe the procedure to setup a pressure transducer with its accompanying tubing system. To setup multiple transducers simply repeat the

procedure. The setup involves 4 stages. First, I install the tube fittings around the transducer and on the inner flume. Second, I connect the transducer and the measuring point. Third, I flush the tubing system with water. Last, I calibrate the transducers in situ.

\section{C.1 InSTALL TUBE FITTINGS}

\section{C.1.1 Tube fitting attached to the transducer}

\section{Components needed}

1. One measurement Specialties LM31-00000F-001PG gauge pressure transducer.

2. One threaded plastic cap with straight edges, thread size NPD $1 / 2$

3. One stainless steel screw for plastic, buttoned cap, length less than $1 / 2$ of the outer diameter (OD for short) of the plastic cap.

4. One rubber O-ring, with inner diameter (ID for short) the same or slightly smaller than the screw diameter. 
5. One brass or stainless steel Yor-Lok tube fitting for tube OD $1 / 8$ in, male pipe end.

6. One roll of Teflon tape.

\section{Tools needed}

1. Two adjustable wrenches.

2. One screw driver.

3. One handheld electric drill with drill bits.

4. Thread formers whose sizes match the end size of the tube fitting and the screw.

\section{Procedure}

1. Drill a hole that is slightly smaller than the end size of the tube fitting at the end of the plastic cap using the handheld drill; make sure to drill through the wall of the cap.

2. Use the thread former to create thread along the newly drilled hole that matches the tube fitting.

3. Wrap the male end of the tube fitting with Teflon tape and drive it through the end hole and tighten with the wrenches from either side.

4. Drill a hole that is slightly smaller than the size of the screw through the side of the plastic cap at a location close to the end of the cap.

5. Use the thread former that matches the screw to create thread along the newly drilled hole.

6. Place the rubber O-ring underneath the cap of the screw, then drive the screw into the side hole with the screw driver. Tighten the screw to the point where the rubber O-ring is slighted compressed between the screw cap and the plastic cap. It is important to not drive the screw in too much because the 115 
screw cap can push the rubber O-ring out and the plastic cap would not be able to seal water.

7. Wrap the thread on the pressure transducer with Teflon tape and drive it into the end cap, tighten with the wrenches.

\section{C.1.2 Tubing system attached to the inner flume}

\section{Components needed}

1. One brass Yor-Lok through the wall tube connector.

2. One tube of silicon sealant.

\section{Tools needed}

1. Two wrenches.

2. One handheld electric drill with drill bits.

\section{Procedure}

1. Drill straight holes at desired locations through sidewall of the inner flume.

2. Remove the detachable nut from the connector and push the connector through the hole.

3. To hydraulically seal, apply silicon sealant into the gap between the connector and inner wall of the hole it went through.

4. Put the removable nut back on and wrench tighten so that the connector is stable.

5. Set the inner flume aside to let the sealant to cure for 24 hours.

\section{2 INSTALLING TUBES}

\section{Components needed}

1. One piece of stainless steel tube, OD $1 / 8$ in, ID 1/16 in, length 3 in. 
2. One piece of clear/semi-clear flexible nylon tube, OD $1 / 8$ in, ID $1 / 16$ in, length $10 \mathrm{ft}$.

\section{Tools needed}

1. Two wrenches.

\section{Procedure}

1. Install the stainless steel tube into the tube fitting that is inside the inner flume and tighten the screw onto the stainless steel tube to create a seal.

2. Install one end of the nylon tubing into the tube fitting that is outside of the inner flume, tighten the screw.

3. Install the other side of the nylon tubing in step 2 to the tube fitting on the plastic cap, tighten screw.

\section{C.3 FLUSH THE TUBING SYSTEM}

To ensure accurate measurement of pore pressure the tubes and the cap over the transducer need to be filled with water and air free.

\section{Tools needed}

1. One handheld vacuum cleaner (because water can get into the device a cheap handheld vacuum cleaner is better suited than a vacuum pump).

2. One screw driver.

\section{Procedure}

1. Place the inner flume inside the outer flume and set the sliding gate aside.

2. Fill the outer flume with water.

3. Remove the screw on the side of the plastic cap over the pressure transducer and set it aside. 
4. Rotate the plastic cap so that the side with the opening (where the screw was) is facing up and fix the cap onto a stable surface.

5. Point the inlet of the vacuum cleaner at the opening on the cap.

6. Turn on the vacuum cleaner to drain air from the tube system. At the same time monitor the water flowing in the nylon tube.

7. Turn off the vacuum cleaner when the water in the tube is close to the plastic cap and let the pressure difference between the end of the stainless steel tube and the chamber over the pressure transducer drive water into the cap and flow out of the opening.

8. When there is no more air bubble coming out of the opening, drive the threaded screw with an O-ring underneath its cap back into the opening. Tighten the screw until the O-ring is slightly compressed between the cap of the screw and the cap.

9. Check for water leaks from the tube fitting and the plastic cap over the transducer.

\section{C.4 CALibration OF THE TRANSDUCERS}

I calibrate the transducers in situ, i.e., when they are connected to the tubing systems, after they have been filled with water. The calibration factor is calculated as the changes in pressure per unit change in voltage output. I change the pressure by changing the water level in the flumes; the change in pressure is simply the change in water level multiplied by the unit weight of water.

\section{Procedures}

1. Setup the transducers according to previous sections. 
2. Connect the transducers to the data logging system.

3. Control the pump and the drain of the outer flume to adjust the water level in the flumes to desired initial height.

4. Close off pumps and drains, record the water level. Take care to not disturb the water surface.

5. Turn on the data logging system and record for 30 seconds. Stop logging data and save the file. Record the file name with the water level measurements.

6. Turn on the water pump to slowly increase the water level by a few centimeters (it is impractical to accurately control the change in water level in a flume).

7. Turn off water pump and allow the water surface to settle. Record the water level when the water surface is stable.

8. Turn on the data logging system and record for 30 seconds. Stop logging data and save the file. Record the file name with the water level measurements.

9. Repeat steps 6-9 a few times until the final water level is at least $10 \mathrm{~cm}$ above original water level at step 3 .

10. Open the drain of the outer flume to slowly drop the water level by a few centimeters.

11. Shut off drain and allow the water table to settle. Record the water level when the water surface is stable.

12. Turn on the data logging system and record for 30 seconds. Stop logging data and save the file. Record the file name with the water level measurements.

13. Repeat $10-12$ a few times until the final water level is close to the original water level at step 3. 
14. Repeat steps 6-13 as many times as needed to get a consistent calibration factor.

\section{Process data}

1. Calculate the difference between each recorded water level and the first recorded water level to get the changes in water level, $\Delta l$.

2. Calculate the changes in pressure with $\Delta u=\Delta l \rho_{w} g$, where $\rho_{w}$ is the density of water and $g$ is gravitational acceleration.

3. Calculate the average voltage reading for each of the 30 second recordings.

4. Calculate the difference between each averaged voltage reading and the first voltage reading to get the change in voltage, $\Delta V$.

5. Use linear regression to find the best fit between $\Delta u$ and $\Delta V$; the slope of this fit is the calibration factor for the transducer. 

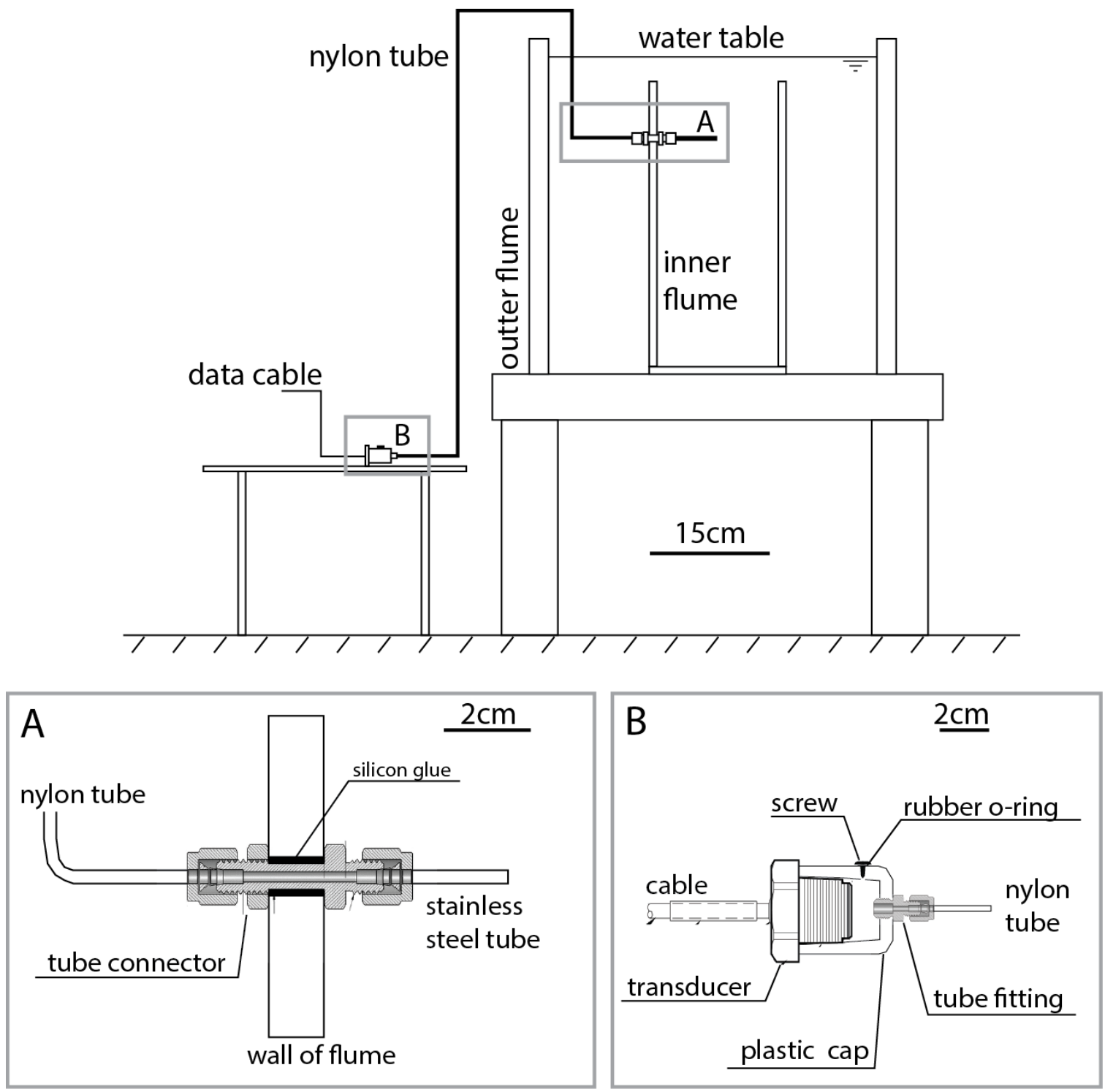

Figure C.1: Sketch of the setup for pore pressure measurements. 


\section{Appendix D: Procedure for setting up flume}

Here I describe the procedure to setup and run slope failure experiments in the flume (Figure D.1).

\section{D.1 SETUP OF THE EXPERIMENT}

1. Clean outer flume and affix mesh screen at water outlet to catch sediment.

2. Line the sliding door slot on the inner flume with silica grease to ease movement of the door.

3. Load inner flume into outer flume.

4. Align so that inner flume is parallel to the outer flume and the inner flume is in the center of the outer flume (Figure D.1). Inner flume sits $\sim 2 \mathrm{~m}$ upstream from outlet of the outer flume.

5. Fill flume with water up to near top of outer flume.

6. Flush the tubing system according to procedures in Appendix C.

7. Insert the sliding gate for the inner flume in place.

8. Load sand into buckets, measure and record the weight of each bucket.

9. Deposit sand into the inner flume with scoops. Control the deposition rate of sand so that sediment falls as individual grains and no air is trapped in the inner flume.

10. Vigorously tap on the deposit with the rubber mallet when flume is $1 / 3,1 / 2$, $2 / 3$, and $3 / 3$ full of sand.

11. For every $1 / 6$ of the deposit built, deposit a small amount of sand with a different color than the rest of the deposit. Spread the sand so that it forms a thin bed. 
12. Measure and record the weight of each bucket after filling.

13. If preparing for a dense deposit: once flume is full, place two $25 \mathrm{lb}$ deadweight blocks on top of sand and let sit for at least $16 \mathrm{hrs}$.

\section{D.2 RUNNING THE EXPERIMENT}

1. Remove weights placed on top of the deposit.

2. Attach sonar probes to their respective instrument arms. The horizontal sonar should be perpendicular to the sliding gate with its head located between $5 \mathrm{~cm}$ to $10 \mathrm{~cm}$ from the sliding gate.

3. Attach camera to a tripod and set it up at desired location, with the camera frame level (some cameras have internal inclinometer to assist the adjustment).

4. Attach black masking in locations needed to minimize reflection and shadow cast in the view of the camera.

5. Turn on and check sonar probes and pressure transducers. Verify the setup for the probes are all correct, setup their respective recording file names and write them down with the time of experiment and sediment used.

6. Measure and record the depth of the deposit in the inner flume.

7. Measure and record the sonar head's position with respect to the floor of the inner flume and the sliding gate.

8. Start camera recording video and stop watch concurrently.

9. Begin recording data and end stop watch concurrently, record the time interval as the time offset between video and data recordings. 
10. Slide out front door of inner flume from standing position atop outer flume, as quickly as possible. 

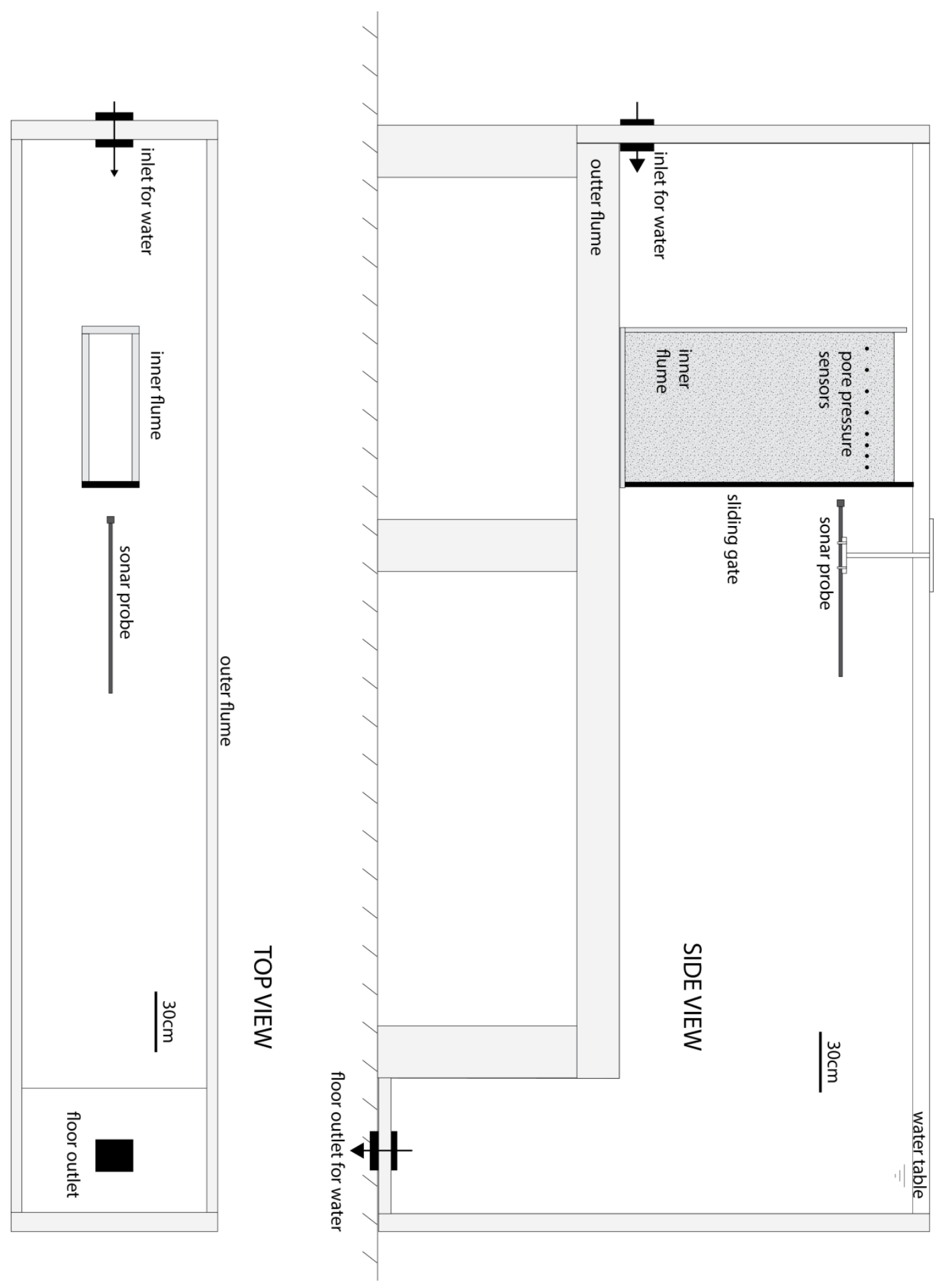

Figure D.1: Setup of the flume and measuring instruments for slope failure experiments. 


\section{References}

ASTM, 1970, Standard Method of Test for Permeability of Garnular Soils (Constant Head): West Conshohocken, PA, ASTM International.

-, 2006, Standard test method for one-dimensional consolidation properties of saturated cohesive soils using controlled-strain loading (Standard D 4186-06): West Conshohocken, PA.

Balmforth, N. J., and Kerswell, R. R., 2005, Granular collapse in two dimensions: Journal of Fluid Mechanics, v. 538, p. 399-428.

Beard, D. C., and Weyl, P. K., 1973, Influence of texture on porosity and permeability of unconsolidated sand: American Association of Petroleum Geologists Bulletin, v. 57, no. 2, p. 349-369.

Been, K., and Jefferies, M., State parameter for sands, in Proceedings International Journal of Rock Mechanics and Mining Sciences and Geomechanics Abstracts1985, Volume 22, Elsevier Science, p. 198-198.

Bennett, R. H., and Stockstill, J., 1999, Sediment analyses and dive team reports, final report part II. NATO phase II field exercise in the C-1 area off the coast of Holland.: SEAPROBE, Inc.

Bohne, D., Fischer, S., and Obermeier, E., 1984, Thermal, Conductivity, Density, Viscosity, and Prandtl - Numbers of Ethylene Glycol - Water Mixtures: Berichte der Bunsengesellschaft für physikalische Chemie, v. 88, no. 8, p. 739-742.

Bolton, M., 1986, The strength and dilatancy of sands: Geotechnique, v. 36, no. 1, p. 6578.

Breslau, L. R., 1967, The normally-incident reflectivity of the sea floor at $12 \mathrm{kc}$ and its correlation with physical and geological properties of naturally-occurring sediments: DTIC Document.

Casagrande, A., 1936, Characteristics of cohesionless soils affecting the stability of slopes and earth fills: Contributions to Soil Mechanics 1925-1940, p. 257-276.

Chamberlain, T. K., 1964, Mass transport of sediment in the heads of Scripps Submarine Canyon, California, [Chapter] 4, in Miller, R. L., ed., Papers in Marine Geology, Shepard Commemorative Volume: New York, Macmillan, p. 42-64.

Curry, C. W., Bennett, R. H., Hulbert, M. H., Curry, K. J., and Faas, R. W., 2004, Comparative study of sand porosity and a technique for determining porosity of undisturbed marine sediment: Marine Georesources and Geotechnology, v. 22, no. 4, p. 231-252.

de Koning, I. J., 1970, Neue Erkenntnisse beim Gewinnen und Transport von Sand im Spiilprojekt Venserpolder: VDI Tagung" Bauen im Ausland", Hamburg. New knowledge about the mining and transport of sand, from the reclamation project Venserpolder (The Netherlands), p. 1-9.

Demmel, J. W., Eisenstat, S. C., Gilbert, J. R., Li, X. S., and Liu, J. W., 1999, A supernodal approach to sparse partial pivoting: SIAM Journal on Matrix Analysis and Applications, v. 20, no. 3, p. 720-755. 
Dill, R. F., 1964, Contemporary submarine erosion in Scripps Submarine Canyon [Ph.D. Dissertation]: University of California, San Diego, 269 p.

Dill, R. F., 1969, Earthquake effects on fill of Scripps submarine canyon: Geological Society of America Bulletin, v. 80, no. 2, p. 321-328.

Dromart, G., Quantin, C., and Broucke, O., 2007, Stratigraphic architectures spotted in southern Melas Chasma, Valles Marineris, Mars: Geology, v. 35, no. 4, p. 363366.

Eke, E., 2008, Breaching as a mechanism for generating sustained turbidity currents [M.S. Thesis]: University of Illinois at Urbana-Champaign, $88 \mathrm{p}$.

Eke, E., Viparelli, E., and Parker, G., 2011, Field-scale numerical modeling of breaching as a mechanism for generating continuous turbidity currents: Geosphere, v. 7, no. 5, p. 1063-1076.

Flemings, P., Long, H., Dugan, B., Germaine, J., John, C., Behrmann, J., Sawyer, D., and IODP, E., 2008, Pore pressure penetrometers document high overpressure near the seafloor where multiple submarine landslides have occurred on the continental slope, offshore Louisiana, Gulf of Mexico: Earth and Planetary Science Letters, v. 269, no. 3-4, p. 309-325.

Freeze, R. A., and Cherry, J. A., 1977, Groundwater, Prentice-Hall.

Gibson, R., 1958, The progress of consolidation in a clay layer increasing in thickness with time: Geotechnique, v. 8, no. 4, p. 171-182.

Hampton, M. A., Lee, H. J., and Locat, J., 1996, Submarine landslides: Reviews of Geophysics, v. 34, no. 1, p. 33-59.

Hostler, S. R., 2004, Wave propagation in granular materials [Ph.D. Dissertation]: California Institute of Technology, $111 \mathrm{p}$.

Houthuys, R., 2011, A sedimentary model of the Brussels Sands, Eocene, Belgium: Geologica Belgica, v. 14, no. 1-2, p. 55-74.

Iverson, R., 2005, Regulation of landslide motion by dilatancy and pore pressure feedback: Journal of Geophysical Research-Earth Surface, v. 110, no. F2.

Iverson, R., Reid, M., Iverson, N., LaHusen, R., Logan, M., Mann, J., and Brien, D., 2000, Acute sensitivity of landslide rates to initial soil porosity: Science, v. 290, no. 5491, p. 513-516.

Jaky, J., 1944, The coefficient of earth pressure at rest: Journal of the Society of Hungarian Architects and Engineers, v. 78, no. 22, p. 355-358.

Kneller, B. C., and Branney, M. J., 1995, Sustained high-density turbidity currents and the deposition of thick massive sands: Sedimentology, v. 42, no. 4, p. 607-616.

Lamb, M. P., and Mohrig, D., 2009, Do hyperpycnal-flow deposits record river-flood dynamics?: Geology, v. 37, no. 12, p. 1067-1070.

Li, X. S., Demmel, J. W., Gilbert, J. R., Grigori, L., Shao, M., and Yamazaki, I., 1999, SuperLU Users' Guide.

Limber, P. W., Patsch, K. B., and Griggs, G. B., 2008, Coastal sediment budgets and the littoral cutoff diameter: A grain size threshold for quantifying active sediment inputs: Journal of Coastal Research, v. 24, no. 2B, p. 122-133. 
Lowe, D. R., 1976, Subaqueous liquefied and fluidized sediment flows and their deposits: Sedimentology, v. 23, no. 3, p. 285-308.

Lube, G., Huppert, H. E., Sparks, R. S. J., and Freundt, A., 2005, Collapses of twodimensional granular columns: Physical Review E, v. 72, no. 4.

Mastbergen, D., and Van den Berg, J., 2003, Breaching in fine sands and the generation of sustained turbidity currents in submarine canyons: Sedimentology, v. 50 , no. 4 , p. 625-637.

McAdoo, B. G., Pratson, L. F., and Orange, D. L., 2000, Submarine landslide geomorphology, US continental slope: Marine Geology, v. 169, no. 1-2, p. 103136.

Meijer, K. L., and van Os, A. G., 1976, Pore pressures near moving underwater slope: Journal of the Geotechnical Engineering Division, v. 102, no. 4, p. 361-372.

Metz, J. M., Grotzinger, J. P., Mohrig, D., Milliken, R., Prather, B., Pirmez, C., McEwen, A. S., and Weitz, C. M., 2009, Sublacustrine depositional fans in southwest Melas Chasma: Journal of Geophysical Research-Planets, v. 114, p. E1002.

Morgenstern, N., 1967, Submarine slumping and the initiation of turbidity currents: Marine geotechnique, p. 189-220.

Mulder, T., Syvitski, J. P., Migeon, S., Faugeres, J.-C., and Savoye, B., 2003, Marine hyperpycnal flows: initiation, behavior and related deposits. A review: Marine and Petroleum Geology, v. 20, no. 6, p. 861-882.

Nedderman, R., 1992, Statics and kinematics of granular materials, Cambridge University Press.

Oda, M., 1972, The mechanism of fabric changes during compressional deformation of sand: Soils and foundations, v. 12, no. 2, p. 1-18.

Oda, M., Konishi, J., and Nemat-Nasser, S., 1980, Some experimentally based fundamental results on the mechanical behaviour of granular materials: Geotechnique, v. 30, no. 4, p. 479-495.

Onoda, G. Y., and Liniger, E. G., 1990, Random loose packings of uniform spheres and the dilatancy onset: Physical Review Letters, v. 64, no. 22, p. 2727.

Pahwa, A., Whitman, R. V., and Germaine, J. T., 1987, Quick release tests on centrifuge of wall retraining saturated sand backfill: Department of Civil Engineering, Massachusetts Institute of Technology.

Perillo, M. M., Buttles, J., Mohrig, D., Kane, I., and Pontén, A., in prep., New acoustic reflection technique for direct and noninvasive visualization of subaqueous, highconcentration sediment-laden flows.

Piper, D. J. W., and Normark, W. R., 2009, Processes that initiate turbidity currents and their influence on turbidites: a marine geology perspective: Journal of Sedimentary Research, v. 79, no. 5-6, p. 347-362.

Polya, G., and Szegö, G., 1970, Aufgaben und Lehrsätze aus der Analysis: 1. Band: Reihen, Integralrechnung, Funktionentheorie, Springer.

Pryor, W., 1972, Reservoir inhomogeneities of some recent sand bodies: Old SPE Journal, v. 12, no. 3, p. 229-245. 
Radin, C., 2008, Random close packing of granular matter: Journal of Statistical Physics, v. 131 , no. 4 , p. 567-573.

Richardson, M. D., Briggs, K. B., Bibee, L. D., Jumars, P. A., Sawyer, W. B., Albert, D. B., Bennett, R. H., Berger, T. K., Buckingham, M. J., and Chotiros, N. P., 2001, Overview of SAX99: Environmental considerations: Oceanic Engineering, IEEE Journal of, v. 26, no. 1, p. 26-53.

Rutgers, R., 1962, Packing of Spheres: Nature, v. 193, no. 4814, p. 465-466.

Scott, G. D., Charlesworth, A. M., and Mark, M. K., 1964, On the Random Packing of Spheres: Journal of Chemical Physics, v. 40, p. 611-612.

Shepard, F. P., and Marshall, N. F., 1973, Storm-generated current in La Jolla Submarine Canyon, California: Marine Geology, v. 15, no. 1, p. M19-M24.

Siavoshi, S., and Kudrolli, A., 2005, Failure of a granular step: Physical Review E, v. 71, no. 5 , p. 051302.

Skempton, S. A., 1954, The pore pressure coefficients A and B: Géotechnique, v. 4, p. 143-147.

Smith, W., Foote, P. D., and Busang, P., 1929, Packing of homogeneous spheres: Physical Review, v. 34, no. 9, p. 1271.

Sture, S., Costes, N. C., Batiste, S. N., Lankton, M. R., AlShibli, K. A., Jeremic, B., Swanson, R. A., and Frank, M., 1998, Mechanics of granular materials at low effective stresses: Journal of Aerospace Engineering, v. 11, no. 3, p. 67-72.

Terzaghi, K., 1951, Mechanism of landslides, Harvard University, Dept. of Engineering.

Terzaghi, K., 1956, Varieties of submarine slope failures, in Proceedings 8th Texas Conference on Soil Mechanics and Foundation Engineering, Austin, TX, 1956, p. $1-41$.

Vaid, Y., and Negussey, D., 1988, Preparation of reconstituted sand specimens: Advanced triaxial testing of soil and rock, ASTM STP, v. 977, p. 405-417.

Van den Berg, J., Van Gelder, A., and Mastbergen, D., 2002, The importance of breaching as a mechanism of subaqueous slope failure in fine sand: Sedimentology, v. 49, no. 1, p. 81-95.

Van Rhee, C., Erosion of granular at high flow velocity, in Proceedings The 17th International Conference on the Hydraulic Transport of Solids, Cape Town, 7-11 May, 2007 2007, BHR group, p. 551-560.

Van Rhee, C., and Bezuijen, A., The breaching of sand investigated in large-scale model tests, in Proceedings Costal Engineering, Copenhagen, Denmark, 1998, Volume 3, American Society of Civil Engineers, p. 2509-2519.

Visher, G. S., and Part, 1967, Relation of grain size to sedimentary processes, American Association of Petroleum Geologists Bulletin, Volume 51: United States, American Association of Petroleum Geologists : Tulsa, OK, United States, p. 484-484.

Visscher, W. M., and Bolsterl.M, 1972, Random packing of equal and unequal spheres in 2 and 3 dimensions: Nature, v. 239, no. 5374, p. 504-507.

Wood, D., 1990, Soil Behaviour and Critical State Soil Mechanics, Cambridge University Press, Cambridge. 